\title{
Active Lockdown: Exploring the effect of Government enforced lockdown on physical activity habits and the corresponding relationship with wellbeing
}

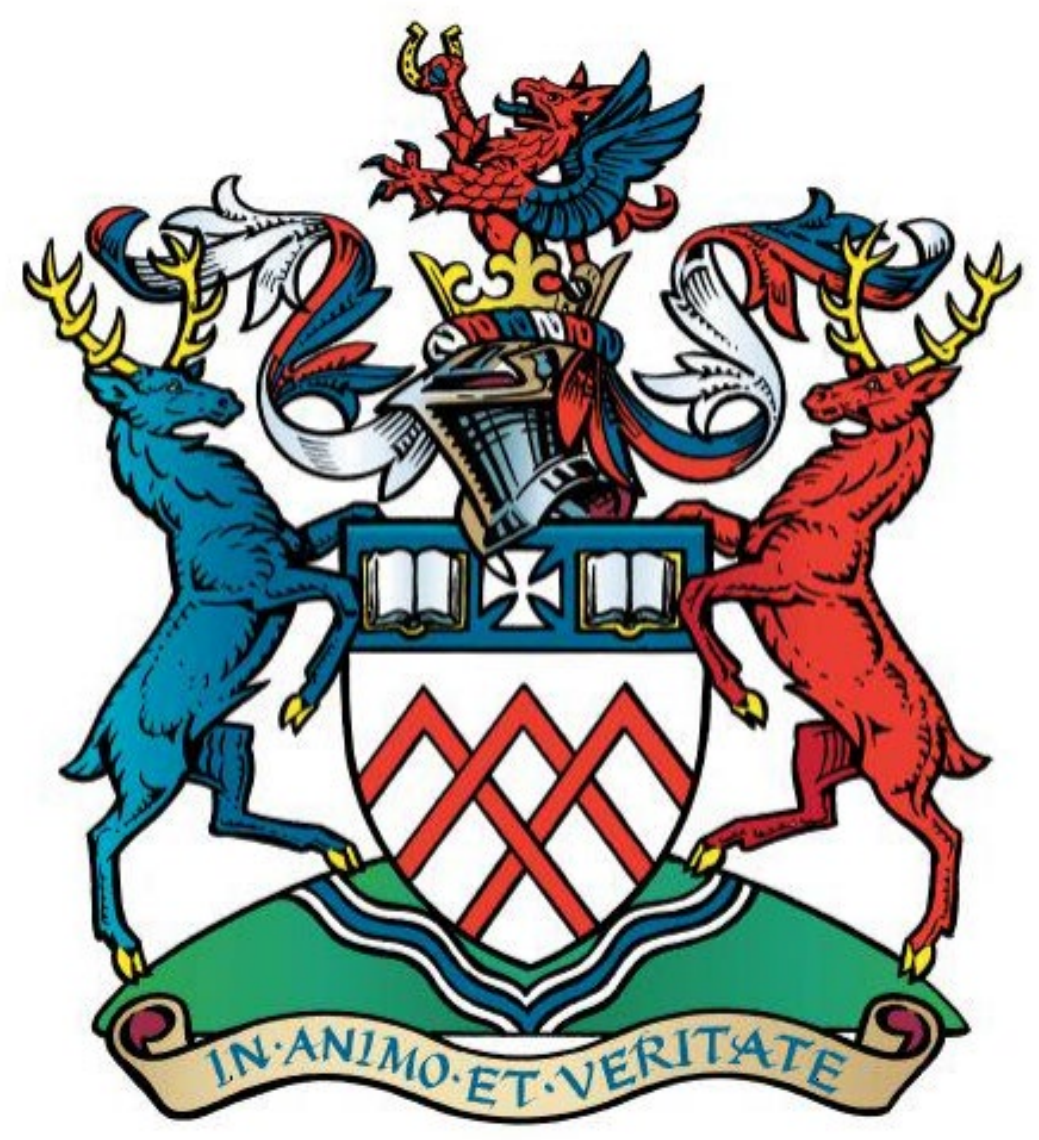

Samuel Warne, s1602969

Presented as part of the requirement for an award within the Postgraduate Masters by Research at University of Gloucestershire

December, 2020 


\section{Declaration}

This thesis is the product of my own work and does not infringe the ethical principles set out in the University's Handbook for Research Ethics.

In submitting this thesis, I agree that it may be made available for reference via any and all media by any and all means now known or developed in the future at the discretion of the University.

doi: 10.46289/FFPE4210 


\section{Acknowledgements:}

First and foremost, I would like to thank my two dissertation supervisors, Dr Steven Baker and Dr Kimberley Schenke, for their incessant help and guidance from start to finish, even during the unprecedented circumstances of a global pandemic.

Additionally, my thanks and love must go out to my family (Mum, Dad and Lucy), not only for their eternal support, but also for keeping me motivated, focussed and determined to conduct meaningful research, despite the stressful moments, each leading the way for me, making me the person that I am today - extra thanks (and apologies) must be given for their tolerance of me during lockdown, when the entire research project was planned and conducted.

My appreciation must also go out to every person who participated in the research, for without them research would not be possible - but also to every person who made unquestionable sacrifices throughout the pandemic, for these saved countless lives. 


\section{Table of Contents}

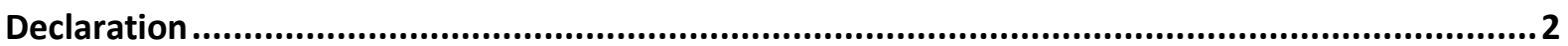

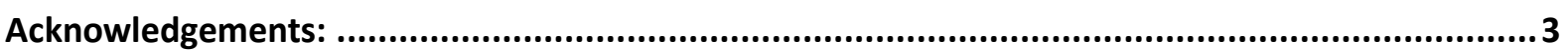

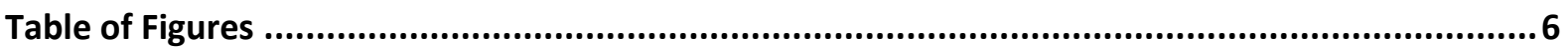

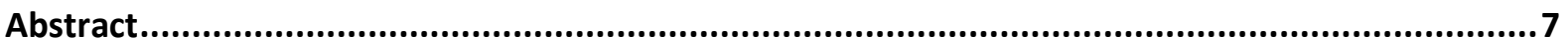

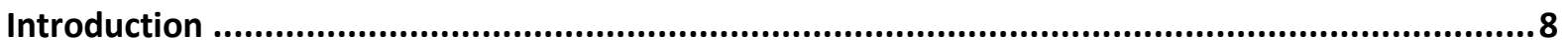

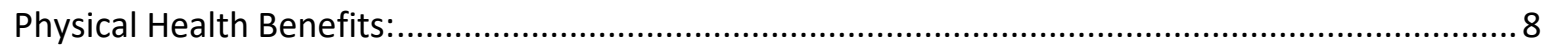

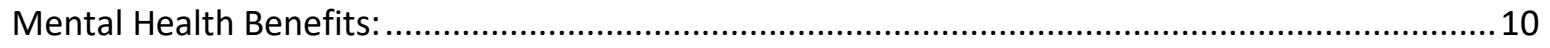

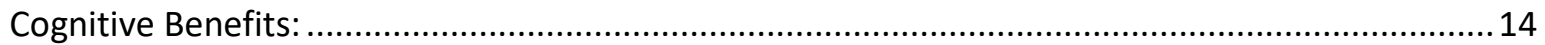

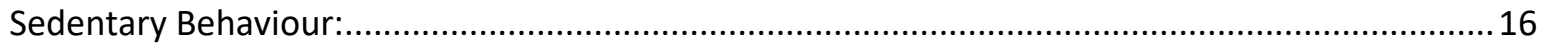

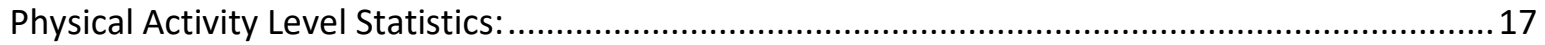

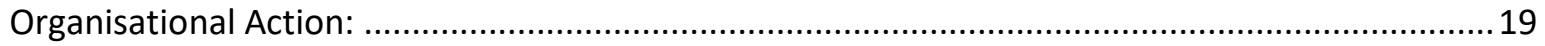

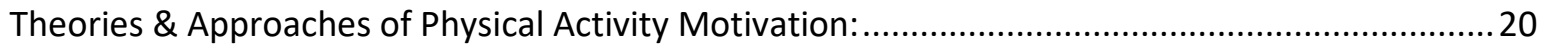

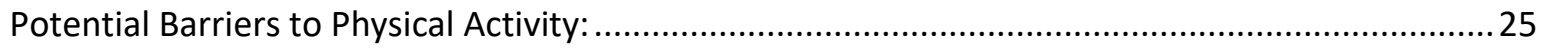

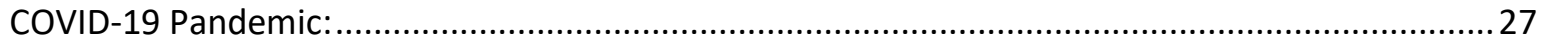

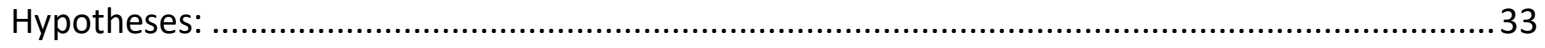

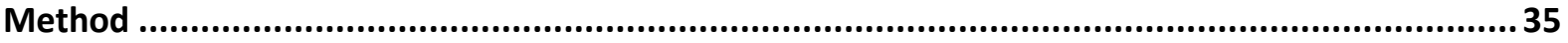

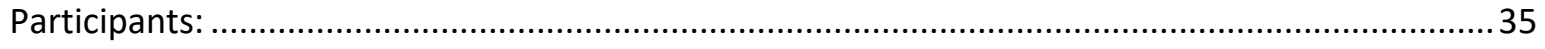

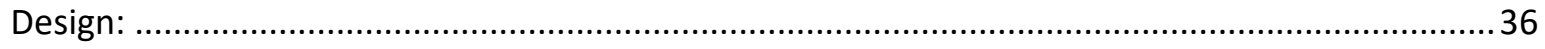

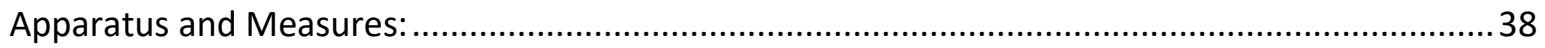

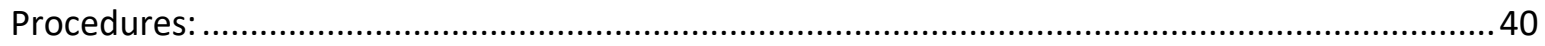

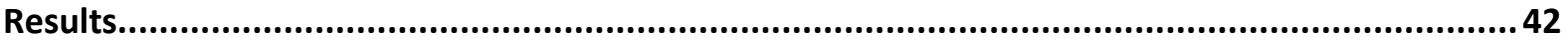

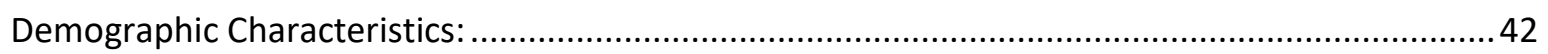

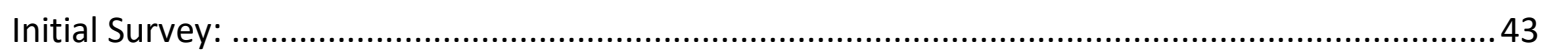

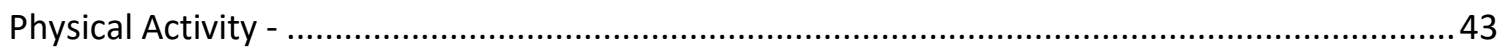

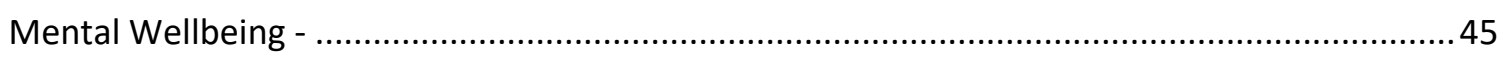

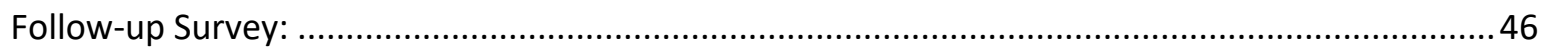

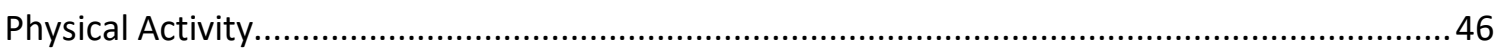

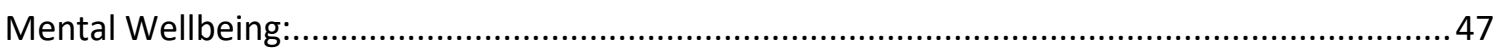

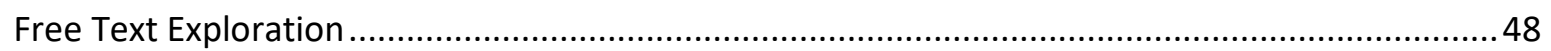

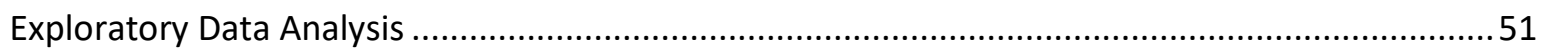

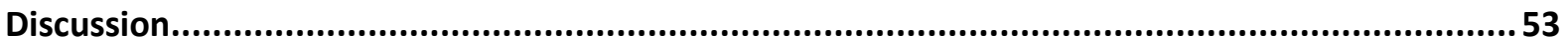

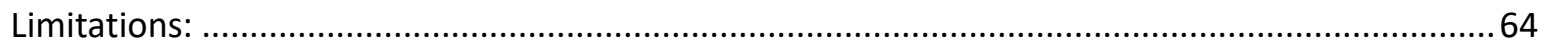

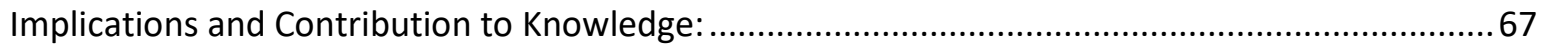

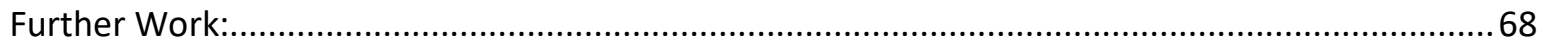

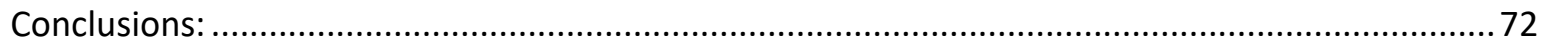




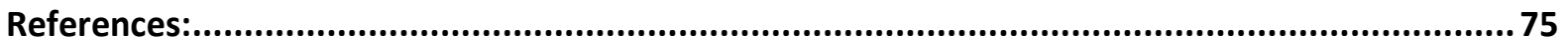

Appendix:

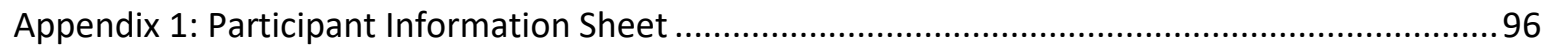

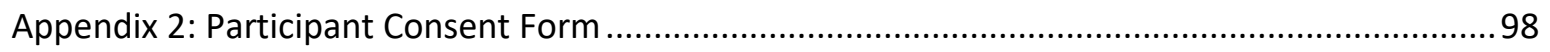

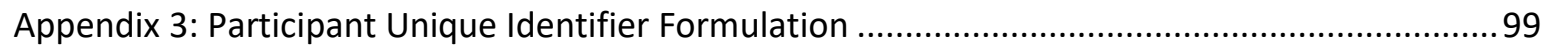

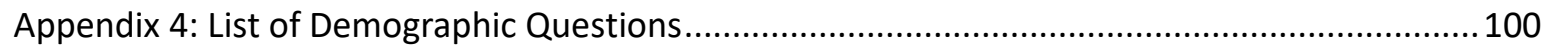

Appendix 5: Warwick-Edinburgh Mental Wellbeing Scale .......................................................... 101

Appendix 6: Past-Week Modifiable Activity Questionnaire ........................................................102

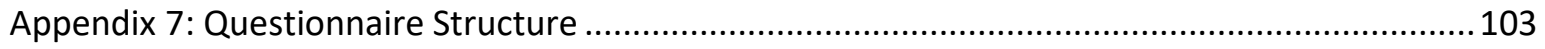

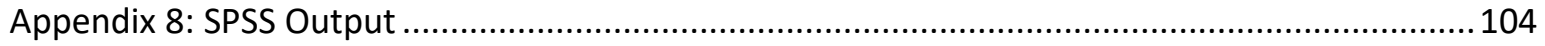

Appendix 9: A Table demonstrating the significances of the tests of differences between Work Statuses and their impact on Mental Wellbeing

Appendix 10: A Table demonstrating the significances of the tests of differences between types of accessible Open Spaces and their impact on Mental Wellbeing

Appendix 11: A Table demonstrating the significances of the tests of differences between Work Statuses and their impact on METhrs/week difference scores

Appendix 12: A Table demonstrating the significances of the tests of differences between types of accessible Open Spaces and their impact on METhrs/week difference scores.

Appendix 13: A Table demonstrating the significances of the tests of differences between Work Statuses and their impact on time spent engaging in physical activity difference scores

Appendix 14: A Table demonstrating the significances of the tests of differences between types of accessible Open Spaces and their impact on time spent engaging in physical activity difference scores 


\section{$\underline{\text { Table of Figures }}$}

Figure 1 - A Timeline Figure displaying when each element of the study was conducted, and how this fit within the context of lockdown restrictions in England....

Figure $\mathbf{2}$ - Bar Charts displaying the four measurements of physical activity levels of participants, Pre-Lockdown and During-Lockdown ....

Figure 3 - Bar Charts displaying the comparisons of the physical activity differences between stages of lockdown, based on whether the participant perceived themselves to have more spare time during lockdown.

Figure 4 - Scatter Plots displaying the correlational relationships between the four measurements of physical activity and mental wellbeing during lockdown.

Figure 5 - Bar Charts displaying the mean physical activity levels of participants across all three time points.

Figure 6 - Bar charts displaying the comparisons of the physical activity differences between preand eased-stages of lockdown, based on whether the participant perceived themselves to have more spare time during eased lockdown

Figure 7 - Scatter Plots displaying the correlational relationships between the self-reported measurements of physical activity and mental wellbeing in the period of eased- lockdown.

Figure 8 - Word Cloud 1: What factors are important in the motivation to exercise amongst those who feel that they do ample physical activity?

Figure 9 - Word Cloud 2: What factors prevent physical activity behaviour amongst those who feel that they do not do ample physical activity?

Figure 10 - Word Cloud 3: What factors influenced physical activity behaviour during the Coronavirus lockdown?

Figure 11 - Word Cloud 4: What did participants feel safe leaving their houses to do during lockdown? 


\section{Abstract}

Whilst regular physical activity benefits our health, both physically and mentally, many people do not meet recommended activity levels - often because of a lack of enjoyment, motivation or spare time. The current study investigated whether the COVID-19 government-enforced lockdown in the UK in March 2020 (which saw many furloughed from their work and only able to leave the house to exercise or for essentially activities) influenced physical activity habits.

An initial survey collected data around physical activity levels (both self-reported and via smart device activity trackers) for the week preceding lockdown and a week during lockdown. It also collected data on mental wellbeing during lockdown. A second survey collected the same measures (plus questions regarding motivations to exercise) once the lockdown restrictions eased and non-essential shops reopened.

Analyses indicated that lockdown significantly increased the length of time participants spent engaging in physical activity compared to pre-lockdown levels, though metabolic equivalency and accelerometer data did not see such significant results. There was no statistically significant difference in physical activity levels in the period of eased-lockdown when compared to during-lockdown. Those with the perception of having more spare time during lockdown elicited significant effects in self-reported data, such that those with the perception did greater levels of physical activity than those without. However, when 'eased lockdown' data was examined, this was not deemed statistically significant. Correlational analyses examining the relationship between physical activity levels and mental wellbeing showed a significantly weak, positive relationship between self-reported physical activity and mental wellbeing during lockdown.

The findings demonstrate that lockdown increased the total time people engaged in physical activity, though the activities were seemingly of low metabolic equivalency. Though when lockdown was eased, these levels did not differ significantly to during lockdown. Results also found that those with spare time during lockdown elicited greater self-reported physical activity levels than previously. The data also supported previous literature outlining the positive relationship between physical activity and wellbeing, despite the extremely negative circumstances that caused the lockdown. 


\section{Introduction}

Physical activity can be defined as 'bodily movement produced by muscle contractions that raise energy expenditure above resting levels' (Caspersen et al., 1985, p. 126). The umbrella term 'physical activity' incorporates sport, dance, leisure activities and (physical) exercise (Amatriain-Fernández et al., 2020). Whilst the terms physical activity and exercise are often used interchangeably (Owen et al., 2010a), exercise is generally considered to be a planned, structured, repetitive and purposeful intervention, formed of physical activity (Wegner et al., 2020). Though, as both are considered appropriate within the context, throughout this paper, as with previous research, the terms are used interchangeably.

\section{Physical Health Benefits:}

\section{"Those who think they have not time for bodily exercise will sooner or later have to find time for illness." - Lord Edward Stanley (19 th Century)}

Cited over 350 times to date, a relatively recent and comprehensive systematic review of reviews demonstrated that research has consistently shown that regular exercise has positive physical effects on the body, decreasing the chances of around 25 somatic complaint developments (Warburton \& Bredin, 2017) such as coronary heart disease, hypertension, diabetes, cancers and osteoporosis (Warburton et al., 2006).

Frequent exercise has been shown to reduce the prevalence of breast (Holmes et al., 2005), colon (Thune \& Furberg, 2001) and many other cancers (Friedenreich, 2001). It is believed that the beneficial effects of regular physical activity on cardiovascular health are, in part, due to the mitigation of hypertension and hyperlipidemia (Warburton et al., 2006), as well as obesity, which are major risk factors of cardiovascular disease ((Pearce, 2008; Poirier et al., 2006; Wiklund, 2016)). In addition, physical activity is positively correlated with bone health and can help alleviate the effects of fibromyalgia (Goldenberg et al., 2004). Even just doing a 
small amount of energy expenditure every week (burning $\sim 15 \mathrm{kcal}$ a day) enhances fitness levels, and subsequently improves health and reduces risk of all-cause mortality (Pearce, 2008).

In addition to this, regular physical activity has the potential to positively impact the immune system reducing the risk of developing illnesses such as the common cold, through strengthening the defence against bacterial and viral infections (Shephard \& Shek, 1994). However, it has been noted that while infection resistance increases following moderate exercise (Brenner et al., 1994), respiratory infections are actually more prevalent in long distance runners and those who engage in a high level of physical activity (Gleeson et al., 2013; Nieman et al., 1993), though this may be due to the increased levels of stress on the individual's bodies and minds. Despite this, bouts of moderate-to-vigorous exercise less than an hour in length are believed to be important in the enhancement of the immune system (Nieman \& Wentz, 2019). Adults with higher levels of physical activity have also repeatedly been shown to display decreased levels of inflammatory biomarkers (Nieman \& Wentz, 2019).

Given the aforementioned benefits of physical activity (reducing the risk of ill health in the first place, both in terms of somatic complaints and infections), doctors have been prescribing physical activity (as a supplement to medication) to high-risk individuals (and those in recovery) from any of the aforementioned diseases for many years. These prescriptions can be tailored by frequency, length and intensity (Pearce, 2008).

The possible use of physical activity as a preventative treatment was known as early as 460-370 BC when Hippocrates wrote that engaging in exercise may be the safest way to achieve health (Sallis, 2009). However, the first recorded instance of this being applied was during the First World War, where McKenzie prescribed exercise regimes as a rehabilitation technique for wounded soldiers (Moore, 2004).

Given its beneficial impact on health, and the potential healthcare savings associated with healthier living, many governing bodies now promote exercise. For example, there have been widespread campaigns to get people exercising more regularly, such as the 'Couch to 5k' (NHS, 2020) and 'Parkrun' (Parkrun, 2020) initiatives within the United Kingdom. This began with the American College of Sports Medicine's (ACSM) suggestion in 1996 that every individual should be 
partaking in a minimum of 30 minutes of moderate intensity physical activity every day. The ACSM then launched a partnership project with the American Medical Association in 2007 named 'Exercise is Medicine', which has the primary goal to make the assessment and promotion of physical activity standard procedure during clinical care (American College of Sport Medicine, 2020). Though beginning as a national project within the USA, Exercise is Medicine soon became multi-national, and is now operating in 37 countries (spanning North \& South America, Europe, Africa, Asia and Australia - but not within Great Britain), providing assessments, advice, exercise prescriptions and resources in each (American College of Sport Medicine, 2020).

Only recently in 2018 did the UK launch a similar project, announcing 'Moving Medicine' - a service developed by the Faculty of Sport and Exercise Medicine in partnership with Public Health England and Sport England. This service not only conducts research, but aims to become a tool which clinicians and other professionals can use to create, prescribe and monitor activity-based therapies based on real research, whilst also incorporating established behavioural techniques (Faculty of Sport and Exercise Medicine, 2021). The website itself (https://movingmedicine.ac.uk/) allows individuals to tailor a consultation plan by age and circumstances/condition, with a combination of physical and mental health conditions available to choose from, as well as designating a section of the website to emphasising why exercise is important (Moving Medicine, 2021).

\section{Mental Health Benefits:}

In addition to the physical benefits of physical activity, it has also been frequently shown to improve general wellbeing (Ekkekakis et al., 2013) and mental wellbeing (Blumenthal \& Ong, 2009) for all ages (Zubala et al., 2017). This has informed treatment for many mental disorders. For example, within England, the National Institute for Clinical Excellence (now the National Institute for Health and Care Excellence) advised patients of all ages with mild depression' of the potential benefits of 3 hours of structured exercise per week (NICE, 2004). This was later developed to suggest exercise programmes to anyone with persistent subthreshold depressive symptoms or mild-to-moderate depression (National Collaborating Centre 
for Mental Health \& National Institute for Clinical Excellence, 2010). Other international authorities in Scotland, Netherlands, Australia, New Zealand and Canada also recognise these benefits of physical activity on wellbeing (Ekkekakis \& Murri, 2017). Indeed, in areas where therapy resources are scarce, physical exercise is often deemed to be sufficient and cost-effective to treat those in need (Budde et al., 2018). Such is the belief in the effect of physical activity on mental health, in Australia and New Zealand, policy states that exercise is 'Step Zero' in the treatment of depression. Thus, counselling or drug treatment is only administered if there is evidence that Step Zero is being undertaken, but is not a solely sufficient course of treatment (Ekkekakis \& Murri, 2017; Malhi et al., 2015).

The rationale behind these increasingly popular policies is the consistency in which the antidepressant effects of physical activity are being reported (Schuch et al., 2018). The consensus from a multitude of good-quality systematic reviews is that exercise can significantly reduce the symptoms of depression, and thus becomes a useful tool in psychotherapy and the treatment of mental health disorders (Cooney et al., 2013; Kvam et al., 2016). Further reviews have highlighted that not only can exercise help reduce depressive symptoms, but those who have low physical activity levels are also more likely to develop depressive symptoms - and thus the relationship is suggested to be bidirectional (Mammen \& Faulkner, 2013). These changes are not only short-lived, but, when engaging in an appropriate amount of physical activity for a whole year, incidental depressive symptoms are greatly decreased, and thus frequent exercise is greatly beneficial for those with depression.

Recent laboratory studies have shown depression to be linked with cerebral brain flow issues (Chin Fatt et al., 2020; Cooper, 2017; Cooper et al., 2013), as well as low serotonin and dopamine levels (Dunlop \& Nemeroff, 2007; Field et al., 2005), and abnormalities in cortisol levels (Burke et al., 2005). Though, it is not only theorised, but also supported by quality research results that physical activity mitigates these issues by stimulating cerebral brain flow (Maass et al., 2015), and elevates hormones such as cortisol, serotonin and dopamine to ease depressive symptoms (Buckworth \& Dishman, 2002; Heijnen et al., 2016; Sacheli et al., 2019). Thus, exercise stimulates the neurotransmitters, which are typically targeted by prescription drugs for depression such as Selective Serotonin Reuptake Inhibitors (SSRIs), Monoamine Oxidase Inhibitors (MAOIs) and Dopamine/Norepinephrine 
Reuptake Inhibitors (DNRIs), which work by obstructing the reuptake of the current neurotransmitters in the system, forcing the body to increase production and thus increasing the concentration of the hormone in the synapse of adrenergic or serotonergic nerve endings (Attard, 2012; Dear \& Bateman, 2016). Indeed, according to a review of both human and animal studies, regular physical activity upregulates dopamine concentrations within the brain (Lin \& Kuo, 2013; Vučcković et al., 2010). The serotonergic system is believed to be modulated by exercise, dependent on intensity, duration and brain location (Lin \& Kuo, 2013); such that a week of high-intensity activity has the potential to increase hippocampal serotonin levels (Chennaoui et al., 2000), while a month of moderate-intensity activity does not impact serotonergic levels within the amygdala (Chen et al., 2008). Though this example refers to the effect of exercise on depressive symptoms, serotonin and cortisol-based research has also suggested physical activity to be an effective anxiety and stress reliever in the same way, previously portrayed with a similar combination of both animal and human studies (Greenwood et al., 2007; Greenwood \& Fleshner, 2008, 2011).

There are also vast psychosocial benefits that are suspected to link physical activity to a reduction in depression (Kandola et al., 2019), such as increased levels of selfesteem, self-efficacy and social support. Defined as the evaluation of self-worth and self-image (Sharma \& Agarwala, 2014, 2015), low levels of self-esteem have repeatedly been seen in people with depression (Kandola et al., 2019; Keane \& Loades, 2017), though through regular bouts of aerobic physical exercise physical self-perception can be enhanced (Moore et al., 2012). For instance, the Exercise and Self-Esteem Model (Sonstroem \& Morgan, 1989) focuses on improved self-esteem being a key component in physical activity improving mood (Kandola et al., 2019). Another aspect is the social interactions associated with exercise (Scarapicchia et al., 2017); engagement with physical activity increases socialisation, allowing opportunity for social support, which is something that those with depression often report to be lacking (Väänänen et al., 2014). Besides self-esteem and social support, increased self-efficacy is a further factor deemed to be correlated with reduced depressive symptoms (Trumpeter, 2015). Increased through repeated engagement in physical activity (Rodgers et al., 2014), self-efficacy is a mediator in the relationship of depression scores and physical activity levels (Pickett et al., 2012). 
However, there is an overarching issue with all of these theories, and that is just that, they are no more than theories. The notions of self-esteem, social support and selfefficacy are all very subjective in nature, and as such, the findings discussed above can only have associations or correlational relationships, and it cannot be claimed that they cause any behaviour or health change. Furthermore, depression is not the only mental health issue that benefits from frequent physical activity, with anxiety also being shown to have a similar relationship. The positive effect of physical activity has been seen in both state and trait-based anxiety, with the suggestion that much like with depression, anxiety levels reduce when self-efficacy and self-esteem increase (Fox, 1999, 2000). As well as these psychosocial mechanisms, it has been suggested that the impact of exercise on neurotransmitters alleviates anxiety in a similar fashion to with depression (Ströhle, 2009, 2019). Moreover, the sense of mastery achieved when physical activity is completed, as well as distraction and an element of exposure therapy have all also been suggested as potential mechanisms for the reduction of anxiety (Jayakody et al., 2014). The proposition of exercise as exposure therapy has been highlighted due to the similarity in physical responses to anxiety (Smits \& Otto, 2013). For instance, in reaction to a stimulus deemed threatening, our bodies begin to sweat, and our heart rate increases; these are also experienced after exercise. Therefore, if these physiological reactions can be subconsciously linked to a feeling of safety and/or enjoyment, then it is possible that should the bodily response reoccur in the presence of a stimulus, the symptoms are associated with the new positive feelings of safety/enjoyment instead of one of danger and worry. There have also been indications within prior research that irrespective of how exactly it is achieved, significant reduction in anxiety has been seen following both aerobic and anaerobic exercise (Martinsen et al., 1989).

A potential contributor to the alleviation of mood disorders such as depression and anxiety may be down to physical activity's stress relieving properties (Carmeli, 2013). This is, again, deemed to be due to the neurological changes within the brain, with the aforementioned moderation of cortisol lightening the effect of potential stressors (Greenwood et al., 2003) and greatly reducing the chance of stress-induced immunosuppression (Fleshner, 2005). Exercise has been linked to lower levels of stress (Taylor-Piliae et al., 2010), with those engaging in moderate-intensity exercise reporting half as much perceived stress than those who do not exercise (Aldana et 
al., 1996); this has been seen in both controlled trials (Atlantis et al., 2004) and natural settings (Schnohr et al., 2005). Despite frequent demonstrations of the relationship between increased physical activity and decreased stress, it has been acknowledged that the association may be reciprocal, as those who are stress-free are potentially more likely to exercise in the first place (Da Silva et al., 2012; StultsKolehmainen \& Sinha, 2014), although again, despite some biological markers which have been explored in some more recent studies, the majority of research in this area has also been subjectively measured.

\section{$\underline{\text { Cognitive Benefits: }}$}

Supported by the vast majority of the literature (Nazlieva et al., 2020), regular physical activity has been also been linked to higher levels of cognitive functioning (Cheval et al., 2020), with those who exercise frequently showing improved cognition - including action, perception, intellect and memory (Donnelly et al., 2016; Fernandes et al., 2017). Mental and cognitive benefits were initially believed to be the indirect side-effect of exercise, believing that obesity and diabetes (for instance) were causing negative brain health, and when the severity of these conditions decreased, cognitive function improved accordingly (Warburton et al., 2006). In fact, regular physical activity itself influences the structure and enhances function within the brain (Voelcker-Rehage \& Niemann, 2013), increasing blood flow (Steventon et al., 2020), and subsequently improving attentional processes, memory and learning. This cognitive behaviour enhancement, has been seen following varying lengths of physical activity (Howie \& Pate, 2017) among all age groups (Lista \& Sorrentino, 2010), and physically active children have been shown to perform better on verbal, perceptual and arithmetic tests (Voss et al., 2011) leading to measurable effects in academic performance (Budde et al., 2008; Maher et al., 2016).

In acknowledgement of the years of consistent findings regarding resultant cognitive improvements, the optimal conditions of physical activity for increasing blood flow were investigated. Aerobic exercise (any activity using large muscle groups that can be maintained continuously (Wahid et al., 2016)) provided greater cognitive enhancement than that of anaerobic exercise (intense activity fuelled independently of inhaled oxygen, (American College of Sport Medicine, 2013)), with a single bout of 
moderate-intensity aerobic exercise showing enhancements to cognitive function, as well as mental wellbeing (Basso \& Suzuki, 2017; Ludyga et al., 2016). Though, importantly, this finding is not a one-time phenomenon, as chronic aerobic exercise (multiple, repeated bouts of physical exercise) has also demonstrated effective neuroplasticity encouragement, vastly improving cognitive functions and generating a persistent increase in perceived mental wellbeing (Gökçe et al., 2019; Guiney \& Machado, 2013; Mandolesi et al., 2018), thus showing a further justification for why regular physical activity is beneficial. Additionally, these findings have been seen in human studies with 'real-world' settings as well as lab-based research, which is often conducted on animals such as rats (Lachman et al., 2006; Whitbourne et al., 2008).

It has previously been suggested that the total accumulation of an individual's physical activity engagement over the course of a month is significantly associated with their memory performance (Richards et al., 2003) - this association has also been seen based on the individual's previous day activity levels irrespective of gender or health status (Whitbourne et al., 2008). This may be, in part, due to the relationship with dopamine and working memory within the hippocampus and prefrontal cortex - with individuals showing improvements in working memory performance when dopamine levels are increased (Abdulrahman et al., 2017). Whilst the majority of research focuses on the stages of life where the brain is known to be either developing (childhood) or deteriorating (Older adults - >65 years old), it has been suggested that the mid-life stage is a critical period for brain health (Macpherson et al., 2017). This is a time when Alzheimer's may begin to emerge asymptomatically, before the recognisable symptoms present themselves in later-life (Lockhart \& DeCarli, 2014). Therefore, the maintenance of good brain health is encouraged throughout life, and physical activity is considered an effective way to do this, encouraging vital neuroplasticity (Macpherson et al., 2017). 'Mid-life' research has found an association between self-reported physical activity levels and brain volume (Rovio et al., 2010), which itself is positively associated with cognitive functioning (Smith et al., 2013).

As well as memory, exercise is believed to positively impact attention (Ma et al., 2015). This executive function is our ability to focus on stimuli relevant to a task, without distraction (Bedard et al., 2003), and has been the subject of a wealth of 
research in school-age children. The results of which suggest that just 4 minutes of high-intensity physical activity is enough to improve attention (Ma et al., 2015), or 10 minutes of moderate-intensity (Budde et al., 2008; Tine \& Butler, 2012), which has the potential to have real-world implications. It is highlighted that, though not effective for all forms of cognition, attention can be improved even through lowintensity aerobic exercise (Tivadar, 2017; Vidoni et al., 2015).

\section{Sedentary Behaviour:}

We each have a basal metabolic rate, which refers to "the minimal rate of energy expenditure compatible with life" (Mitchell, 1962, p.3). Whilst this is the absolute minimum that one can achieve, realistically with breathing, thinking and other necessary reactions, the true lowest level of energy expenditure possible is referred to as our resting metabolic rate (McClune et al., 2015). Every activity in life can be adjudged using an equivalence rate to this, indicating the intensity and corresponding level of oxygen required to complete a task, defined as a MET (Franklin et al., 2018; Jetté et al., 1990). 'Any waking behaviour characterised by an energy expenditure of $\leq 1.5$ METs while in a sitting, reclining or lying posture' is classed as sedentary (Sedentary Behaviour Research Network, 2012; Tremblay et al., 2017, p.5).

As such, there is an argument that sedentary behaviour and physical inactivity are essentially the same notion. However, at definition level, while a sedentary life entails a large amount of time with an energy expenditure less than five METs, the World Health Organisation (WHO) labels someone physically inactive if they do not meet their recommended weekly levels of 150 minutes of activity between 3-6 METs per week (Tremblay et al., 2017). Thus, someone could spend the majority of their day acting sedentarily, but through engaging in roughly 30 minutes of moderateintensity activity (such as jogging) each day, they would meet WHO recommendations, and thus would be deemed both physically active and also living sedentarily (van der Ploeg \& Hillsdon, 2017). This demonstrates the need to consider physical activity and energy expenditure as a ratio-based spectrum, whereby instead of aiming to spend $2 \%$ of our waking hours engaging in physical activity, as WHO suggest, we should ensure that we are spending as much of the 
other $98 \%$ in light-intensity activity (1.5-3 METs) as possible (van der Ploeg \& Hillsdon, 2017). The NHS and WHO are now highlighting a need to increase the daily rate of light-intensity physical activity (i.e., that doing little and often is better than doing nothing; (NHS, 2019; WHO, 2020).

Such are the known dangers of a sedentary lifestyle, it has recently been claimed that 'sitting is the new smoking' (Chau et al., 2019, p.1). It is believed that if people spend over 8 consecutive hours sedentarily, their mortality rate increases by $8 \%$ each hour (Chau et al., 2013). Shockingly, adults spend, on average, $70 \%$ of their waking hours behaving sedentarily (Owen et al., 2010), a figure that appears to be increasing year on year (Thivel et al., 2018). This may be due to the development of technology, machinery and transport systems, which has changed the way we live, with very little physical activity actually required day to day (Anithakumari et al., 2019; Owen et al., 2010).

Though not currently collected by the UK Office for National Statistics, evidence from the USA suggests this has led to a rise in office-based jobs, with over $80 \%$ of jobs in USA being classed as predominantly sedentary ( $43 \%$ of which are deemed highly sedentary) with workers spending $89 \%$ of their time at work sitting (Church et al., 2011; Gremaud et al., 2018). This is extremely problematic given that seated occupational activity has a negative impact on mortality (Menotti et al., 2014; Van Uffelen et al., 2010). The decreasing need to be active, when considered alongside the mortality impact of sedentary behaviour, is particularly dangerous due to humans' apparent innate favouring of effort minimisation and energy conservation (Thivel et al., 2018).

\section{Physical Activity Level Statistics:}

Within the UK, over a third of men, and nearly half of women are not deemed active enough to maintain a good level of health (Public Health England, 2019), with approximately $40 \%$ of adults ( 20 million people) not meeting the WHO physical activity recommendations (British Heart Foundation, 2017). This figure is similar in all parts of the UK, though for Northern Ireland the figure is closer to $50 \%$. Whilst indeed, research has shown that between 40\% (GOV.uk, 2019) and 66\% of English 
men believed that they met the recommendations and classed themselves as physically active (Sustrans, 2019). Similarly, the U.S. Department of Health and Human Services (2017) report that only 1 in 3 American adults meet the WHO guidelines for physical activity, with previous research finding that $28 \%$ of American adults believed they had done no moderate or vigorous exercise over the course of an entire year (Germano, 2015). The article also stated that since the surveys began in 2007 , the number of physically inactive people in the US had consistently risen, with the statistic nearing $50 \%$ at the time of publication (Centers for Disease Control and Prevention, 2014). Official worldwide statistics published in The Lancet showed the global age-standardised prevalence of insufficient physical activity to be $27.5 \%$, a significant increase from the 23.3\% recorded in 2010 (Guthold et al., 2018). Alarmingly, the prevalence was more than double in high-income countries $(36.8 \%)$ compared to low-income countries $(16.2 \%)$, increasing from the initial iteration of the research, which found the figure in high-income countries to be $31.6 \%$ in 2001 (Guthold et al., 2018).

Though, as previously discussed, physical activity and sedentary behaviour are different constructs, the statistics surrounding them both demonstrate a very similar story, that physical activity levels need to be increased, and sedentary behaviour needs to be reduced. Whilst the problem exists worldwide, countries of a 'first-world', high-income nature appear to be particularly prone, with Australian adults averaging over 9 hours of sedentary behaviour every day, and the USA recording figures around 8 hours on average (Healy et al., 2008). Additionally, though the source of the research is unclear, the NHS (2019) acknowledge that they believe a large proportion of the population are sedentary for over 9 hours each day. The prevalence of the issue in these areas perhaps further suggests the effect technology has had. In 2012, UK-based research found that around 30\% of adults were sedentary for over 6 hours during weekdays, a figure that increased to nearly $40 \%$ on weekends (Heron et al., 2019; NHS, 2013). This is a worrying statistic when it is considered that over 8 hours of sedentary behaviour can increase the chance of all-cause mortality (Patterson et al., 2018). Indeed, based solely on UK statistics from 2016, 11.6\% (just under 70,000) of all deaths were associated with sedentary behaviour (Heron et al., 2019; NHS, 2019a). Yet it is estimated that even a 30\% reduction in sedentary lifestyles could have saved around 17,500 lives (Heron et al., 
2019). In addition to this, the total cost to the NHS in treatments attributed to sedentary behaviour, in the financial year 2016-2017 alone, was in the region of $£ 675-£ 750$ million, over $1 \%$ of the whole year's budget (Heron et al., 2019; NHS, 2019a). This figure has also been estimated to have risen to around the $£ 1.2$ billion mark in direct costs to the UK's healthcare system, estimating that of healthcare systems worldwide to be in the vicinity of around $£ 35$ billion every year (British Heart Foundation, 2017). In 2008 alone, the WHO attributed over 3.2 million deaths to physical inactivity (WHO, 2008), a substantial increase on the reported figures in 2002, when they claimed that the figure was around 2 million deaths (WHO, 2002).

\section{Organisational Action:}

The consistency of the research finding that physical activity benefits health and wellbeing has resulted in the WHO acknowledging the physical inactivity issue, such that those who are insufficiently active may have up to $30 \%$ greater risk of death (WHO, 2018). As previously highlighted, in 2010 official recommendations for the minimum amount of physical activity that individuals should be doing per week were released (WHO, 2010), with a general target of 150 minutes of moderate-intensity activity each week. Additionally, in 2013, the World Health Assembly challenged all countries to reduce their premature mortality rates by $25 \%$ and reduce their number of physically inactive individuals by $10 \%$ by the year 2025 (WHO, 2013). Yet four years later, in the UK alone, around 3 in 5 adults were still unaware of the physical activity engagement guidelines set in place by WHO in 2010 (British Heart Foundation, 2017).

An update to 2013's 'Global Action Plan' followed in 2018, alongside the release of the 'ACTIVE Technical Package', which reiterated the agreed targets set in 2013, while also adding the target of a 15\% reduction in physical inactivity by 2030 (WHO, 2018c). The toolkit focussed on making societies, environments, people and systems more active-friendly, suggesting that in order to insight real change, the campaign would need to alter the social norms; promote accessible infrastructure that enables walking and cycling; ensure that everyone has fair access to physical activity opportunities; and strengthen governance so that all policies could be implemented with optimum effect (WHO, 2018c). Additionally, this release also provided an update 
on the progress of countries in meeting the targets set five years prior, highlighting that no country was on track, and in total the effort was significantly below what was expected, with some high-income countries' physical inactivity rates actually increasing (Guthold et al., 2018).

Most recently, the 2020 WHO Physical Activity guidelines release compounded the need to ensure that people are engaging in the appropriate amounts of physical activity, but that any activity that is not sedentary, even light-intensity activity, can make a difference to one's health - with this they launched the 'Every Move Counts' slogan. Upon announcing these new releases, Dr Fiona Bull importantly stated that "Guidelines do not change behaviour, it is what we do with them and how we implement them that matters" (WHO, 2020), further reiterating that if people are going to benefit from physical activity, then the appropriate infrastructure to support them is required.

\section{Theories \& Approaches of Physical Activity Motivation:}

Over the years, there have been many attempts to understand behaviour and motivation in the area of physical activity (Table 1). These have been based on a variety of templates, including dual-process models, informed decisions, evolution/nature and others taking more holistic approaches. It is the personal preferences of the author to consider the latter, which acknowledge that behaviour and motivation in this context are inherently complex, and cannot be simplified to only consider one or two potential factors. 
Table 1 - A Summary of a Selection of Theories \& Approaches of Behaviour Change and Motivation, including a short description alongside the positives and negatives of each within the context of Physical Activity

\begin{tabular}{|c|c|c|c|c|}
\hline $\begin{array}{c}\text { Author(s) \& } \\
\text { Year }\end{array}$ & Theory Name & Simple Description & Positives & Negatives \\
\hline $\begin{array}{l}\text { Ekkekakis et } \\
\text { al. (2018) }\end{array}$ & $\begin{array}{l}\text { Rational } \\
\text { Educational } \\
\text { Approach }\end{array}$ & $\begin{array}{c}\text { If a person is given } \\
\text { information to say a stimuli } \\
\text { can benefit them, they will } \\
\text { be attracted to it }\end{array}$ & $\begin{array}{c}\text { Builds on our evolutionary } \\
\text { desire to use available tools to } \\
\text { aid survival }\end{array}$ & $\begin{array}{l}\text { If it were true, everyone } \\
\text { would meet exercise } \\
\text { guidelines, but they do } \\
\text { not, and the model cannot } \\
\text { explain this }\end{array}$ \\
\hline $\begin{array}{l}\text { Ekkekakis } \\
(2017)\end{array}$ & $\begin{array}{l}\text { Affective- } \\
\text { Reflective } \\
\text { Theory }\end{array}$ & $\begin{array}{l}\text { Dual-Process theory; two } \\
\text { concurrent systems within } \\
\text { us whereby one is } \\
\text { dependent on affective- } \\
\text { valence, and the other is } \\
\text { dependent on available } \\
\text { information }\end{array}$ & $\begin{array}{l}\text { Considers emotion as well as } \\
\text { information, which is important }\end{array}$ & $\begin{array}{l}\text { Misses many other } \\
\text { potential factors involved } \\
\text { in behaviour motivation, } \\
\text { such as external } \\
\text { influences }\end{array}$ \\
\hline $\begin{array}{l}\text { Brand \& } \\
\text { Cheval } \\
(2019)\end{array}$ & $\begin{array}{l}\text { Energetic Cost } \\
\text { Minimisation }\end{array}$ & $\begin{array}{l}\text { As a species, humans will } \\
\text { not use energy that may be } \\
\text { required for survival, unless } \\
\text { there is a suitable level of } \\
\text { reward upon completion }\end{array}$ & $\begin{array}{l}\text { Draws on popular evolutionary } \\
\text { theories, and can explain some } \\
\text { real-life behaviour }\end{array}$ & $\begin{array}{l}\text { Misses many other } \\
\text { potential factors involved } \\
\text { in behaviour motivation, } \\
\text { such as emotional } \\
\text { influence }\end{array}$ \\
\hline $\begin{array}{l}\text { Prochaska \& } \\
\text { DiClemente } \\
(1992)\end{array}$ & $\begin{array}{l}\text { Transtheoretical } \\
\text { Model of } \\
\text { Behaviour } \\
\text { Change }\end{array}$ & $\begin{array}{l}\text { A five-stage mental process } \\
\text { involving } \\
\text { Precontemplation, } \\
\text { Contemplation, } \\
\text { Preparation, Action, and } \\
\text { Maintenance }\end{array}$ & $\begin{array}{l}\text { Acknowledges that people may } \\
\text { not be able to go from } \\
\text { something to nothing (or vice } \\
\text { versa) straight away, and that } \\
\text { behaviour change is a process }\end{array}$ & $\begin{array}{l}\text { In a physical activity } \\
\text { context, this theoretical } \\
\text { framework is best suited } \\
\text { to those already in the } \\
\text { action and maintenance } \\
\text { stages, and cannot be } \\
\text { used simply to increase } \\
\text { motivation in those in the } \\
\text { early stages of the cycle } \\
\text { (Parker et al, 2010). }\end{array}$ \\
\hline $\begin{array}{l}\text { Ryan \& Deci } \\
(2000)\end{array}$ & $\begin{array}{l}\text { Internal Locust } \\
\text { of Causality }\end{array}$ & $\begin{array}{l}\text { Meaningful behaviour } \\
\text { change only occurs when } \\
\text { an individual is willing to do } \\
\text { a behaviour without } \\
\text { tangible reward }\end{array}$ & $\begin{array}{c}\text { Appears to bridge gaps in } \\
\text { previous theories, for instance it } \\
\text { may explain why many struggle } \\
\text { in the 'Maintenance' stage of } \\
\text { Transtheoretical Model, and } \\
\text { relapse }\end{array}$ & $\begin{array}{l}\text { It disregards controlled } \\
\text { motivations (where there } \\
\text { is an end goal) as though } \\
\text { they have no purpose, } \\
\text { though there is certainly a } \\
\text { place for these }\end{array}$ \\
\hline $\begin{array}{l}\text { Ajzen } \\
(1991)\end{array}$ & $\begin{array}{l}\text { Theory of } \\
\text { Planned } \\
\text { Behaviour }\end{array}$ & $\begin{array}{c}\text { Behaviour change decisions } \\
\text { are based on a combination } \\
\text { of affective attitude, } \\
\text { consideration of social } \\
\text { norms and also perceived } \\
\text { task difficulty (behavioural } \\
\text { control). Social-cognitive in } \\
\text { nature. }\end{array}$ & $\begin{array}{l}\text { Highlights the importance of } \\
\text { whether an individual believes } \\
\text { they can do a task, and the } \\
\text { impact this can have on } \\
\text { motivation }\end{array}$ & $\begin{array}{l}\text { Though acknowledging } \\
\text { the affective attitude of } \\
\text { the individual towards the } \\
\text { physical activity itself, it } \\
\text { does not allow for the } \\
\text { influence of other } \\
\text { emotions, or other } \\
\text { external factors that could } \\
\text { have an impact. }\end{array}$ \\
\hline $\begin{array}{l}\text { West \& } \\
\text { Michie } \\
(2020)\end{array}$ & $\begin{array}{l}\text { COM-B Model } \\
\text { of Behaviour }\end{array}$ & $\begin{array}{l}\text { Behaviour change can only } \\
\text { occur if internal and } \\
\text { external factors from the } \\
\text { categories Capability, } \\
\text { Opportunity and } \\
\text { Motivation all occur, in } \\
\text { favour of a behaviour } \\
\text { change, simultaneously }\end{array}$ & $\begin{array}{l}\text { Takes a holistic approach, which } \\
\text { acknowledges that there are } \\
\text { factors that the individual can } \\
\text { control, but also that factors out } \\
\text { of their control that can prevent } \\
\text { a behaviour change. Also notes } \\
\text { that if something from any of } \\
\text { the three categories is not in } \\
\text { favour of the behaviour, it will } \\
\text { not occur. }\end{array}$ & $\begin{array}{l}\text { It has been argued that if } \\
\text { the motivational desire or } \\
\text { 'want' to do something is } \\
\text { great enough, an } \\
\text { individual will attempt to } \\
\text { do this irrespective of } \\
\text { their capabilities or } \\
\text { opportunities (Marks, } \\
\text { 2020) }\end{array}$ \\
\hline
\end{tabular}


It may be that while all the theories are 'nearly there' and are compatible with many cases, to explain the behaviour change process fully a combination of them all is needed that takes aspects of evolutionary models, as well as psychological and biological to form a complete framework. For example, the Transtheoretical Model of Behaviour Change (Prochaska \& DiClemente, 1992) has a reasonable framework in place, but on closer inspection, elements of the rational education approach, Energetic Cost Minimisation theory (Brand \& Cheval, 2019) and Affective-Reflective theory (Ekkekakis, 2017) are all present, in the transfer between stages. If you consider the first progression (Precontemplation to Contemplation) to be the initial internal 'suggestion' of physical activity, then in order to proceed to 'Preparation' an immediate decision is required. At this stage, the first response will be that of System 1 , and so a positive valence is vital before any information processing (System 2) can impact the decision (as in dual-process models). However, on an evolutionary basis, this information must then highlight a tangible reward that is deemed worthy of energy output, thus incorporating elements of multiple cross-discipline theories in order to explain behaviour changes. This shows how despite each being compatible with some case studies, when pieced together, these theories can produce a more complete explanation, with the gaps in some theories being answered by another,

Previous literature has argued that the most effective theory for explaining individual's motivations to exercise is Ajzen's (1991) Theory of Planned Behaviour (Wu et al., 2020). A social-cognitive theory, and the most popular and widely accepted of Ajzen's work, which includes the Theory of Reasoned Action (I. Ajzen \& Fishbein, 1980) and the Reasoned Action Approach (Fishbein \& Ajzen, 2011), the Theory of Planned Behaviour considers the stages involved within the earlier 'Theory of Reasoned Action', acknowledging the importance of the individual's affective attitude towards a behaviour and the subjective social norms surrounding it, while also incorporating a third element, which they label 'perceived behavioural control' (Icek Ajzen, 1991; Conner, 2020). This additional element accounts for the individual's perception of task-difficulty, thought of as a continuum with the simplest task imaginable at one end, and the specialised skills of a world-class expert at the other (Conner, 2020). It has been suggested that the perceived behavioural control may be the most important (Conner, 2020), as someone is highly likely to engage in exercise if they have a positive attitude (or affective valence) towards it, 
acknowledge the social norm (to meet the WHO recommendations) and also feel confident that they can comfortably perform the task without requiring any specialised skill. However, if the considered activity was a sport that required a level of technique and specialised skill such as golf, martial-arts or high jump, then they would be far less likely to engage than they would with a technically simpler activity such as jogging, as humans naturally try to avoid difficulty and make tasks as easy as possible (Power, 2019). Additionally, as highlighted in Table 1 above, there are still a number of potential factors that this theory does not consider. For instance, though the theory acknowledges that a positive affect is important, this is in reference specifically to the stimulus (in this case physical activity), and does not allow for consideration of factors out of the control of the individual, such as the weather, which has previously been shown to impact how happy an individual is to go outside for the purpose of exercise (Eichorn et al., 2018).

It is for this reason that the primary model which formed the key foundation of this research is the COM-B model of behaviour, which is more holistic in nature, and allows consideration of a wide range of factors. Considered to be a dynamic system, underpinned by the Plans-Responses-Impulses-Motives-Evaluation ("PRIME") Theory of Motivation (West \& Michie, 2020). The model is based on the principle that a behaviour can, and will, only occur if the environment allows it to, such that the individual in question has the capability and opportunity to engage in the behaviour, and that they are more motivated to perform that specific behaviour than any other potential behaviour (Michie et al., 2011). In this sense, capability refers to whether the individual is fit to do a behaviour, in terms of both the physical attributes that the individual possesses which may be required to perform the task, but also the psychological capabilities, such as adequate cognitive functioning to overcome what is required (West \& Michie, 2020). The opportunity aspect is one required from the environment as opposed to the individual, and it highlights the necessity that the environment can facilitate the behaviour, whether it be in a monetary sense or a cultural/social sense (West \& Michie, 2020). The model then suggests that it is not these factors that influence the production of the desired behaviour, but instead these influence the individual's motivation to complete the behaviour. This 'motivation' stage corresponds with previously discussed models (such as AffectiveReflective Theory) as it considers two aspects of motivation, the automated, 
instinctive affective thoughts (System 1) and also the reflective considerations where known information evaluation is processed (System 2). It is then suggested that only when both aspects of capability and both aspects of opportunity are all in place, at one corresponding moment, that the behaviour will be possible (West \& Michie, 2020).

West and Michie (2020) personify these constructs as being 'logic gates', and motivation can only trigger a behaviour if the gates for both capability and opportunity are open simultaneously. This is then developed further to suggest that each time the behaviour is desired it becomes easier to achieve because our capability to do a task is improved (assuming we improve with practice) and opportunities may appear to arise more often at simultaneous moments (West \& Michie, 2020). This theory can explain why people may choose not to engage in a behaviour, and why if we believe a task is going to be difficult, we may deem our capability 'gate' to be closed. Similarly it just explain why if we feel as though the environment is hostile and judgemental, we may deem the social opportunity 'gate' to be closed. The model (and subsequent analogy) principally gives aspects of motivation the chance to stop an individual completing a task if an element of consideration does not induce a positive environment.

As aforementioned, it is completely underpinned by the PRIME Theory of Motivation (West, 2007). PRIME theory acknowledges a key principle in the study of motivation, which is that as humans, 'we act in pursuit of what we most want or need at that exact moment' (West \& Michie, 2020, p.1). This theory was initially developed to bring together lots of smaller theories with specific focuses (such as emotion), instead of disregarding them, it takes note of the widespread notions of motivation as links them all as one framework (West \& Brown, 2013). The theory actually considers the structure of the motivational system, with each of the five letters of PRIME representing a stage. The overarching aim of each motivation is to form a Plan, the conscious mental decision to perform a behaviour; the initial trigger is a Response to a stimuli or environment; which is influenced by Impulses and Motives within us; and these Motives come to arise through our subconscious evaluations of situations, environments and information (West, 2007; West \& Michie, 2020). Therefore, our motivation to exercise is fundamentally based on our affective 
response, and so without a positive attitude towards physical activity, as well as an exercise-friendly environment, it is unlikely that any behaviour change can occur.

The COM-B model has been used a framework not in only in the work of psychologists (particularly those studying addictions), but also in medical areas such as barriers to certain disease testing (McDonagh et al., 2018) and also in a multidisciplinary study of midwifery and endocrinology (Boyd et al., 2020), which all used the framework successfully. However, this theory has also been used in a study exploring the impact of a physical activity intervention on individual's motivation levels, explicitly emphasising how naturally the model mapped onto the issues surrounding motivation to exercise (Howlett et al., 2017).

\section{Potential Barriers to Physical Activity:}

As highlighted above, the COM-B model acknowledges that there are many factors that can prevent physical activity taking place, at both the individual and external levels. There is plenty of research suggesting why people remain 'inactive' according to the WHO definition. It has been suggested that many are not engaging in physical activity because they quite simply do not enjoy it - finding that it is a boring, tedious task, and that they would rather use the time to do something else (Bice et al., 2016). This research from Bice et al. (2016) also found that the consequential effects of exercise (such as being drained of energy) cause a lack of enjoyment and subsequently, a loss of interest. However, a common theme that has emerged amongst previous literature is that individuals feel that they do not have the time to engage in regular physical activity (Strazdins et al., 2011). Even those who now prescribe exercise as a form of preventative medicine were once found to be physically inactive, with 4 in 5 medical professionals identifying time as their primary barrier to regular exercise (Stevenson \& McKenzie, 1992). A factor that may have influenced the WHO to highlight the importance of changing social norms, exercise has repeatedly been deemed an inconvenience that interferes with daily lives and routines, while also coming at a cost, with both energy and often money being required (Gebhardt et al., 1999). Time is a valuable, finite resource, and many find it tough to complete all the tasks they wish to within a given time frame; for instance, educational, career and family obligations are all regular reasons given as to why an 
individual may be physically inactive, valuing the task as low priority in comparison (Ryan et al., 2009). Research found that $40 \%$ of Europeans would rather do other things with their spare time than be physically active (European Commission, 2014; Teixeira et al., 2012). It is possible that people's lives are becoming subjectively busier, and their health is being seemingly discarded as a result, however, it should also be acknowledged that this perceived 'lack of time' and their definitively sedentary lifestyle is not necessarily self-inflicted, as for many, a large proportion of daily sedentary hours is due to working hours and work environment, for example, a 9am to 5pm desk job with limited breaks (Commissaris et al., 2016; Parry \& Straker, 2013; Thorp et al., 2012). It is also noted that in recent years, individual's working hours have increased, with over a third of full-time employees in the UK working over 46 hours a week, the highest proportion of any European country (Kodz et al., 1998). In America, it has been suggested that $94 \%$ of working professionals work 50 hours a week, and nearly $50 \%$ work close to 65 hours, not including the anticipated 25 hours extra spent monitoring emails and doing added work using the technology available in the modern world (Perlow \& Porter, 2009). This has been repeated more recently, finding results of a lesser extent, yet still showing that many work 13.5 to 18.5-hour days, due to the ease and ability to work from home on a smartphone (Deal, 2015). Therefore, any health promoting intervention must ensure that it is feasible, and possible for most to complete without the need to offset 'too much' time, else it cannot be effectively engaged with (Tannahill, 2008). In the context of the COM-B model, having time available is extremely beneficial in terms of allowing the opportunities gate to be open, and if this gate is open more frequently, there is a greater chance of all aspects at once - which theory suggests would also lead to an increased level of physical activity. Conversely, on occasions where an individual has less time, as is the case in the circumstances described above, when people are working long days it is more likely that their opportunity gate would be closed, given the finite nature of time.

The importance of allowing some time to exercise instead of work is best contextualised when it is considered that, as previously discussed, those who do not engage in regular physical activity are more likely to become ill, and those with poor health are actually less productive when working either through absenteeism or presenteeism (Johns, 2011). Quantifying this, recent research has suggested that 38 
days' worth of productive work hours are lost per employee per year, a vast increase compared to 2014, when 23 days were lost (Vitality Health \& Financial Times, 2019). This lost productivity is estimated to cost the national economy around $£ 92$ billion per year (Vitality Health \& Financial Times, 2019), an avoidable deficit if health and wellbeing was effectively investigated in and suitable infrastructure was implemented.

\section{COVID-19 Pandemic:}

In March 2020, the United Kingdom was placed on an enforced 'quarantine lockdown' in order to help stop the spread of the novel coronavirus (COVID-19) outbreak. This government action enforced all not deemed to be 'key workers' (frontline healthcare workers, education workers or necessary goods -groceries etcworkers) to work from home. For those for whom this was not an option (roughly 9 million UK workers, from $50 \%$ of the UK's businesses), the UK Government introduced the Furlough scheme, whereby individuals were temporarily deemed partially unemployed and thus received benefit for their lack of work, at a rate of $80 \%$ of their expected income (Verity, 2020). By August 2020, the total number of individuals who had, or were still receiving, furlough payments reached over 9.6 million, approximately 1 in 4 of the UK's working population (BBC, 2020; Clark, 2020).

With much of the country working from home or considered furloughed, many individual's may have found themselves with greater control over their schedule, and more time on their hands. Given that a lack of time is a common reason for not exercising, this may have meant that more people had the option to spend this 'extra' time engaging in physical activity. Indeed, the enforced lockdown offered the opportunity for individuals to adjust their routines such that they could make time for physical activity, which could potentially change their motivation and behaviours in the long-term. Initial lockdown measures stated that individuals were allowed a maximum of 60 minutes of exercise outside of their home each day. After six weeks of lockdown this was extended such that unlimited outdoor exercise was permitted, as long as $2 \mathrm{~m}$ social distancing guidelines were adhered to (Ministry of Housing. 
Communities and Local Government, 2020). Thus, as exercise was one of only a few permitted activities, there was opportunity to increase physical activity levels for those furloughed and without carer responsibilities, doing as much or as little physical activity as they wished. While it was not planned for the purpose of a physical activity intervention, and was the result of government advisors deeming it safe, the delayed nature of the unlimited exercise policy corresponds with many of the theories previously discussed, as it allowed individuals to do short bouts of physical activity, while in the presence of other individuals that they likely felt comfortable amongst (their own household). This may have enabled many who had negative affective attitudes towards physical activity to get the chance to alter this attitude through short 'trial' sessions and thus have positive experiences, which as previously mentioned can have a significant bearing on one's motivation to exercise.

Besides this, the limited venues that were allowed to open (for example tennis courts and golf courses) were often only open to members, due to social distancing policies, so for many, simple exercise such as walking, running and cycling were the only available and sustainable options. These 'simple' exercises would likely be deemed towards the 'easy' point of the task difficulty continuum that the Theory of Planned Behaviour suggests to be vital in motivation, thus an increase in activity at this level could increase motivation to exercise in the future. The proposition that many were engaging in short bouts of physical activity (even through boredom and a desire to leave their house), and the potential that attitudes were positively altered as a result, mean that it is possible that the pandemic lockdown period in the United Kingdom could have indirectly had a positive effect on the silent physical inactivity endemic.

As previously described above, the COM-B model describes a behaviour change as a 'gated' system, whereby it is acknowledged that if there are barriers of any form, that cannot be overcome, that certain 'gate' is closed and so a behaviour is much less likely to occur, whilst also suggesting that when there are no barriers, the 'gates' are open and so a behaviour is more likely. In the context of the pandemic, the COM-B model would suggest that lockdown may have provided the perfect physical and social opportunity for some individuals to increase their physical activity habits, and alter their behaviour. For instance, for those who were on furlough and had no caring responsibilities (and potentially those who no longer needed to spend time 
commuting into work), the 'opportunity gate' for increasing physical activity would be open, and thus the model would predict that these individuals may increase their physical activity levels as they potentially have more time to exercise. Additionally, if they were isolating in a household where they were all in the same position, this may have opened another gate by providing social opportunities, as they may not be exercising alone, which the model suggests makes physical activity more likely.

On the other hand, those who say their workload increased during the pandemic, or who had additional caring responsibilities, would have likely had the opportunity gate closed for them, as they had less time available. Therefore the COM-B model would predict that these individuals would be less likely to do physical activity. Indeed, it was estimated that there were roughly 10 million key-workers during the pandemic (Office for National Statistics, 2020a), each of whom were likely asked to perform extra hours at work due to the strain placed on the companies they worked for. However, although they may not be able to engage in formal exercise as such, it is likely that many of these roles were physically active. This is especially true for those key workers who worked within the hospitals, as previous research has identified that their jobs tend to lead to them meeting WHO's physical activity guidelines (Jun et al., 2019), even before the hospitals became overcrowded with people suffering with Coronavirus, and the demands of each worker were further increased. Therefore, though time may not have been readily available for those who were deemed to be key workers, it's possible that the increase in working hours and potential increased intensity of the work meant that key workers were not missing out on physical activity, but lacked the time to do activity of their own choosing.

Additionally, it's possible that some people who changed to work from home had previously relied on their daily commute to work for their physical activity, with work and home responsibilities not allowing for leisure-time exercise. Indeed, the 2019 National Travel Survey (Department for Transport, 2019) showed that of a sample of nearly 75,000 respondents who are reliant on only one mode of transport for their work commute, $6 \%$ walk and $3 \%$ cycle, whereas $75 \%$ commute via car. It is highly likely that a number of these $9 \%$ of active commuters were no longer required to commute, whether that be through working from home or being furloughed. It's possible that instead of the active commute, the individuals were instead spending longer working, as they were able to be at their home-working stations quicker than 
they would have otherwise, allowing for a longer working day, which could also lead to a lengthier bout of sedentary behaviour. Kun et al. (2020) found that despite an average decline of 41 minutes of commuting each day, this time was often offset into doing additional work, with those in a management position doing an extra 56 minutes of work each day on average. Furthermore, it is also possible that given the danger that the pandemic possessed, some individuals may have been afraid to leave the house due to the risk of contracting Coronavirus, or leaving the house less to minimise their risk. As such, with these points considered, there is certainly a chance that for some individuals, regardless of whether they perceived themselves to have more spare time or not, these possible reasons could have prevented their opportunity gates from being open, and as such, it is unlikely there would be any behaviour change, as the circumstances would not allow it.

In regards to the capability aspects of the COM-B model, due to the many 'more skilled' activities being unachievable due to closures, the majority of available activities were, as mentioned, towards the 'simple' end of the subjective taskdifficulty continuum, thus encouraging the physical capabilities 'gate to be open'. The lack of specialist knowledge for activities such as walking meant that it was likely that almost everyone had the psychological capacity to achieve the task, with very few cognitive resources necessary. The final aspect of the model is the motivation stage, which the rational education approach (Ekkekakis et al., 2018) would suggest should be high due to the knowledge of the benefits of exercise (Reflective motivation), and also the urge to leave the confines of the area in which the individual was experiencing lockdown (Automatic motivation), to overcome any cabin fever they may be experiencing (Crawford \& Crawford, 2021).

Isolation style periods, such as the 2020 Coronavirus pandemic lockdown and 2003 SARS outbreak and 2014 EBOLA outbreak quarantines, have previously been shown to have extremely negative effects on wellbeing (Brooks et al., 2020). A likely contributing factor to which, is the loss of routine. Often shown to be extremely beneficial to our health (Arlinghaus \& Johnston, 2019), humans are 'creatures of habit' and strive for an element of routine in everyday life (Ersche et al., 2017). This level of routine was put under threat by the emergence of COVID-19, and the consequential lockdown period that followed, as many were unable to work, shops were closed, meeting those outside your own household was banned and organised 
sport was prohibited. This was believed to be another reason that people may begin to engage in more regular physical activity, using one of the only permitted out-ofhouse activities to gain some form of routine during the isolation period. It has been claimed that humans require a form of 'meaning' in life (Maslow, 1968), and that the perception of having meaning benefits us physically (Roepke et al., 2014), mentally (Boyle et al., 2010; Steger \& Kashdan, 2009) and socially (Stillman et al., 2011). Having a sense of routine is said to heavily contribute to this sense of purpose and meaning (Bond \& Feather, 1988; Martela \& Steger, 2016). In general, it is believed that there is a strong association between routine and mental wellbeing (Heintzelman \& King, 2019), with links to a sense of comfort and control (AvniBabad, 2011), which were likely to have been lacking during the pandemic.

Within the context of the 2020 Coronavirus government-enforced lockdown, a popular method of gaining a sense of routine through exercise was through engagement with Joe Wicks' 'PE with Joe' online videos, which were 30-minute exercise routines shared on YouTube at 9am every weekday morning throughout lockdown. Such was the popularity of these videos, Joe Wicks earned a Guinness World Record for the most viewers ever to watch a fitness/workout livestream, with almost one million viewers on March $24^{\text {th }}$ - roughly a week into lockdown restrictions (Guinness World Records, 2020). Not only were these videos a potential source of routine throughout lockdown, but also became something of a small virtual community, which may have contributed to individual's sense of belonging.

However, despite the many benefits outlined, and the motivational boosts that may arise during lockdown, when looking at the effectiveness of previously held interventions with a view to increase physical activity levels, it seems likely that whilst there is a chance physical activity levels may see a short-term increase (during the lockdown), it is possible that when everyday routine returns to 'normal', many individuals will revert to their usual routine once they begin to consider time 'a luxury' again (Müller-Riemenschneider et al., 2008; Rhodes et al., 1999). A systematic meta-analysis review into the efficacy of exercise interventions found that while twothirds of those studied did show positive intervention effects, the number of those enrolled who were adhering to the physical activity recommendations ranged from $4.6 \%$ to $81 \%$ - therefore demonstrating that although most interventions increased physical activity levels, there was still certainly vast room for improvement (Müller- 
Riemenschneider et al., 2008). The wealth of research suggesting that many interventions fail to provide meaningful, long-lasting behaviour change is why it is not only important to assess whether having more control over one's time increases physical activity, but also to see whether the behaviour change is reinforced and thus persistent, or whether people relapse into previous habits upon returning to their normal routine. Therefore, it is highly possible that regardless of any potential change in behaviours during lockdown, when 'normality' is resumed and the element of spare time has been lost (as people will have to return to work), many will relapse to their original levels of activity. This would also be in fitting with the COM-B model, as the physical opportunities would be reduced without as much spare time available; however, in spite of this, the frequency of social opportunities may increase when other activities are allowed to reopen, and households can meet again. A decrease in activity levels is also possible, when it is considered that the individual's internal locust of causality may not have fully developed towards the new, altered behaviour, and without the controlled motivation aspect of lockdown, with the tangible reward of actually leaving the confines of one's house for a shortspell, the individual's motivation to exercise may not be present, and subsequently, levels may drop.

Therefore, though it is known and accepted that physical activity can provide meaningful benefits on many aspects of health (Warburton \& Bredin, 2017), physical activity habits worldwide are not consistently meeting WHO targets, and motivation to exercise seems to be a major barrier around this, with a lack of spare time being a particular concern (Strazdins et al., 2011). The COVID-19 pandemic led to a national lockdown, where many suddenly found themselves in unprecedented circumstances where their only permitted activity outside of the household was physical activity. This provided a novel opportunity for many to engage with physical activity as much or as little as they wished, potentially increasing motivation levels, which when considered using psychological theories and frameworks, may in the long-term lead to permanent behavioural changes.

The pandemic and ensuing lockdown meant that lab-based data collection for previously planned research regarding potential ways to increase the length of time that people engage in physical activity became unattainable for an unknown length of time. This planned research was idealistically founded upon the desire to increase 
motivation and enjoyment of exercise, drawing elements of various theoretical frameworks and hypotheses to make physical activity more attainable and less daunting, so to try and improve the rate of physical inactivity. However, due the pandemic, the research focus shifted to use survey-based research investigate how physical activity habits may have changed during lockdown. This was based on the COM-B model principles that multiple factors must align at once, and the commonly reported reasons for not being able to exercise can be explained using this model. With spare time potentially being attained by more individuals than usual as a result of the pandemic, the circumstances meant there was an undeniable opportunity to use the theory behind the COM-B model to research physical activity engagement and behaviour, and compare how this spare time was used both at an individual level, but also between those who did and did not gain an increase in spare time.

As such, the present study investigated the effect of the COVID-19 pandemic lockdown enforced by the UK Government (on 23 ${ }^{\text {rd }}$ March 2020) on physical activity levels and wellbeing, especially amongst those for whom the lockdown provided more spare time. The study also tracked these changes after the lockdown restrictions were eased in England on $15^{\text {th }}$ June 2020, whereby non-essential shops were allowed to re-open.

\section{Hypotheses:}

There were six overriding hypotheses within the research, which were each tested using four measurements: the total length of time engaged in physical activity during a given week (mins); the total intensity of the physical activity during said week (in Metabolic Hours per Week [METhrs/week]); and, where possible, total step count and total distance covered $(\mathrm{km})$ for the week was also assessed.

Firstly, based on the initial survey, it was hypothesised that physical activity levels would increase during lockdown compared to before the restrictions came into place. Secondly, those who perceived themselves to have more spare time during the lockdown restrictions (compared to before) would engage in higher levels of physical activity levels during lockdown compared to before. This was to be tested using difference scores (by subtracting the pre-lockdown physical activity levels from 
the during lockdown physical activity levels) as the dependent variable. Third, it was hypothesised that there would be a positive relationship between mental wellbeing and physical activity levels during lockdown.

Based on the follow up survey, it was hypothesised that, fourthly, there would be differences in physical activity levels across the three time points (pre-lockdown, during lockdown and eased lockdown). Specifically, pre-lockdown physical activity levels would be lowest and physical activity levels would be highest during lockdown. Fifth, those who perceived themselves to have more spare time after the lockdown restrictions eased (compared to before they began) would engage in higher levels of physical activity levels once the restrictions eased compared to before. This was tested using difference scores (by subtracting the pre-lockdown physical activity levels from the physical activity levels once the restrictions eased) as the dependent variable. Finally, there would be a positive relationship between mental wellbeing and physical activity levels during the period of eased lockdown. Again, physical activity was measured using self-reported time and intensity engaged in physical activity (which was converted into the number of Metabolic Hours per week - METhrs/week) and, for those with a smart device, the number of minutes and steps per week exercised for, and the distance covered (in $\mathrm{km}$ ) per week. 


\section{Method}

\section{Participants:}

Power analysis (based on the planned MANOVA analyses) using the software G*Power 3.1.9.2 (Faul et al., 2007) determined that for .95 power, with an alpha level of .05 and a medium effect size of .30 (Davey et al., 2008), a sample size of 52 participants was recommended. Participants were required to meet two inclusion criteria for the present research: (1) They had to be living in England during the COVID-19 pandemic (so to experience a standardised set of 'lockdown' procedures and restrictions), and (2) they must be between the ages of 18-73 (as this is required for the Warwick-Edinburgh Mental Wellbeing Scale).

Utilising an opportunity sample, gained through the use of online social networks (Facebook, Twitter and Linkedln) and facilitated by participant word-of-mouth, the study recruited 277 participants (175 females, 102 males, Mage $=36.4, S D=15.2$ ). Of this sample, 59 also provided data from their smart device. The research gained ethical approval from the University of Gloucestershire Ethics panel before the survey was distributed, and all participants gave their digital consent. At the response screening stage, 77 responses were omitted (40 for failing to provide time data during completion of the PWMAQ and 37 for failing to complete both the before and during COVID lockdown questionnaires without time data). Thus, the final sample for this research comprised of 200 adult participants (128 females and 72 males; $\left.M_{\text {age }}=36.1, S D=14.8\right)$.

On 04/08/2020, a follow-up study was emailed to those participants who had provided a contact email address to take part in a further survey. Of the initial sample, 46 (Mage = 38.4, $S D=15.7,30$ females, 16 males) participated in the follow up study but only 10 provided data from their smart device. When the responses of the follow up study were screened, 13 of the 46 participant responses were omitted for failure to complete at least one of the three time points correctly during the research. Therefore, the final sample for the follow up study was 33 participants 
(Mage $=36.9,25$ females, 8 males $)$. Of this sample, 10 provided data from their smart device.

It is acknowledged that this method of sampling may result in a biased sample (Arigo et al., 2018), as it is probable that those who enjoy and engage in physical activity may be more likely to click on a link to complete research about physical activity levels. Additionally, those who were still working, that had not been furloughed may have had the time to be able to complete the research (and may have been more likely to have the time to exercise). As the participant recruitment was conducted via social media platforms (Facebook, Twitter \& Linkedln), there was also potential that this may have impacted the participant pool based on the stereotype that those who use social media tend to be younger. As of April 2021, over $67 \%$ of Facebook users in the UK were 44 or younger, with $\sim 4 \%$ in the $18-34$ age bracket (Tankovska, 2021b), additionally, Sloan (2017) found that Twitter users in the UK also tended to be young, with an age distribution noticeably younger than the age distribution of the UK. However, as of April 2021, 58\% of Linkedln users were between 25-34 and 22.1\% were between 35-54 years old (Tankovska, 2021a), though the research was also shared by word of mouth, so it is possible that others were reached aside from via social media. It is also highlighted that social media has been noted as being well-suited for the recruitment of participants for health-based research, as well as for studies centre around health behaviour changes (Arigo et al., 2018).

\section{Design:}

Firstly, to determine the effect of the stages of lockdown on physical activity habits, two one-way MANOVAs were conducted (one using self-reported data and the other using fitness tracker data) whereby the independent variable was the stage of lockdown (Pre or During), while the two dependent variables were the measurements of the participant's physical activity levels, Metabolic Hours per Week (METhrs/week) or Time (minutes). Independent samples t-tests were then utilised to compare the difference scores for each of the four measured variables, by the perception of spare time - for example, (METhrs/week during Lockdown METhrs/week before lockdown) x Perception of having more Spare time during 
lockdown (Yes or No). Using the difference scores in this instance allowed the true impact of spare time to measured, as spare time was the focussed factor in these hypotheses. The relationship of each of the four activity measurements with participant wellbeing during lockdown, was also analysed using Pearson's correlations.

The follow up study followed the same design as the initial survey; using MANOVAs to assess the effect of the three time points (Pre, During and Eased Lockdown) on physical activity levels, as well as independent sample t-tests to assess the difference that having a perception of more spare time in eased-lockdown (compared to pre-lockdown) has on physical activity levels (this time with the template METhrs/week Eased Lockdown-METhrs/week before lockdown $\times$ Perception of having more Spare time during lockdown (Yes or No)). The relationship between physical activity levels and mental wellbeing in the period of eased lockdown was again analysed using Pearson's correlations.

The follow up also had the addition of two open questions purporting to the motivations to exercise, and reasons why people do not exercise. The analysis of these incorporated noting the frequency in which answers appeared, to produce a visual representation of word frequency, known as a word cloud, whereby the more often a response is present within the dataset, the larger the word is (Atenstaedt, 2012; Zhang \& Shaw, 2020). These word clouds have been identified to be effective when there is little detail in qualitative data, highlighting the primary focus of written material (Atenstaedt, 2012). This form of manifest content analysis (Potter \& LevineDonnerstein, 1999) took the responses at face value, analysing the data based on the appearance of a particular word or phrase within the responses, and therefore the quantification was not attempting to infer any form of meaning, and was simply a mere word count, thus remaining a quantitative analysis (Hsieh \& Shannon, 2005; Kondracki \& Wellman, 2012). 


\section{Apparatus and Measures:}

The survey was conducted online, using Jisc Online Surveys technology (Online Surveys; Bristol, UK). Firstly, the survey collected various items of demographic data, this included: participant age, gender, work status before and during COVID19 , as well as numerous questions regarding their living circumstances during COVID lockdown, such as whether they were living or exercising alone, what type of outdoor area they had access to, as well as whether they had any carer responsibilities. The final question on this page asked participants whether they felt that they had more spare time during lockdown than they had previously - something that was eluded to within the literature as being a potential barrier to engaging in physical activity. In total, this demographics page (not including specification boxes where 'Other' had been answered), comprised of 11 forced-choice questions (see Appendix 4).

Additionally, this research used two existing psychological measures within the formation of its survey, in order to explore the level of physical activity by each participant, and also the participant's mental wellbeing at that moment in time. The first existing psychological measure employed was that of the Warwick-Edinburgh Mental Well-being scale (WEMWBS; Tennant et al., 2007). This scale features 14 statements ascertaining to an aspect of an individual's mental well-being, and requires the participant to score each statement using a 5-point Likert scale based on how well the statement reflects them, where 1 denotes 'None of the Time', through to 5 denoting 'All of the Time'. This scale is popular within literature, and has a very high validity, with a Cronbach's alpha of 0.91 amongst the general population (Stewart-Brown et al., 2011; Stewart-Brown et al., 2009; Tennant et al., 2007). The scale has also been shown to be reliable, with a test-retest reliability of 0.83 , and it being noted that social desirability bias influence is lower or similar than that of comparable scales (Stewart-Brown et al., 2009; Tennant et al., 2007). It was elected that this research would assess the impact that the experience of lockdown had on mental wellbeing as a whole, as it was considered to be unknown exactly what elements this novel circumstance would affect the most - for instance, research on previous similar situations has acknowledged the potential effects on depression, anxiety and stress (Brooks et al., 2020). The primary focus of the research was the 
potential behaviour change in physical activity habits, and so subsequently, it was decided that mental wellbeing would be viewed as a whole, with each of the individual elements of mental health encapsulated within the 14-item scale, under the umbrella of mental wellbeing. It was also acknowledged that exploring the individual aspects (depression, anxiety and stress) would substantially increase the length of the survey, which may have jeopardised the number of participants that completed the research.

The second measure used was the Past-Week Modifiable Activity Questionnaire (PWMAQ; Pettee Gabriel et al., 2011). The PWMAQ is an American intervieweradministered survey designed to assess an individual's leisure-based physical activity over a seven-day period (Pettee Gabriel et al., 2011), which uses estimates of the metabolic equivalent of each activity, alongside their reported time spent completing each, in order to compute the number of metabolic hours per week (MET.h/week) for each individual (Kriska et al., 1990). Though there are many questionnaires that measure physical activity levels, such as the commonly used International Physical Activity Questionnaire (IPAQ; International Physical Activity Questionnaire, 2005) or the Global Physical Activity Questionnaire (GPAQ; WHO, 2002), it was decided that in the circumstances, the PWMAQ was better suited. This questionnaire focusses specifically on leisure-based activity, disregarding occupational and transport-based physical activity, as previous research had shown little variation in these sectors among certain population subgroups (Newman et al., 2009; Pettee et al., 2007). The omission of these activities makes it well-suited to research of this nature, during a time where circumstances meant that many could not work, and were not travelling anywhere. Therefore, using the IPAQ or GPAQ in this situation would not have produced valid or reliable responses, as the final calculation would be made impossible without any time figures for these categories. These circumstances also meant that face-to-face interviews, the intended design of the questionnaire, were not possible, however following personal correspondence with the creator (Pettee-Gabriel, personal communication, 04/05/2020), it was decided that the questionnaire was suitable to be modified for use as an online survey, as the system being used allowed for skip logic. The questionnaire was modified to suit the English sample by removing typical US activities that were not common in England (such as baseball, hunting and snow shoeing) and adding in 
common English activities (such as cricket, rugby and gymnastics). The number of activities included in the questionnaire remained at 38 . The questionnaire itself has been shown to be substantially reliable, with a test-retest reliability of 0.74 when selfadministered (Pettee Gabriel et al., 2011). The PWMAQ also has been shown to have relatively substantial validity when compared with pedometer and Actigraph data, at 0.60 and 0.51 respectively (Pettee Gabriel et al., 2011).

In addition to these self-report questionnaires, those with smart devices were also asked to provide information from their accelerometers (such as Fitbit [California, USA], Garmin [Kansas, USA] and AppleWatch [California, USA] devices). Here, participants were asked for their weekly step count and distance data (they were given the option to input this in kilometres or miles) to be used as an objective measure to supplement the questionnaire responses. Wrist-worn accelerometers such as these devices have been shown to have a strong reliability rating for stepcounts when compared to Actigraphs (ICC=0.57; Sushames et al., 2016), and have also demonstrated a strong validity (Diaz et al., 2015; Evenson et al., 2015). When distance reporting was investigated, reliability was found to be high, despite a tendency to over-estimate when walking at slower speeds, and under-estimate when walking quickly (Takacs et al., 2014). These objective measures were taken due to the well-established reliability issues surrounding self-reported questionnaires, and their vulnerability to bias (van de Mortel, 2008).

\section{Procedures:}

The initial online survey began with an information sheet (Appendix 1) and a consent form (Appendix 2). Following this, each participant was required to create a Unique Identifier Code to ensure their anonymity (Appendix 3 ).

Next, participants completed the demographics questions (Appendix 4), before carrying out the WEMWBS (Appendix 5), based on their thoughts and feelings during the moment they were completing the questionnaire (thus capturing the participant's mental wellbeing during lockdown). 
Then, participants completed two iterations of the PWMAQ (Appendix 6), which was first based retrospectively on a week during the month of February, before governmental lockdown restrictions began within England, and then a second time based on the 'present' (during the English Coronavirus lockdown, at the stage when unlimited exercise was permitted). Upon cessation of each iteration, those with activity trackers were invited to input the required objective data for the respective time period. They were asked for step count data and also distance data, which they able to enter in miles or kilometres (the data entered in miles was converted to kilometres before analysis by multiplying by 1.609).

Finally, participants had the opportunity to provide an email address to participate in follow up surveys on the topic, before receiving the debrief (summarising the research and supplying participants with relevant contacts).

The follow-up survey took the same format: Information sheet, consent form, unique identifier creation, demographic questions, WEMWBS, PWMAQ (and fitness tracker data if applicable). However, the follow-up survey had an additional page before the debrief, where participants were asked to answer two open questions regarding their motivation to exercise, and any reasons why they might not exercise.

Figure 1 - A Timeline Figure displaying when each element of the study was conducted, and how this fit within the context of lockdown restrictions in England

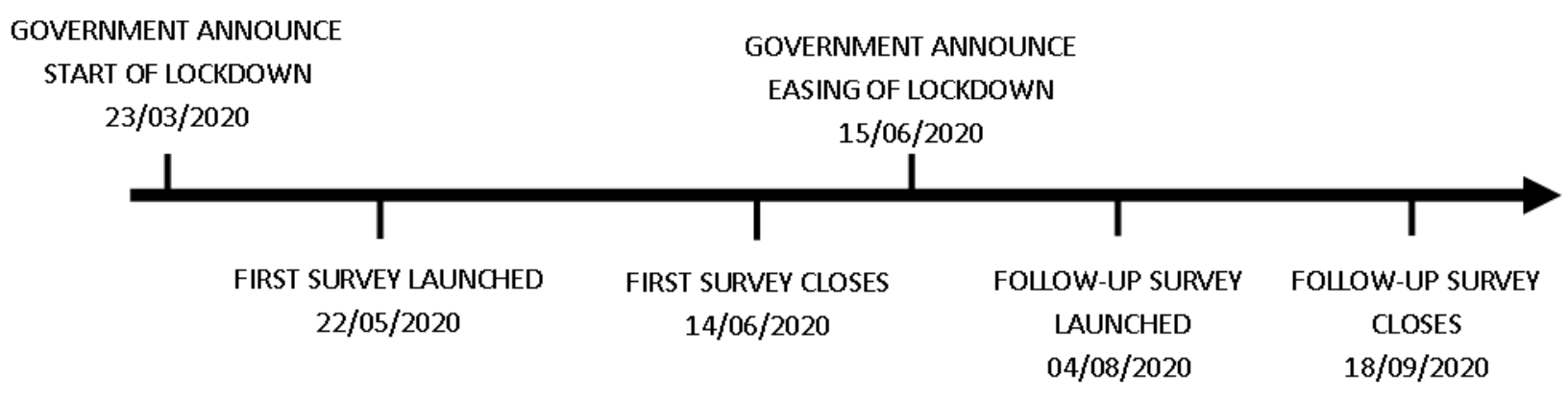




\section{$\underline{\text { Results }}$}

\section{Demographic Characteristics:}

The majority of participants were working full-time pre lockdown, with a smaller number of students and part-time workers. This number in full-time work reduced during lockdown restrictions as a number of these were furloughed, forced to work from home or could only work part-time (see Table 2).

Table 2 - A breakdown of demographic information

\begin{tabular}{|c|c|c|c|}
\hline & Male & Female & Total \\
\hline Age (Mean) & 33.82 & 37.52 & 36.13 \\
\hline \multicolumn{4}{|l|}{ Pre-Lockdown Employment Status } \\
\hline Full-Time & 48 & 59 & 107 \\
\hline Full-Time (Working from Home) & 0 & 0 & 0 \\
\hline Part-Time & 5 & 34 & 39 \\
\hline Part-Time (Working from Home) & 0 & 1 & 1 \\
\hline Student & 14 & 26 & 40 \\
\hline Unemployed & 1 & 2 & 3 \\
\hline Retired & 3 & 2 & 5 \\
\hline Other & 1 & 4 & 5 \\
\hline \multicolumn{4}{|l|}{ During-Lockdown Employment Status } \\
\hline Full-Time & 18 & 18 & 36 \\
\hline Full-Time (Working from Home) & 14 & 28 & 42 \\
\hline Part-Time & 4 & 6 & 10 \\
\hline Part-Time (Working from Home) & 1 & 15 & 16 \\
\hline $\begin{array}{l}\text { Part-Time (Covid19 Related Reduced } \\
\text { Working Hours) }\end{array}$ & 3 & 7 & 10 \\
\hline Furloughed & 13 & 16 & 29 \\
\hline Student & 11 & 23 & 34 \\
\hline Unemployed & 3 & 6 & 9 \\
\hline Retired & 3 & 2 & 5 \\
\hline Other & 2 & 7 & 9 \\
\hline \multicolumn{4}{|l|}{ Isolating Alone? } \\
\hline Yes & 7 & 10 & 17 \\
\hline No & 65 & 118 & 183 \\
\hline \multicolumn{4}{|l|}{ Access to an Open Space? } \\
\hline Yes & 70 & 122 & 192 \\
\hline No & 2 & 6 & 8 \\
\hline \multicolumn{4}{|l|}{ Description of Open Space? } \\
\hline Small Garden & 29 & 54 & 83 \\
\hline Large Garden & 16 & 46 & 62 \\
\hline Field & 8 & 11 & 19 \\
\hline Woodland & 8 & 6 & 14 \\
\hline Park & 6 & 3 & 9 \\
\hline Other & 3 & 2 & 5 \\
\hline \multicolumn{4}{|l|}{ Carer Responsibilities? } \\
\hline Yes - Childcare & 13 & 22 & 35 \\
\hline Yes - Carer & 1 & 10 & 11 \\
\hline Yes - Both Childcare \& Carer & 1 & 1 & 2 \\
\hline No & 57 & 95 & 152 \\
\hline \multicolumn{4}{|l|}{ More Spare Time During Lockdown? } \\
\hline Yes & 47 & 78 & 125 \\
\hline No & 20 & 44 & 64 \\
\hline Unsure & 5 & 6 & 11 \\
\hline
\end{tabular}




\section{Initial Survey:}

\section{Physical Activity -}

Repeated measures MANOVAs compared physical activity levels before and during the lockdown restrictions. Two of these tests were conducted, the first regarding the self-reported data and the second regarding the objective, fitness tracker data - two were needed so that the total sample size was not reduced to only those that provided all four forms of physical activity measurement. Whilst significantly higher levels of physical activity were seen during lockdown compared to before when physical activity levels were measured by self-reported time spent engaging in physical activity, $F(1,187)=13.89 p<.001, d=.31$, self-reported METhrs/week, $F(1,187)=2.63, p=.106 . d=.139$, and the data from the smart devices did not demonstrate statistically significant differences (Number of steps:

$F[1,45]=0.20, p=.659, d=.063$, distance travelled in $\mathrm{km}, F[1,41]=0.23, p=.638$, $d=.09)$. These results are summarised in Figure 2.

Figure 2 -

Bar Charts displaying the four measurements of physical activity levels of participants, Pre-Lockdown and During-Lockdown
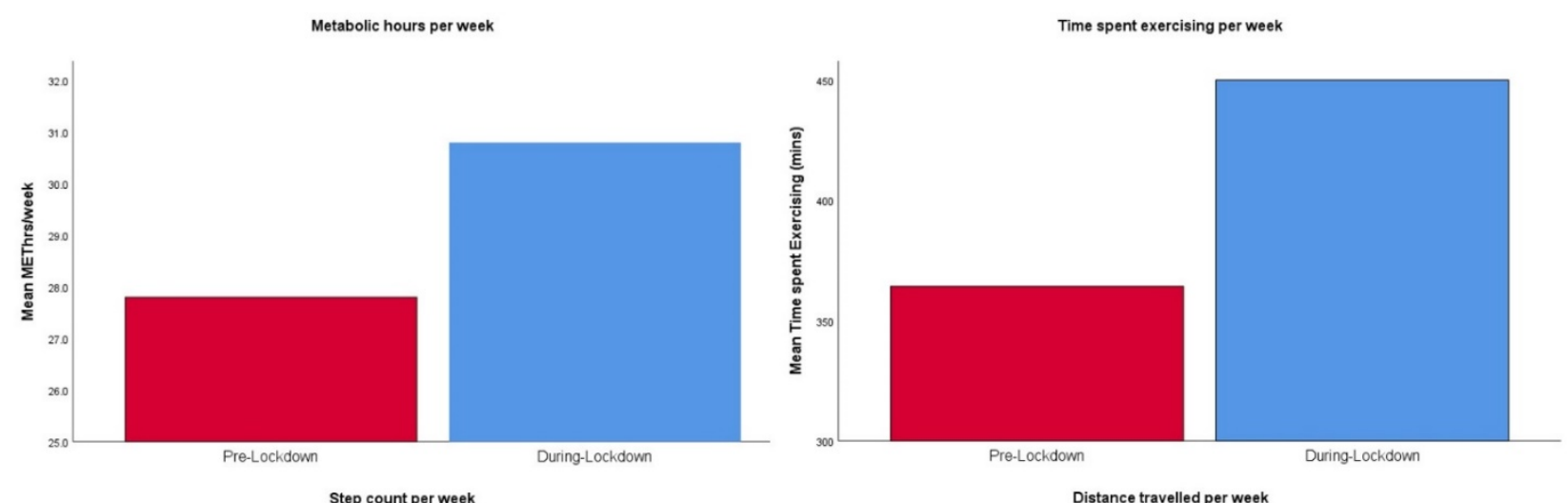

Step count per week

Distance travelled per week
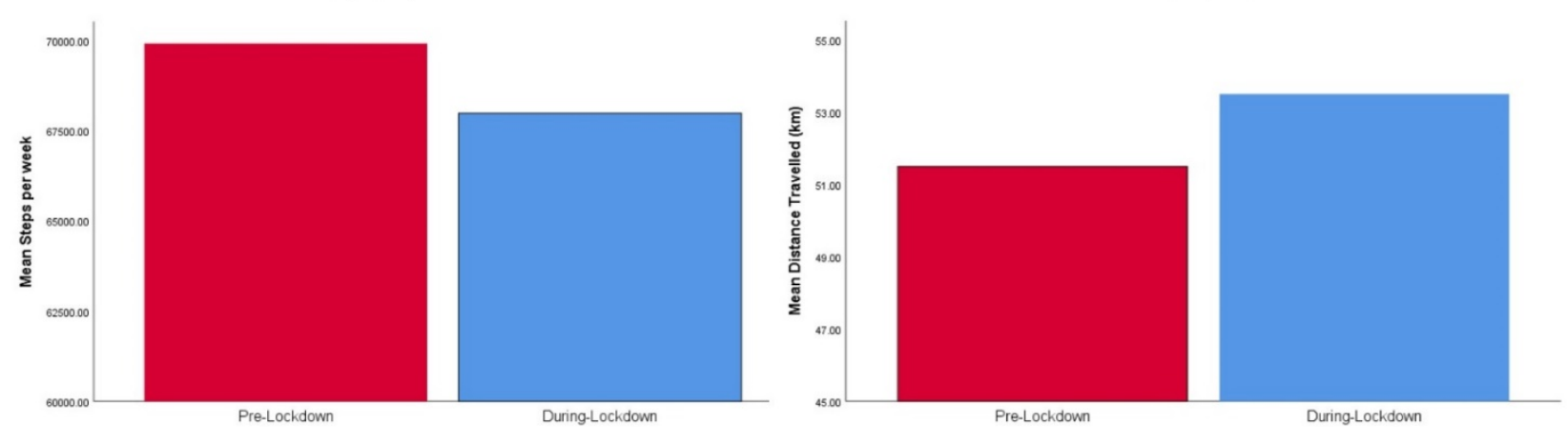
Data was then split into those who perceived themselves to have more spare time during the lockdown restrictions compared to before $(\mathrm{N}=125)$ and those who did not $(\mathrm{N}=63)$. Independent $\mathrm{t}$ tests compared these two groups using the difference score between physical activity levels before and during the lockdown restrictions as the DV. Here, whilst the self-reported measures of METhrs/week $(t[181])=-2.21$, $p=.028, g=.35)$ and time spent engaging in physical activity levels $(t[180]=-2.45$, $p=.015, g=.38$ ) demonstrated that those with more spare time did engage in more activity during than before lockdown compared to those who did not have more spare time, the data from the smart devices did not demonstrate statistically significant differences (number of steps: $t[39]=-1.11, p=.272, g=.42$, distance travelled in $\mathrm{km}, t[36]=-1.72, p=.094, g=.69)$. Effect sizes within this test were measured using Hedge's g, due to the disparity in sample sizes between each group (Lakens, 2013). These results are summarised in Figure 3.

Figure 3 -

Bar Charts displaying the comparisons of the physical activity differences between stages of lockdown, based on whether the participant perceived themselves to have more spare time during lockdown.
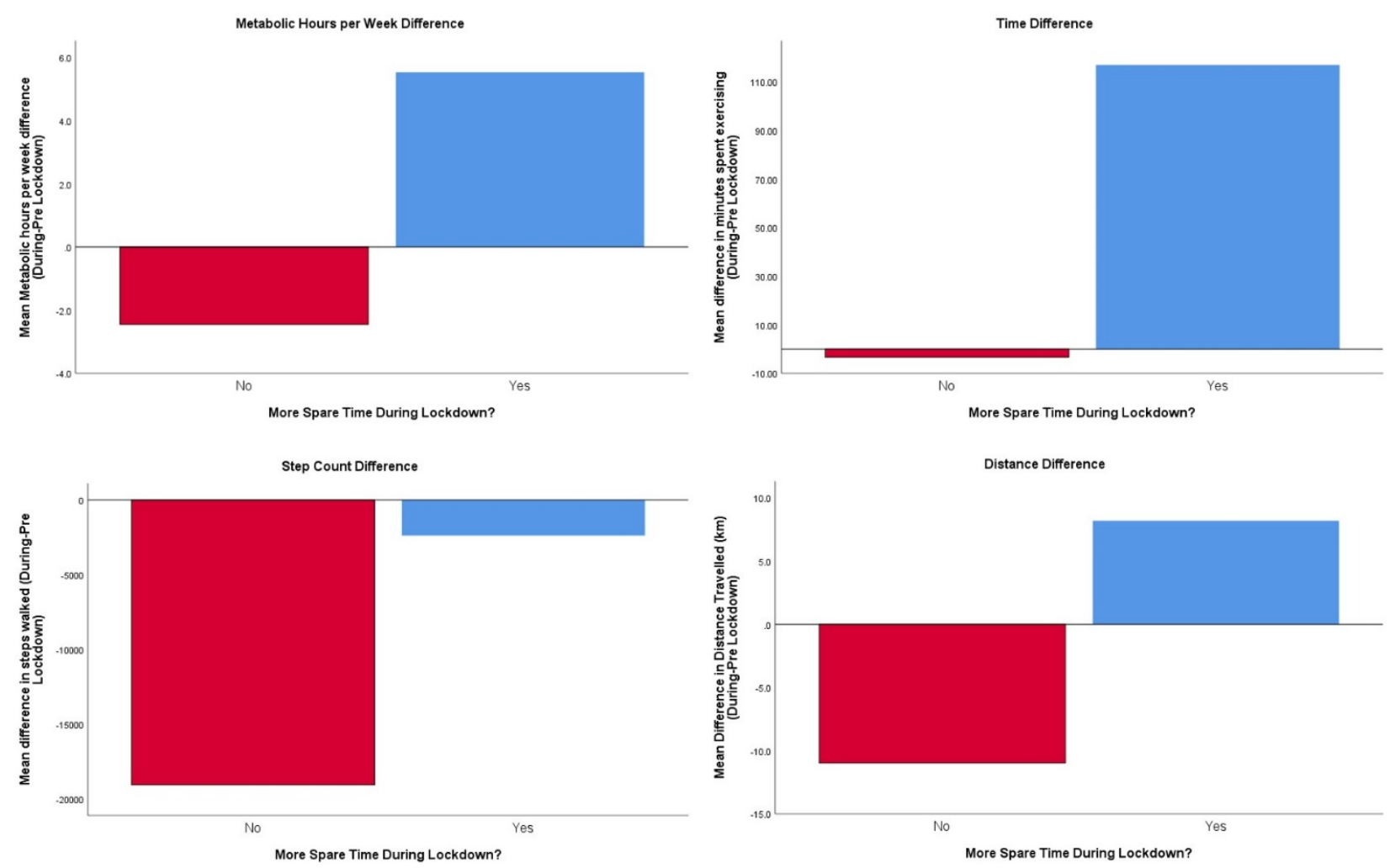


\section{Mental Wellbeing -}

Pearson's correlations were conducted to identify whether there was a relationship between physical activity levels and participant wellbeing during lockdown (see Figure 5). Whilst the self-reported measures of METhrs/week ( $r$ 190]= $.25, p<.001)$ and time spent engaging in physical activity $(r[190]=.26, p<.001)$ were weakly positively correlated with wellbeing, the data from the smart devices did not demonstrate statistically significant correlations with wellbeing (number of steps: $r[47]=0.07, p=.331$, distance travelled in $\mathrm{km}, r[42]=.05, p=.373$ ).

\section{Figure 4 -}

Scatter Plots displaying the correlational relationships between the four measurements of physical activity and mental wellbeing during lockdown.
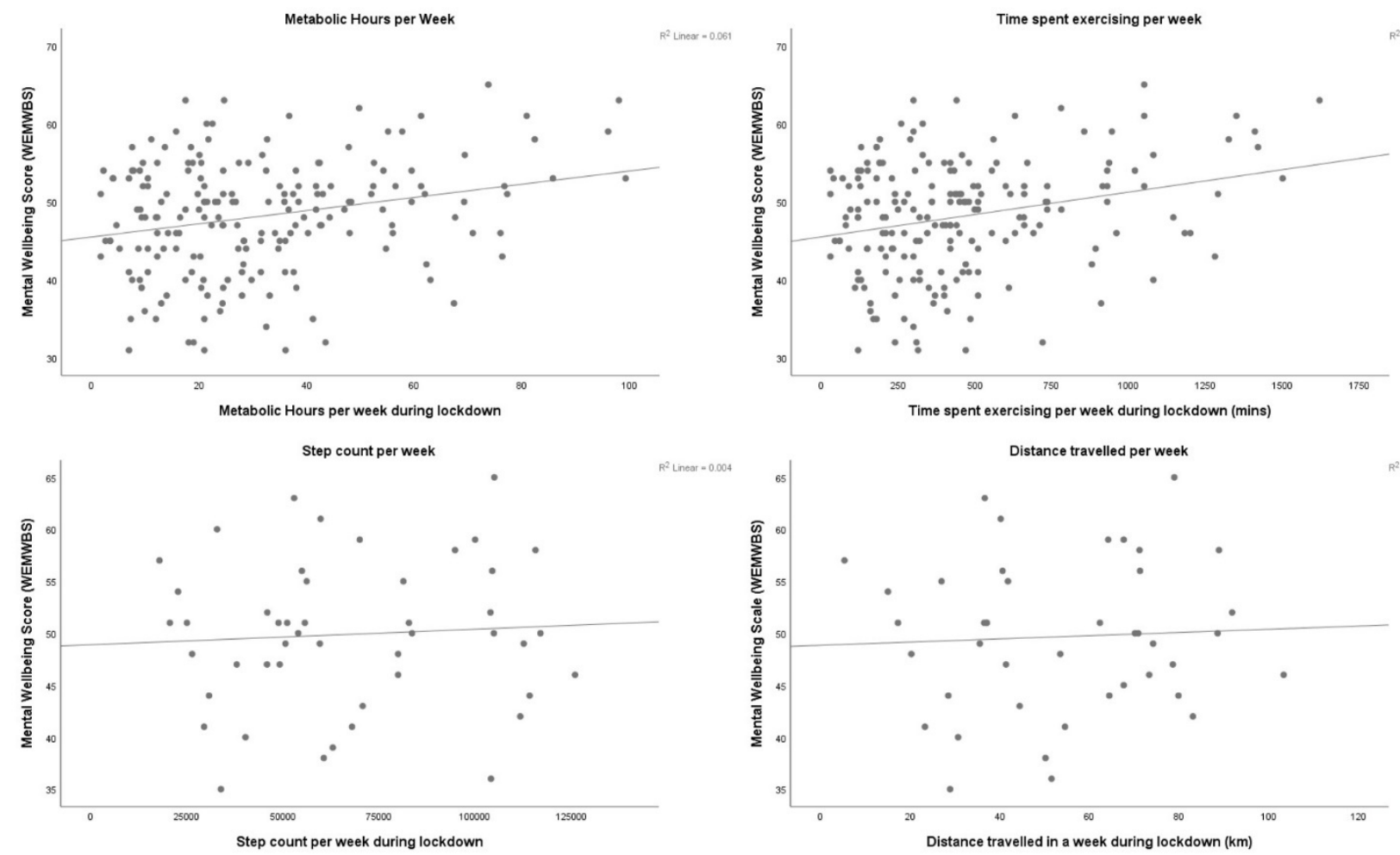


\section{Follow-up Survey:}

\section{Physical Activity}

A much smaller sample completed the follow-up questionnaire and there was insufficient power $(1-\beta=.26)$ to conduct reliable analyses on the data from the smart devices (only 10 participants), so only METhrs/week and time were analysed across the three time points (pre-lockdown, during lockdown, after lockdown eased). Whilst a repeated measures MANOVA for physical activity levels across the three time points did not reveal statistically significant differences for METhrs/week $(F[2,56]=0.14, p=.867)$, there were statistically significant differences in physical activity levels for Time $(F[2,56]=3.99, p=.024)$. Here, Bonferroni pairwise comparisons revealed that whilst significantly more physical activity was seen during lockdown compared to before $(p=.011)$, there were no statistically significant differences in physical activity levels between pre-lockdown and eased-lockdown $(p=.060)$ or between during-lockdown and eased-lockdown $(p=.484)$. These results can be seen demonstrated in Figure 5.

Figure 5 -

Bar Charts displaying the mean physical activity levels of participants across all three time points.
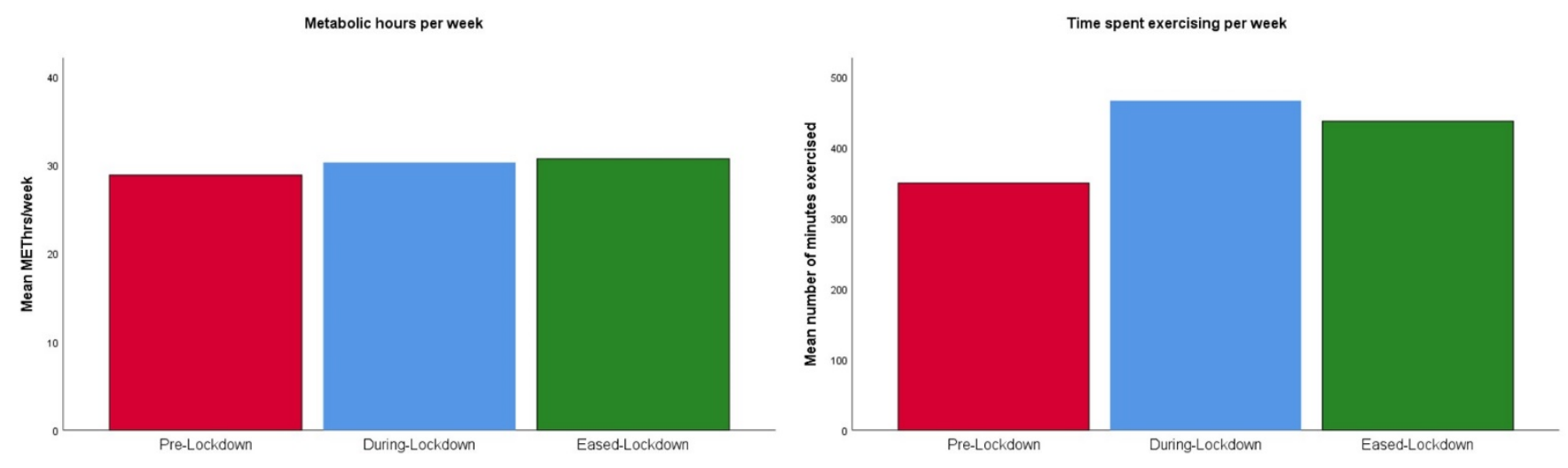

To assess whether physical activity levels were influenced by whether participants perceived themselves to have more spare time once lockdown restrictions were eased compared to before lockdown using difference scores as the DV, independent 
samples t-tests were conducted. However, no statistically significant differences were found for METhrs/week ( $t[27]=-0.72, p=.475, d=0.27)$ or time spent exercising $(t[26]=-0.72, p=.481, d=0.27)$. This can be seen below in Figure 6 .

Figure 6 -

Bar charts displaying the comparisons of the physical activity differences between pre-and eased-stages of lockdown, based on whether the participant perceived themselves to have more spare time during eased lockdown
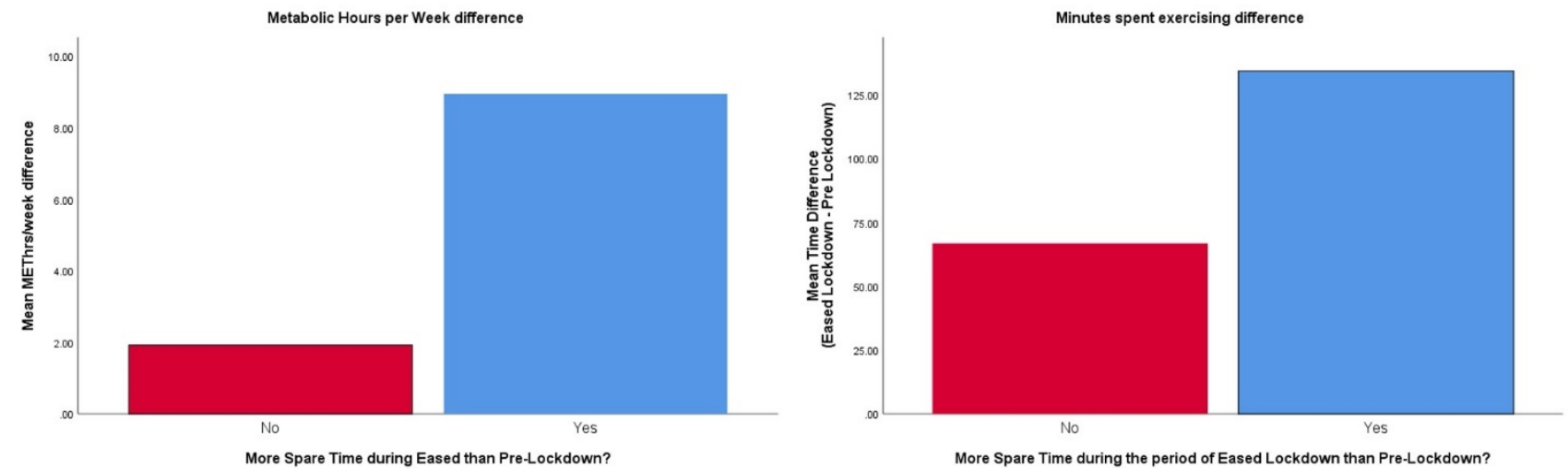

\section{Mental Wellbeing:}

To identify whether there was a relationship between physical activity levels and participant wellbeing once lockdown eased, Pearson's correlations were conducted. However, there were no statistically significant correlations found between wellbeing and METhrs/week $(r[29]=.16, p=.202)$ or time spent engaging in physical activity levels $(r[27]=.14, p=.229)$. This is displayed in Figure 7 below.

\section{Figure 7 -}

Scatter Plots displaying the correlational relationships between the self-reported measurements of physical activity and mental wellbeing in the period of eased-lockdown.
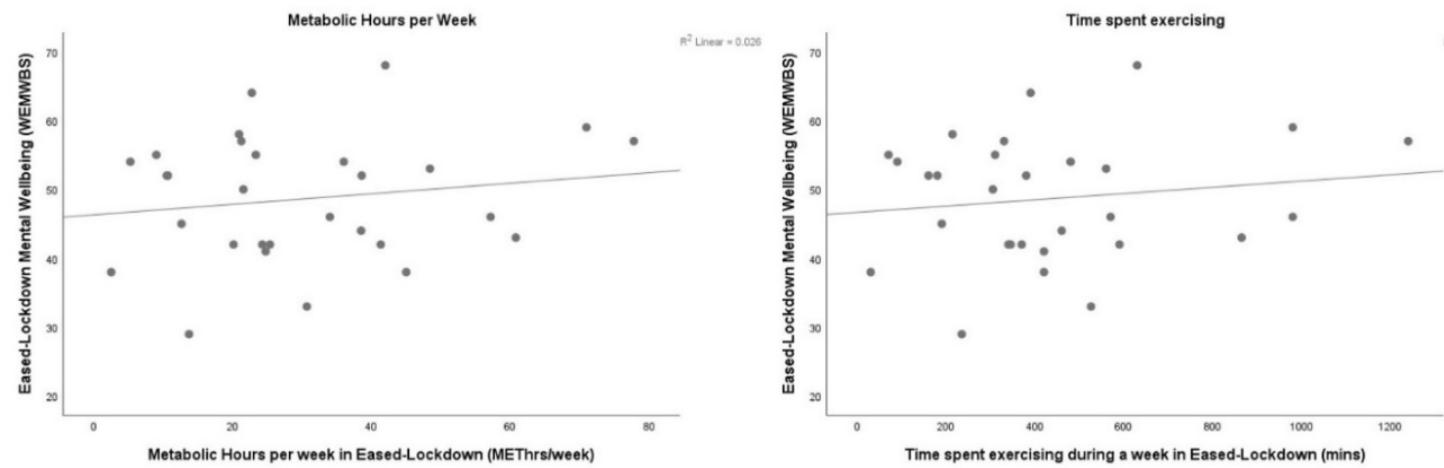


\section{Free Text Exploration}

As shown below, this first word cloud (Figure 8) representatively demonstrates the responses of those participants who felt they do ample physical activity, when asked what motivates them. The most common responses were based around health (physical and mental), whilst others noted that they simply do it because they enjoy it, and that they feel like they should. Whereas, in Figure 9, we see the responses of those who did not feel that they do enough physical activity, answering why this was the case. As was to expected based on prior literature, a lack of time was the most regular response, closely linked to other frequent replies based around the individual's day-to-day responsibilities (e.g. work and childcare).

Figure 8 - Word Cloud 1: What factors are important in the motivation to exercise amongst those who feel that they do ample physical activity?

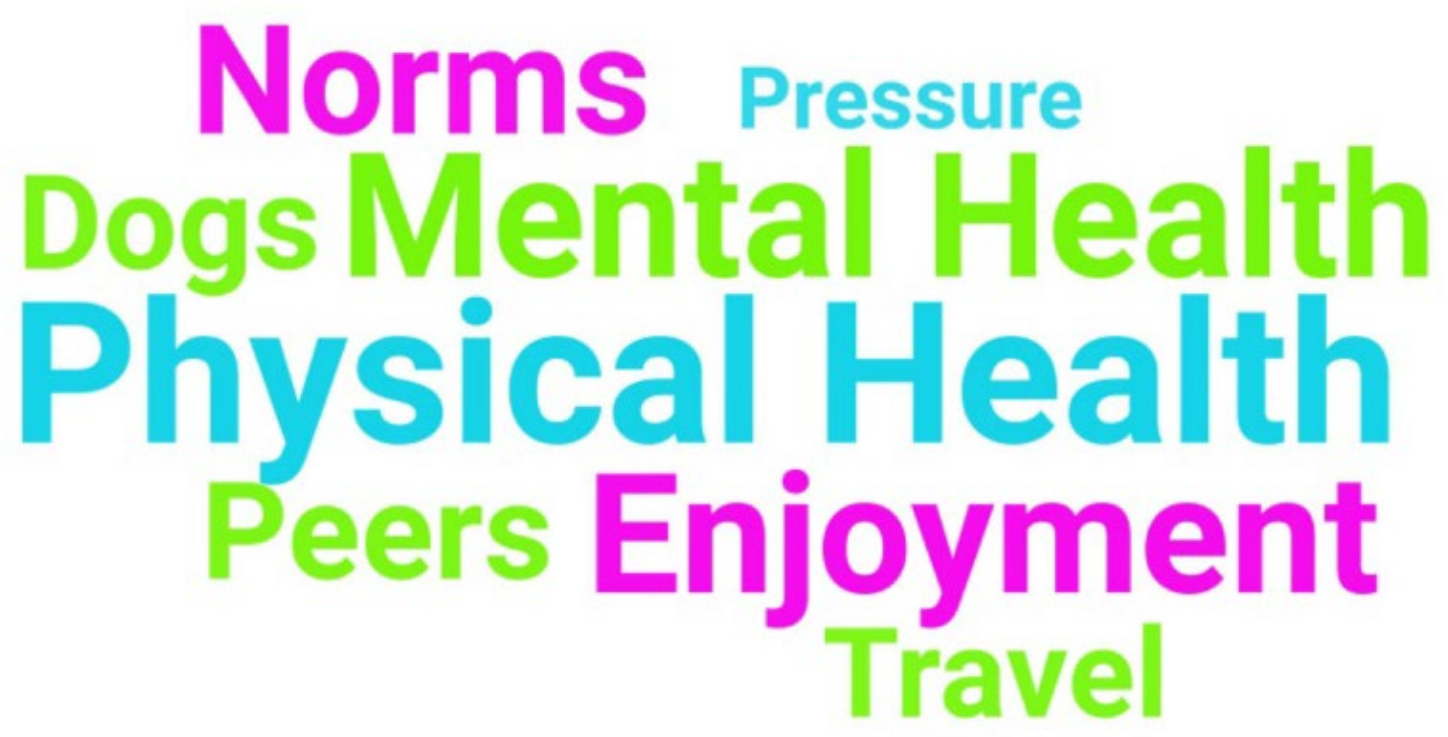




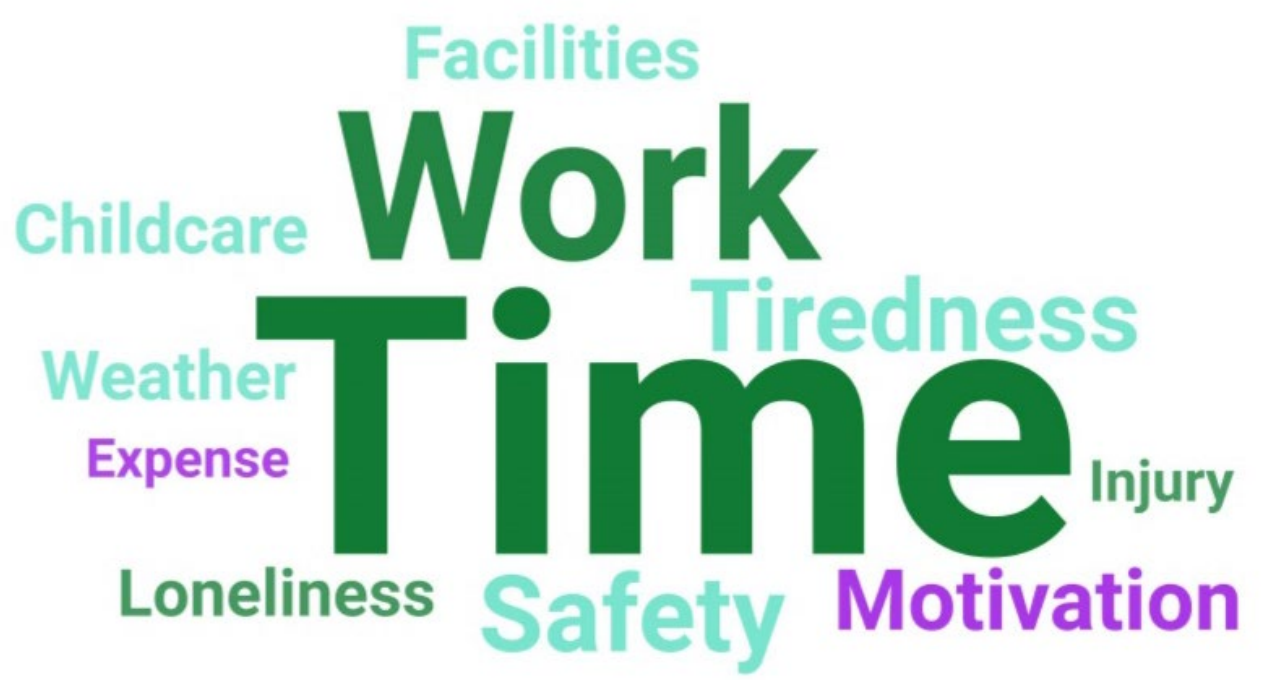

Additionally, participants were asked what factors had an impact on their physical activity levels during the lockdown period. As displayed in Figure 10 below, these responses involved both positive and negative influences, but again the most frequent response was that the element of time had an effect on their activity habits during lockdown, with many also noting that physical activity was able to give them some enjoyment, purpose and a routine. However, there were also the negative influences of lockdown, as some found they were unable to exercise due to the closure of facilities and a lack of equipment, whilst others decided that for their safety they would not leave the house to engage in physical activity.

On that point, participants were also asked whether they felt safe leaving their house, and if so what for. As Figure 11 shows, exercise was actually the most common answer for this, with going shopping also commonly discussed. Interestingly, there was also a number of participants who said that they felt safe when amongst nature, especially where there were not any crowds. 


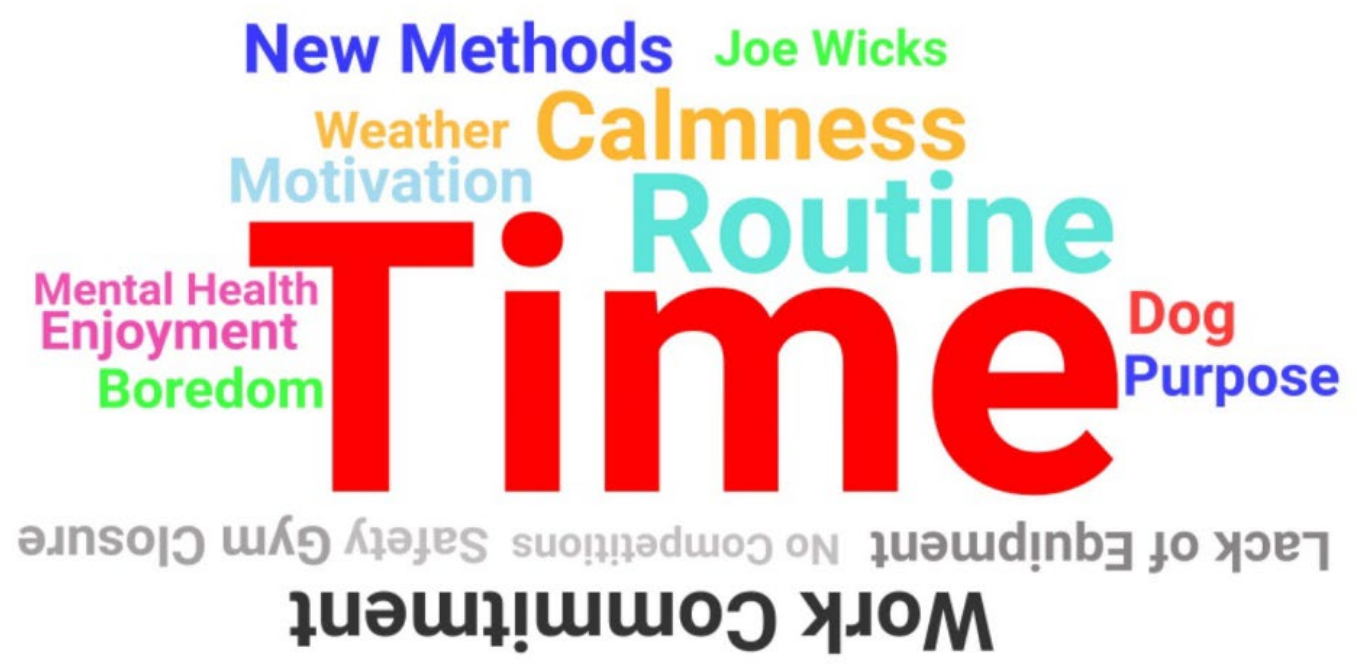

Figure 11 - Word Cloud 4: What did participants feel safe leaving their houses to do during lockdown?

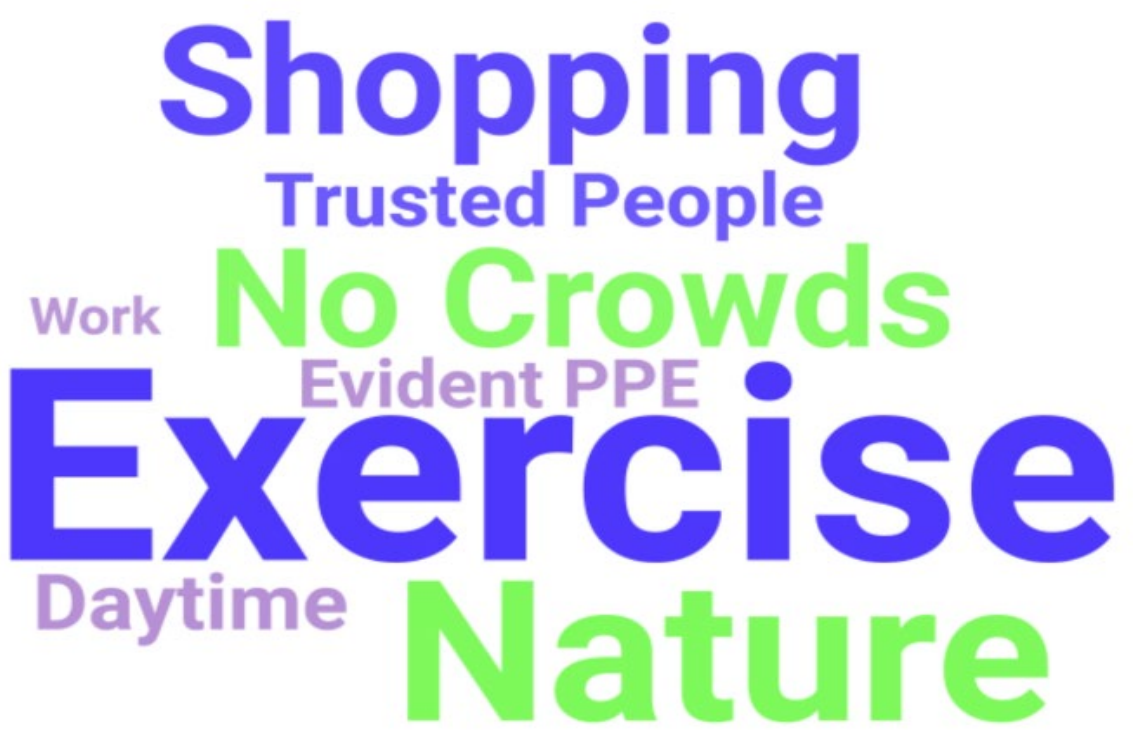




\section{Exploratory Data Analysis}

In order to highlight areas for potential future research, some exploratory data analysis was conducted. Though no hypotheses were declared for these, the analysis entailed both causal and correlational tests, though due to the distinct lack of power for these exploratory tests, and lack of hypotheses, no formal conclusions or claims were drawn as a result of the analyses. These tests were conducted on the demographic data, assessing whether there were any signs of a relationship between these and the Mental Wellbeing of participants, as well as between these and the participant's METhrs/week difference scores, and Time spent engaging in physical activity difference scores.

Age:

The relationship between age and the dependent variables was assessed through the use of Pearson's $r$ correlations. It was found that age significantly correlated with the mental wellbeing of participants during lockdown, thought this relationship was weak in strength, $r=.293, p<.001$. Age was also significantly correlated with both METhrs/week difference scores (though this was also weak in strength, $r=.294, p<$ $.001)$, and also time difference scores $(r=.309, p<.001)$.

Gender:

Tested using independent samples t-tests, gender was found not to significantly effect either mental wellbeing, $\mathrm{t}(197)=-0.65, p=.90$, or time difference scores, $\mathrm{t}(194)=1.86, p=.065$. However, there was a significant difference found between males and females in terms of METhrs/week difference scores, $t(195)=2.68, p=.008$. Isolating Alone:

Also assessed using an independent samples t-test, the impact of isolating alone was no found to have a significant effect on any of the dependent variables (Mental wellbeing, $\mathrm{t}(197)=1.71, p=.90$; METhrs/week, $\mathrm{t}(195)=-0.63, p=.533$; Time spent exercising, $\mathrm{t}(194)=-0.55, p=.582)$, though it is likely this due to the huge disparity between group sizes.

Accessible Open Space: 
The final demographic variable assessed using an independent t-test, it was found that having access to an open space also did not significantly effect any of the dependent variables (Mental wellbeing, $\mathrm{t}(197)=1.16, p=.249$; METhrs/week, $\mathrm{t}(195)=-$ 1.38, $p=.169$; Time spent exercising, $\mathrm{t}(194)=-1.38, p=.170)$, though again, this may be the result of disparate sample sizes in each group.

Type of Open Space:

Though simply having access to an open space did not cause any significant effects, for those who had access, it was still of interest to see whether the type of space accessible had an effect. To do so, univariate one-way ANOVAs were conducted. It was found that the type of open space accessible had a significant effect on mental wellbeing, $F(5,185)=3.26, p=.008$, as well as METhrs/week difference scores, $F(5,183)=2.65, p=.024-$ though this was not the case for time spent exercising difference scores, $F(5,182)=2.03, p=.076$. Post-hoc testing was conducted to determine which types of space significantly differed from the others. Four significant differences were found for the type of space on mental wellbeing (Small GardenLarge Garden; Small Garden-Other; Large Garden-Park; Park-Other), as well as four significant differences between types of space on METhrs/week (Small-GardenWoodland; Large-Garden-Woodland; Field-Woodland; Woodland-Other) and three were found for time spent exercising difference scores (Small-Garden-Woodland; Large-Garden-Woodland; Woodland-Other), these results can be found in Appendix 10, Appendix 12 and Appendix 14 respectively

Work Status During COVID:

Also assessed using one-way univariate ANOVAs was the effect of participant work status on the dependent variables. This was found to be significant for all three dependent variables - Mental wellbeing: $\mathrm{F}(9,189)=2.60, p=.008$, METhrs/week difference scores: $F(9,187)=2.17, p=.026$ and Time spent exercising difference scores: $F(9,186)=2.39, p=.014$. Post-hoc testing was conducted for each, to determine the differences between each work status, and these results can be seen in Appendix 9, Appendix 11 and Appendix 13 respectively. 


\section{Discussion}

The aim of the study was to investigate whether the 2020 Coronavirus pandemic lockdown had an effect on the physical activity habits of the public in England, and whether this influenced wellbeing. An important factor was whether participants perceived themselves to have more spare time during lockdown (as a lack of spare time is often given as a reason for not engaging with physical activity). Thus, the research also compared the effect of lockdown based on whether the participant perceived themselves to have more spare time during lockdown than they did preCOVID19 lockdown, and tracked these changes through to the period of eased lockdown, when non-essential shops were allowed to re-open in England (15/06/2020). The research collected data ascertaining to the physical activity levels of participants by utilising a Past-Week Modifiable Activity Questionnaire to gain data regarding Metabolic hours per week and total length of time spent exercising in a week, and also incorporated the use of fitness trackers/accelerometers (e.g., Fitbits) to gain information on the number of steps walked by participants in a week, as well as the distance travelled $(\mathrm{km})$. This activity data was collected based on three time points: before lockdown (retrospectively), during lockdown and in the period of eased lockdown. Additionally, participants were asked to complete two iterations of the Warwick-Edinburgh Mental Wellbeing Scale, once during lockdown and once during the period of eased lockdown. This data was then analysed using a combination of MANOVAs, t-tests and correlations in order to test the hypotheses of the research.

The key finding was that, as predicted, there was an increase in the time spent engaging in physical activity during lockdown compared to before lockdown whereby participants were doing an average of 87.2 minutes more exercise per week than they were prior to the pandemic. This increase alone is approximately $60 \%$ of the WHO's recommended 150 minutes of moderate-intensity physical activity per week thus greatly supplementing any other physical activity when attempting to meet the recommendation. This highlights how, when given the opportunity, many people do engage in more physical activity. Given the aforementioned vast benefits that physical activity has on physical (Warburton \& Bredin, 2017) and mental (Ekkekakis et al., 2013) health, as well as cognition (Cheval et al., 2020), this is a welcome finding and one that warrants further investigation into exactly why this increase was 
seen. This is especially crucial given that it is currently believed that $25 \%$ of adults worldwide are insufficiently active (WHO, 2018b), and within the UK, 40\% are not meeting the recommended guidelines (British Heart Foundation, 2017).

Interestingly though (and contrary to the hypotheses), there was not a statistically significant difference in the intensity of the physical activity (as measured by METhrs/week). This is likely to be because many leisure facilities (e.g., gyms, swimming pools) were closed and many organised sports clubs (e.g., football, rugby) were suspended. Therefore, unless people had access to personal equipment at home, for most people the options as to how they could exercise were limited (e.g., to walking, running and cycling). Additionally, there were no significant effects in relation to the data from the smart devices. One reason for this could be the relatively small sample sizes involved in the fitness tracker data. Whilst initial power analysis for this test suggested that a sample of 52 participants would be required to find a medium effect size (0.3; Davey et al., 2008); the final sample of step count and distance data were short of this, at 46 and 42 respectively after outliers or missing data were removed.

The current results support other data collected during the lockdown period. For example, Garmin (2020a, 2020b) found an average decrease in daily steps by roughly 1000 across their fleet of accelerometers. They also found that, compared to the same period in 2019 , there were vast increases in the number of walking-based workouts, indoor treadmill, cycling and cardio workouts, yoga and HIIT sessions. The nature of these calisthenic types of physical activity that saw a rise in popularity during lockdown means that they would not contribute highly to steps and distance figures, which also helps to explain why the accelerometer data in the present research found no significant differences across the time periods assessed, despite the significant increase in time spent exercising. Though it could be argued that to own a piece of Garmin technology, one is likely to be 'fitness-minded'.

The current study also supported research in Belgium which found that nearly $60 \%$ of their 'less active' participants demonstrated an increase in their activity levels during the pandemic, and over a third of 'highly active' individuals also increased their activity levels during the pandemic (Constandt et al., 2020). Similar research in India found a 33\% decrease in energy expenditure (recorded in METmins/week) 
during the lockdown period (Srivastav et al., 2020). Whilst these studies support the current findings, it is important to acknowledge that it is difficult to directly compare across countries because each country experienced the unprecedented circumstances of the pandemic differently and had difference levels of restrictions in place. For instance, Belgium re-opened restaurants and bars on 03/06/2020, allowing groups of up to 10 people to socialise, and these establishments could remain open until 01:00 am - whereas pubs and restaurants did not re-open until 04/07/2020 in England, with the restriction of 6 people.

Research by Sport England found that whilst 31\% of respondents were reporting themselves to be doing more activity than previously, $41 \%$ of adults were reporting to do less activity during lockdown than they did beforehand (Sport England, 2020). However, researchers from the University of Edinburgh found that across the UK over $50 \%$ of participants were exercising more, and nearly $70 \%$ of participants were thinking about exercise more than usual, though it also found that nearly $40 \%$ believed they were exercising less often (Robertson et al., 2020).

This disparity suggests that there could be other factors affecting activity levels during lockdown. Whilst many people were furloughed (approximately 9.6m; Clark, 2020), $46.6 \%$ of those in employment were able to work from home (Cameron, 2020) and some were able continue working as normal. In addition, some people may have seen their caring responsibilities increased during the lockdown. Therefore, it is important to consider the extent to which people actually had more spare time during the pandemic. Indeed, the results of the current study suggest that those who perceived themselves to have more spare time did exercise more (on average a mean increase of 5.5. METhrs/week) during lockdown than before, compared to those who did not have more spare time during lockdown (on average a mean decrease of 2.5 METhrs/week). This supports the idea that a lack of spare time is a hugely influential potential barrier to exercise (Herazo-Beltrán et al., 2017; Strazdins et al., 2011). Moreover, those who believed they had more spare time during lockdown had an average increase over 120 minutes greater than that of those without the perceived increase in spare time. Despite this, when the effect of the perception of spare time was investigated within the objective data (steps and distance differences), no significant effects were found for either. Again, this potentially could be explained by the research being underpowered, with $\mathrm{G}^{*}$ Power 
analysis suggesting 484 participants for an independent samples t-test (Effect Size= 0.3, Power= 0.95 and Alpha level= 0.05).

The findings for the self-reported measures support previous claims that the reason so many do not exercise as much as the WHO recommends is due to the belief that they do not have enough time available to engage in physical activity. This research is therefore of importance, showing that when the time is deemed to be available, people do, indeed, use it to exercise, which has subsequent beneficial effects on their physical, mental and cognitive health. In this research, the increase was significantly 2 hours more physical activity a week, which equates to four-fifths of the WHO recommended guidelines.

Research by Constandt et al. (2020) highlighted the likelihood of a short-lived impact of lockdown on physical activity habits, utilising elements of behaviourist and socialcognitive theories, such as the impact of physical activity on self-efficacy and the effect of extrinsic motivations on behaviour, to explain this belief. The present study included a follow-up survey to examine whether physical activity habits did continue beyond lockdown or whether any increases in activity would only be temporary while lockdown occurred leading to a slight decrease in activity levels during the stage of 'eased lockdown'. It was believed that these activity levels during the period of eased lockdown would be greater than that of pre-lockdown due to the behaviour changes anticipated when applying the various behavioural theories discussed within the introduction. For instance, during the previous application of the COM-B theory, it was acknowledged that not only does one have to be physically and mentally capable of performing an activity, but the environment must also create the opportunity to so. In context, during lockdown many had the intrinsic capabilities necessary, and the furlough scheme meant that many were working for home, which in turn led to the extrinsic necessities also aligning and thus, the behaviour (in this case physical activity engagement) was possible. This behaviour change would then likely come under threat when those who were furloughed returned to work, and opportunities to exercise became less frequent; for this reason, a decrease was expected (in comparison to during lockdown). However, it may be that through repeated exercise during lockdown the individual's cognitive affect and attitude 
changed, whereby they began to enjoy exercise, which in turn may have increased their internal motivation to engage in physical activity. This would support the claims of many of the theories previously discussed, such as the Affective-Reflective Theory (Brand \& Ekkekakis, 2018), which would suggest that now that the participant is affectively positive, following pleasurable experiences during lockdown, the emotional evaluation when making a decision, paired with the existing knowledge of the benefits of exercise, is likely to make the participant continue to engage in physical activity in the future.

Due to a reduced sample of responses providing objective data, this potential phenomenon was assessed using only the self-reported responses from participants - which itself only just satisfied power analysis, as $G^{*}$ Power suggested a sample of 33 (again using alpha=0.05, power $=0.95$ and effect size $=0.3$ ). The results showed no statistically significant differences for the period of eased lockdown compared to before lockdown or during lockdown, but the time engaged in physical activity levels were higher during compared to before lockdown. However, no statistically significant differences were found for the impact of lockdown on METhrs/week between any of the three stages of lockdown.

This suggests that, overall, the activity levels that had been shown to significantly increase during lockdown, did not differ significantly when lockdown was eased despite the increased options of activities to fill any spare time, and the return to normal working hours work for many. This therefore suggests in part that Constandt et al's (2020) suggestion of a temporary increase was only partially correct, however this follow-up study was conducted too soon to be able to determine whether the effect has been a long-lasting behaviour change.

Something of great interest arising from the data, is the relationship between total length of time spent exercising and METhrs/week throughout the pandemic, which seemingly differ from each other. As displayed in Figure 6, though METhrs/week are principally determined and calculated by time, time spent exercising peaks during lockdown, whereas METhrs/week instead peaks during the period of eased lockdown. The explanation for this is simple, however the occurrence raises a vital question. The reason that METhrs/week do not increase in a similar fashion to the rise in time spent exercising is likely because lockdown put a stop to the vast 
majority of popular physical activities, including many of those with the highest metabolic equivalences. Team sports such as football and rugby, which each possess a reasonably large metabolic equivalence per hour (7.5 and 10 METs respectively) were halted, and gyms, swimming pools and sports halls were all closed as a result of the pandemic. Consequently, many individuals' usual methods of physical activity became unattainable, and were replaced with lower intensity activities such as walking and gardening (both 3.5 METs). Thus, despite doing the activities for longer, the total metabolic equivalencies were reduced ( 1 hour of rugby is metabolically equivalent to nearly 3 hours of walking). Though, the WHO guidelines suggest 150 minutes of moderate intensity (3-6 METs) or 75 minutes of vigorous intensity (>6 METs), so both walking and gardening are WHO defined to be of a moderate intensity. Yet the question still remains, is it better to do a large number of minutes of activity with little metabolic equivalence, or a shorter burst of activity with a high metabolic equivalency? The guidelines suggest that both are beneficial to our health and reaching the recommendation via either route should be strived for, however it is possible that this may be where the difference between physical inactivity and sedentary behaviour becomes important. By meeting the WHO recommendation, by definition one cannot be deemed to be physically inactive, however if this mark is met by the completion of one 75 minute bout of vigorous-intensity exercise each week, this leaves over 165 hours in the rest of the week where that same individual can behave sedentarily, and thus potentially undo the benefits gained from the physical activity by reintroducing the dangers of a sedentary lifestyle.

As previously eluded to, the resulting data from the present research suggests that those with perceived spare time who engaged in physical activity may have continued to engage in a heightened level of physical activity. This finding suggests that for some, a behaviour change may have occurred, at least partially, so to encourage them to retain a higher level of physical activity, which if maintained, can lead to a healthier life. Ajzen's Theory of Planned Behaviour (1991) can be applied within this particular scenario, and considering its three elements (affective attitude, social norms and perceived behavioural control) suggested explanations for the effects seen can be made. If the previously discussed claim is accurate, and some people did maintain a higher level of physical activity (compared to their levels pre- 
lockdown), it is possible that the participants' intrinsic affective attitude became positive, and the social norms (which already encouraged physical activity due to the knowledge of the benefits) may have also been altered due to the increase in activity by many of the population both in England (Sport England, 2020) and worldwide (Constandt et al., 2020; Di Renzo et al., 2020; López-Bueno et al., 2020). With both of these elements now 'in favour' of physical activity, the final element of 'Perceived Behavioural Control' refers to whether the individual deems the task difficult - which, after repeatedly engaging in the activity throughout lockdown, it is likely the individual deems of little difficulty as they believe they have the capabilities to perform such a task (McCauley et al., 2004). As previously mentioned, the tasks themselves would also likely be of a 'simple' nature due to the lack of facilities available during lockdown. Therefore, this theory also suggests that the potential long-term effect of the increased physical activity during lockdown will be positive, such that many individuals may now do more activity each week than they did prior to lockdown.

Furthermore, this lack of statistical difference between physical activity levels in eased-lockdown compared to during-lockdown is somewhat unsurprising when theories are considered as, as mentioned before, the reduced opportunities to engage in physical activity would have had a negative effect on exercise levels. However, theoretically it would be expected that some of those who did not believe they had more spare time during lockdown may have increased their physical activity levels when lockdown was eased. For example, the aforementioned 'Rational Education' approach, which suggests that people utilise information they are given to make decisions about their behaviour (Ekkekakis et al., 2018). Therefore, it is possible that while these people who did not have the perception of having more spare time during lockdown did know the benefits of physical activity, they potentially acknowledged the risk factor involved with leaving the house during a pandemic and were unwilling to take the risk during such circumstances. However, when lockdown was then eased, and the apparent risk factor was reduced, the benefits became a strong enough rationale to outweigh the potential negatives again, and subsequently the individual began to increase their activity levels again. The varying experiences of lockdown make it extremely difficult to apply homogenous theories to all, and is also likely to have had an effect on the analyses at this point, as at the eased- 
lockdown stage the individual had a lot of choice regarding their behaviours (whether they were willing to take the risk or remained shielding).

Part of the reason that WHO emphasise the importance of physical activity, and set recommendations in place for doing so, is the mental health benefits that it brings, as previously discussed. It was hypothesised that within this research there would be a positive relationship between physical activity and mental wellbeing also, based on the existing literature (Landers \& Arent, 2007; White et al., 2017). As such, the relationship between physical activity levels and mental wellbeing during the imposed lockdown was investigated. The analysis revealed that METhrs/week and time spent exercising during lockdown both had a statistically significant, positive relationship with mental wellbeing, with Pearson's r coefficients of .273 and .258 respectively. Though these tests are statistically significant, when interpreting them using Akoglu's (2018) guide to correlation coefficients, the correlations themselves are considered to be 'Weak' within the field of psychology (Dancey \& Reidy, 2011). The correlations for the objective accelerometer data were not statistically significant, with neither steps nor distance being found to have a statistically significant correlation with mental wellbeing, each achieving a Pearson's r value branded weakto-zero in psychological terms (Dancey \& Reidy, 2011). The results of these correlational analyses show that while there may be a relationship between the mental wellbeing of participants and their level of physical activity, among this sample the relationship was not strong. However, this research takes place at a time where both nationally and worldwide, mental wellbeing was extremely low (Pierce et al., 2020; Singh et al., 2020).

A review of literature surrounding previous quarantine experiences (such as in China and Canada during the 2003 SARS outbreak and African countries quarantined during the Ebola outbreak in 2014) highlighted the high levels of psychological distress it can cause, also informing of the link between PTSD symptoms and even suicide (Brooks et al., 2020). International research also highlighted the increased level of stress, anxiety and depression experienced by individuals during the lockdown environment (Ozamiz-Etxebarria et al., 2020), with over a quarter of their sample reporting to have either depressive, anxious or stressed symptoms during lockdown, whilst in China, over a third reported anxiety during the pandemic (Huang \& Zhao, 2020). This is not surprising, when it is considered that people were asked 
to stay at home for a long period of time, heightening feelings of isolation and reducing social contact, which have previously been shown to negatively impact mental wellbeing (Cacioppo \& Hawkley, 2009; Chen \& Feeley, 2014). While the present research had the potential to compare the mental wellbeing of those living with others and those who lived alone, the disparity between the sample sizes meant it was not viable, with $92 \%$ of the sample living with others during the pandemic. Research conducted on the same time frame did find that those who were doing much less physical activity than they did pre-lockdown experienced a greater 'Negative Mood Score' than those whose physical activity habits stayed the same or improved (Ingram et al., 2020). It has also been considered that technology has developed since the prior lockdown experiences that have been published (e.g., SARS and Ebola), and within this pandemic, individuals also had the element of 'Fake News' to contend with, which may have had the potential to add to the levels of negative mood symptoms (Sun et al., 2020). With all this considered, it should be acknowledged that the lockdown situation potentially caused confounding influences that far outweighed any potential impact that physical activity levels may have had. This can, however, be seen as further evidence of the potential strength of the relationship between physical activity and mental health, as if a significant positive effect can be found whilst the world's circumstances are bleak, then it is perhaps no wonder that in times before lockdown the relationship had been found to have a Pearson's correlation coefficient above 0.5 (Harris, 2018).

Within the follow-up survey, participants were asked whether they felt that they exercised an appropriate amount in a typical week. Based on their response, participants were then either asked what the key barriers were that were preventing it, or the influences that encourage them to exercise. The responses to these questions were then analysed such that the frequency in which words/phrases were mentioned, a word cloud was created, summarising the nucleus of the responses. The first of these regarded what factors were important in motivating those who felt they exercised amply each week (Figure 8). The responses shown within this word cloud further correspond with the behaviourist and social cognitive theories, particularly that of the Rational Education approach which suggested that the biggest influence when changing a behaviour in the long term is the acknowledgement of an overarching benefit where 'the pros' outweigh 'the cons' (such as the belief of 
improved physical and mental health). It also fits naturally with Ajzen's Theory of Planned Behaviour (1991), as the common responses include a positive affective attitude (Enjoyment), social norms/societal pressure and a level of ease may be assumed due to the enjoyment and positive mental health aspects, as failure has been linked to lower mental wellbeing (McMichael \& Hetzel, 1975).

The word-cloud produced regarding the factors preventing people do what they perceive to be ample physical activity (Figure 9) also mimics that of the existing literature and the statistical findings of the current study, with external factors culminating in a lack of spare time being the most common barrier, as found in prior research (Herazo-Beltrán et al., 2017; Lawton et al., 2006; Strazdins et al., 2011). The responses in this word-cloud are seemingly very common across time and globally, with a lack of spare time, motivation and tiredness having been seen to be perceived barriers in a multitude of research (Arango et al., 2011; Herazo-Beltrán et al., 2017).

The responses to the final question asked of participants during the follow-up study 'If you believe that your exercise habits did change during lockdown, please detail the factors that contributed to why this change occurred' also seems to reinforce this argument (Figure 10). However, as this question enabled participants to respond with both positive or negative influences, this was displayed with positive influences shown in colour, and negative factors in greyscale (and upside down). The wordcloud clearly shows that the overarching, subjective theme of the factors that influenced physical activity habits during lockdown was the perception of having the time to do so. As with the previous word-cloud (Figure 9), it is clear that participants felt that they were able to engage in physical activity when they felt they had the time. This theme was not only the most frequent positive influence, but also strongly linked to the most frequent negative factor, 'Work Commitment'. Subjectively speaking, it is inferred that the reason why work commitment negatively impacted the participant's ability to engage in physical activity is that these commitments used a large amount of their time, leaving them only time to complete the 'necessary' tasks required for day-to-day life. This therefore further supports the conclusions drawn from the previous word-clouds, emphasising the idea highlighted by previous literature, that a lack of spare time is one of the most common justifications for low physical activity engagement (Herazo-Beltrán et al., 2017). 
Another popular theme of interest within the word-cloud is the idea that regular physical activity gave participants a sense of routine during the lockdown period. As discussed within the introduction, humans have an innate need for a sense of purpose and meaning in life, as has previously been highlighted in literature (Maslow, 1968), and that the perception of having such meaning benefits us vastly physically, mentally and socially. One of the ways we often achieve this 'purpose' is by having a sense of routine (Bond \& Feather, 1988; Martela \& Steger, 2016), which is strongly associated with a positive mental wellbeing (Heintzelman \& King, 2019) and a sense of comfort (Avni-Babad, 2011). Therefore, it could be argued that it was a natural, innate, nonconscious decision that participants found a way to gain a sense of routine and purpose, in order to attempt to boost one's own mental wellbeing, at a time where 'mental health in the UK had deteriorated' (Pierce et al., 2020), and $30 \%$ of the UK's workforce were furloughed (HM Treasury, 2020), and so did not have any form of shift routine.

The common factor of 'safety' as a negative influence on physical activity habits was not surprising either, considering the follow-up survey also collected data regarding the participant's opinions about their safety. When asked 'In the present moment, do you feel safe leaving your home?', over two thirds said they did, with only one participant saying they did not and the remainder electing for the response 'only for certain things'. Those who selected this option were then also asked for more detail and what exactly it was that they felt safe doing during this time - the results of which are demonstrated in Figure 11. As the figure shows, the most common reasons that participants gave for leaving the house, despite not feeling completely safe were to exercise, to be outdoors and experience nature and also to go grocery shopping, which could perhaps be seen as a necessity as opposed to something that felt safe. The influence that nature had on people, whereby they felt safe experiencing this during lockdown corresponds to the existing literature, where the outdoors has been said to be something of a therapeutic safe-haven (Berger \& Lahad, 2010), and has also been tipped to play a part in our recovery from the COVID19 pandemic (RSPB, 2020; Stonebridge, 2020). Direct contact with nature is believed to elicit feelings of self-connection and enabling internal coping resources (Berger \& Lahad, 2010; Hartig \& Mang, 1991; Naor \& Mayseless, 2020). This is the principal behind nature 
therapy, which focuses on utilising nature's healing powers in a therapeutic setting (Berger \& McLeod, 2006). This also fits with the Attention Restoration approach (Kaplan, 1995), which suggests that when people have a lot to process mentally, it is beneficial for them to spend time with nature as it can rejuvenate attentional processes (Kaplan, 1995) and reduce stress (Ulrich et al., 1991). The influence of exercise on health forms much of the rationale to this present research, and there is a wealth of research on the matter (Warburton \& Bredin, 2017).

\section{Limitations:}

The aim of the study was principally to investigate the effect that the 2020 COVID19 UK government enforced lockdown had on physical activity habits within England, and the corresponding relationship of the activity levels with mental wellbeing. The research also had limitations. Despite meeting the $\mathrm{G}^{*}$ Power suggested sample sizes for a number of tests, the overall sample size was considerably smaller than other studies regarding lockdown, such as Pierce et al. (2020) whose research for 'The Lancet' regarding mental wellbeing during lockdown had a sample of over 50,000 participants. The reduced sample size in this present research led to issues of normality, which means that certain aspects of the data must be treated with caution - it is also possible that more data may have led to a more representative sample where statistically significant findings could have possibly been found. It is commonly found that larger the sample, the more representative it is of the population, and thus normal distribution is found more often amongst larger samples (Krithikadatta, 2014). Though, as previously explained, there is a published belief that normality violations can be ignored completely when the sample has over 100 participants (Altman \& Bland, 1995), and as such this sample should be deemed to be representative.

The present study also asked those with accelerometers (such as Fitbits) to provide the objective data collected by these. Accelerometers have previously been used in research for the same purpose, taking advantage of the ability to quantify activity levels (Van Cauwenberghe et al., 2011). While this was done so that objective data could be analysed as well as subjective self-reported data, the prevalence of 
accelerometer data amongst the sample was lower than expected, and when outliers were removed, the respective sample sizes for the Steps and Distance travelled variables were small $(<50)$, and so it cannot be certain that these were a sample distinctly representative of the total, larger sample, nor population, and they may have been some of the less active participants, thus the lack of significant increase, or indeed some of the most active, who maintained a high level of activity, and so did not register dramatic differences.

The issue of sample size was particularly problematic for the follow up study. Participants were not required to but were given the option to provide a contact email address so that they could receive a link to a follow-up survey, of which less than $50 \%$ of the initial sample did. There was then a poor response rate of $35 \%$ of that reduced sample, meaning that analyses regarding the follow up was conducted on less than 50 participants ( $17 \%$ of original sample). When exclusions were made, the sample was reduced to just 33, with less than a third of these having access to (or providing) accelerometer data for their activity. This meant that some tests became unviable, as the comparison for objective data between the spare time responses in the follow-up survey would have compared 4 and 6 people, which would not have produced any meaningful results, and only having 10 people meant that MANOVAs were also not viable, so assessing the effect of all three stages of lockdown on steps and distance data was not possible. The self-reported data did, however, satisfy the sample size calculated during power analysis, and so the respective tests were deemed viable. It is possible that part of the reason for this drop off in numbers at this follow up stage is that many participants had returned to work (including many of those in the education, retail and hospitality sectors) and so no longer had the 'spare time' to partake in the survey, as well as exercising and completing their necessary day-to-day tasks. This may be a limitation of social media based research recruitment, as it is possible that this was better suited to the lockdown situation where people may have been more likely to be at home than they would be in their usual life.

A further limitation, is the nature of survey-based research. Due to the selfadministered completion of the questionnaires, the process becomes open to validity issues such as social desirability bias (Latkin et al., 2017). This bias is especially 
prevalent when the topic of conversation can cause embarrassment or effect the participant's positive self-concept (Paulhus, 1984; Tourangeau \& Yan, 2007). This is the case within the present research, as participants are likely to be aware that physical activity is beneficial for their health, and so admitting to low levels (at either the pre-lockdown or during-lockdown stage) may cause embarrassment and make the participant feel negative about themselves. The same could be said for mental wellbeing, as if participants realise that they aren't scoring positively during the scale, they may begin to question their wellbeing and this could lead to feelings of negativity (Labott et al., 2013). However, the potential for bias influencing the questionnaire responses was attempted to be minimised through the collection of the objective data.

Additionally, for the pre-lockdown measures, participants were asked to report retrospective physical activity level data as well as their current level, so there are potential issues around the accuracy of this. This is where inaccuracies as a result of social desirability bias may have been most prevalent, though it would also be possible that people may have simply forgotten, as not all physical activity is structured, organised exercise and so people may not accurately remember the exact durations of their recreational activity. Due to the nature of the study, this could not be avoided, but the issue of social desirability was reduced by asking the questions online anonymously rather than face-to-face (Larson, 2019). Additionally, the questions asked participants to reflect on an average week in February (which would have been the most recent time before the pandemic began to seriously impact lifestyles and opportunities) rather than for specifics within any particular week. The change from interview to questionnaire for the PWMAQ, though approved by the creator (Pettee-Gabriel, Personal Correspondence, 2020) may also have presented issues in terms of understanding of the questions.

One final limitation that should also be considered is that the premise of 'spare time' is a very subjective thought, and participants were not given a definition before participation. There is no easy way to define 'spare time' objectively, and with the varying tasks that each individual must complete each day, it cannot be simply summarised. It has previously been acknowledged that the notion of spare time has many different sub-categories (Mingo \& Montecolle, 2014). Therefore, what some 
consider to be 'spare time' others may not - for example, some may include physical activity in their daily plans, and not see the time they are exercising as 'spare time', potentially believing that it is an essential part of their day. This lack of clear definition and inherent subjectivity means that the elements of the study where spare time features may be inaccurate at the core, due to participant's differing perceptions. Due to this subjectivity, it is noted that it may have been prudent to provide participants with a definition for this research, so that the notion of spare time was being judged equally by all, subsequently eliminating the element of doubt in these results due to the potential subjectivity. It is also noted that this research did not assess the behaviour of those who found they had less spare-time during the lockdown circumstances, and doing so may have led to more complete conclusions being drawn.

\section{Implications and Contribution to Knowledge:}

This research has shown that when given the chance individuals are likely to increase their physical activity levels if they perceive themselves to have an increase in available spare time. This suggests that in order to tackle the increasingly important endemics of obesity and deteriorating mental health, it may become beneficial for action whereby individual's lunch breaks are extended to become 'exercise hours', so that routine regular exercise can be introduced nationally- as has been done at companies such as 'Total Wellness' in the US (Kohll, 2019). This could therefore benefit the physical and mental health of workers, but also improve efficiency and quality of their work (Puig-Ribera et al., 2015) - therefore suggesting that although it involves more time away from the desk, it may also benefit the business. This would also break up the time spent sedentarily in a working day, which long bouts of is known to be degrading to health (Chau et al., 2013). Knowing the dangers of a sedentary lifestyle, as well as the benefits of an active one, having an improved general health of the workforce could arguably benefit the workplace as it may mean less members of staff having to take time off for ill-health during the year (Orchard, 2015). This could in turn benefit the economy also, due to the potential for increased productivity, and less necessary spending on health care. By having designated time to exercise, it would potentially rule out the need for people 
to find spare time so that they may increase their physical activity levels. An alternative to this would be for a reduction in weekly working hours, such that perhaps two or three days a week, workplaces closed an hour early, creating potentially 180 minutes of time that could be used for exercise each week (thus meeting the physical activity guidelines set by WHO. Perhaps better still would be 30 minutes every day of the typical working week (Monday-Friday), so that 150 minutes are made 'spare', and also spreads the time out further, reducing the potential for total sedentary days. It would also be worthwhile if companies participated in a workplace based physical activity intervention, such as Step Count Challenge (Paths for All, 2020), to encourage their workers to do more physical activity. If workplaces can be targeted to allow for this, it can help to reach and potentially aid the health of the roughly $75 \%$ of Britons in employment (Office for National Statistics, 2020b), which is a significant proportion of the population.

The research also suggests that even in times of strife and constant negativity, as comes with events like a pandemic and the experience of a lockdown situation, physical activity was still able to have a statistically significant positive effect on mental wellbeing, therefore more should be done to prescribe everybody with physical activity and increase activity levels nationally, in a bid to confront the increase in cases of mental health issues in recent years.

\section{Further Work:}

Before any implications can be put into practice, there would need to be further work on the topic. Though the study entailed a follow-up survey in an attempt to track the physical activity habits over numerous time-points, the pandemic was still ongoing, and so effects may have still been taking place that would cease upon a return to 'normality'. Therefore, without further research it would not be possible to determine whether lockdown had a long-lasting impact on the physical activity behaviours of individuals. Until this research has been conducted, when all restrictions have been eased, a potential vaccine has been released and 'normality' has resumed, it cannot be determined for definite whether lockdown may have positively impacted a number of the population; such that some individuals have developed, and maintained, a long-lasting increase in physical activity levels as a result of the government- 
enforced lockdown - as has been suggested with the help of psychological theories, or whether the results would mimic those of the many failed 'interventions' discussed by Muller-Reimenschneider et al (2008). It also remains to be seen whether these results and trends are truly representative of the population, and whether with a greater sample size, the results of this research would have stayed the same though this would not now be possible without another lockdown situation of similar intensity.

The relationship between physical activity levels and mental wellbeing has been shown on numerous occasions, with a wealth of research to support it, thus it may be interesting to see if the relationship continues, and returns to the previously found correlation strength (as opposed to the understandable weakened correlation strength in the present research) upon the ending of the pandemic, when the many confounds of lockdown are likely to have ceased. Similarly, it may be prudent to follow up on the manifest content analysis element of the research by conducting interviews, or some form of qualitative research, in order to gain a deeper insight into people's experiences of lockdown, in regards to physical activity and mental wellbeing. Research further exploring the relationship between physical activity and wellbeing should be conducted in multiple settings, including care homes for the elderly and also schools. However, the idea of exercising within a care-home may also benefit from the use of technology, to trigger familiar feelings of happiness in virtual settings for those that use it. For instance, the work of the 'Motion' project by Enactus, who installed video call technologies into care homes during the pandemic so that they could continue their exercise sessions, even though external visitors were not allowed into the facility. This was believed to greatly benefit the welfare of the residents during the difficult time (Motion, 2021). Additionally, technology has been seen to assist with dementia in care home patients (Bartle \& Behrens, 2016), as well as Virtual Reality technology being seen to increase physical activity motivation and enjoyment in these settings (Bruun-Pedersen et al., 2016). There is also a growing body of research to suggest that those who are most at risk of falling may benefit from supervised Virtual Reality based exercise (Kaminska et al., 2018).

Furthermore, additional research is required on the factor of perceived spare time. This research shows that within the unprecedented context of lockdown, those with 
the perception of more spare time exercised for a greater length of time. However, research is required to see if when everything is 'back to normal' (and individuals have more freedom, and have returned to their usual routine) the effect is still present. If so, it may be beneficial to put more emphasis on the potential that 'activity hours' within a workplace can have on health, and whether people do use that time to exercise, or whether (as suggested in Bice et al. (2016)) people feel as though something else is a better use of their time, and exercise was only carried out during lockdown due to boredom, and a lack of other possible activities. Should the effect of spare time on physical activity persist in further research, this is potentially an avenue that should be further investigated amongst groups vulnerable to physical or mental disease.

However, these findings are actually potentially applicable to every setting, as it shows that if an individual creates some spare time in their week (subsequently opening the 'Opportunity gate'), they are more likely to do more physical activity, and with this increased physical activity, an abundance of research shows the positive health effects that this can lead to (Warburton \& Bredin, 2017; Schuch et al., 2018). Though, as discussed within the introduction, this is not something that many are motivated to do without external influence, and so it may be that we need to begin encouraging those with influential power to begin suggesting this. Additionally, it is possible that people would like to be able to have more spare time to exercise, but cannot due to other responsibilities, so it may that institutional changes are required that emphasise the importance of exercise, and some form of aid may be required. For example, at Governmental level, it may be that a reform can occur so to change the nationwide structure of the school week, perhaps using shorter lessons, with more frequent exercise breaks, as well as adding an extra opportunity for Physical Education, to get young people moving, and make physical activity a part of their routine from an early age. It has also been suggested that the working week should be changed to four days in duration, instead of five, in order to allow individuals to have more free time. This idea gained popularity even before the lockdown, with many companies implementing it on a trial basis. For instance, Microsoft Japan were one of these companies, and stated that work productivity increased by $40 \%$, and electricity costs were reduced by 23\% (Microsoft Japan, 2019; Kleinman, 2019). It may also be possible that more emphasis can be put on work around doctors 
prescribing exercise, and the 'Moving Medicine' programme discussed previously whether this be individual or group therapy, in the form of subsidised gym memberships or simply wider sharing of the exercise resources already available on the NHS website (NHS, 2019). There is also the Couch to $5 \mathrm{k}$ scheme, which is a free running programme designed for beginners to progressively introduce a greater level of physical activity to individuals schedules.

On the subject of spare time, it may be prudent to further investigate the beliefs of participants, and try to understand how people define spare time, to see whether on the most part, physical activity is something most do in spare time, or deem essential. Once this subjectivity question has been answered, more implications can be made from the results of this research.

Another thought that is worthy of consideration, that arose within the manifest content analysis and is in keeping with the COM-B model is the effect that the time of year had on results. Lockdown began in March 2020, and was eased in July 2020, and thus this research took place during Spring/Summer, with more daylight hours, warmth and sunshine than would be expected had it occurred over the Winter months. The impact of the weather and the time of year should not be underappreciated, and research should be conducted to compare both the general physical activity level differences and also mental wellbeing between the seasons. It has previously been highlighted that the period of darker, colder nights during autumn and winter is often associated with lower mental wellbeing, a phenomenon now recognised by the NHS as Seasonal Affective Disorder. Whilst not fully understood, it is believed that the lack of sunlight can cause issues with the hypothalamus, leading to issues with sleep, appetite and mood due to fluctuating production of melatonin and serotonin (NHS, 2018). For this reason, it may be interesting for future research to explore whether those who engage in greater levels of physical activity during winter experience less signs of Seasonal Affective Disorder, further regimenting the relationship between physical activity and mental wellbeing. Additionally, autumn and winter are associated with darker nights coming in earlier, which may coincide with people's leisure time, such that the hours that have daylight are also the hours they spend in work, and then when they finish it is getting dark outside. This may impact the level of physical activity itself, as certain 
sports (such as golf) require daylight in order to be played, but also it is possible that people do not feel safe exercising at night when it is dark. A study conducted by Nuffield Health and YouGov in late 2020 found that almost $75 \%$ of women are scared to exercise at night during the winter months, a viewpoint also shared by nearly a third of males (Nuffield Health, 2020).

Finally, the exploratory data analysis suggested that work status had a significant effect on both METhrs/week and time spent exercising difference scores, and also mental wellbeing. However, this was underpowered, and no official hypotheses were declared, and thus no formal conclusions should be taken, but the results suggest that this may be worth further research, as if it found that those who work less hours have greater levels of physical activity, and greater mental wellbeing, this may be further evidence to support the movement for a four-day working week. Previous research from USA and Sweden found there to be a relationship between occupation status and physical activity levels, finding that those who had an active job, also spent less overall time being sedentary (Kwak et al., 2015), which suggests that perhaps research should be conducted to conducted to quantify by active or sedentary occupation type, as well as full-time, part time and suchlike that was included in the present study.

\section{Conclusions:}

The research has shown that many are willing to increase their physical activity levels, however until the lockdown period had not had the motivating impetus, nor the spare time to do so. The combination of having perceived spare time and lockdown circumstances (meaning that exercise was one of the only possible activities) led many to increase their physical activity levels. This seemingly instilled the foundations of a behaviour change, as follow-up data showed that even when many were back to work and other activities were possible, the time participants spent engaging in physical activity was higher than pre-lockdown, and the difference between during-lockdown and eased-lockdown had not differed significantly. Though it must be noted that there was also no significant difference between pre-lockdown and eased lockdown, suggesting that the impact of 'normality' did reduce the statistical impact that lockdown had on physical activity. The follow up data also 
showed that metabolic equivalence was beginning to increase, despite many sports still being unavailable at grassroots level at that time.

Crucially, the findings of this research also support the previous claims that a lack of spare time is one of the largest barriers to exercise, clearly showing that when spare time is available, physical activity levels do increase, which though is often subjectively/qualitatively claimed, is rarely if ever studied quantifiably - though when this quantitative investigation was made possible (due to the lockdown circumstances), the result of the present research showed a two hour increase in physical activity among those who felt that they had more spare time.

As well as this, the research demonstrated an important finding that even in times of extreme negativity, where national mental health was extremely low and depression, anxiety and stress symptoms were prominent, higher physical activity levels (METhrs/week and Time spent exercising) were still statistically correlated with higher mental wellbeing scores during lockdown - reiterating the need to exercise not only in order to benefit our physical health, but also our mental health.

To contextualise these findings amongst the aforementioned theories of motivation, it is clear that those explanations of behaviour which do not allow for the consideration of environmental factors are not best-suited in the context of physical activity motivation, arguably failing to encapsulate the vast factors that can influence an individual's motivation. The results of the present paper show that the factor of perceived spare time is crucial in the motivation to exercise, and that elements such as safety and resource availability must also be considered. Therefore, theories such as the COM-B model of motivation should be routinely used, due to its acknowledgement of environmental factors often contributing to why an individual may or may not exercise - as opposed to dual-process theories, which, though can be effectively used when evaluating some behaviours, are not well suited to physical activity.

This study therefore contributes to the existing body of knowledge by providing statistical evidence that during a global pandemic the population may make use of the situation to engage in more physical activity than usual, especially so in the presence of the perception of having more spare time. Subsequently, in doing this, 
they are also likely to improve their mental health and wellbeing in doing so. These findings may be of interest to organisations and government sectors interested in the areas of both health, health psychology and sport, especially in the coming months and years, where restrictions may be frequently imposed and there is a potential for further periods of lockdown. 


\section{References:}

Abdulrahman, H., Fletcher, P. C., Bullmore, E., \& Morcom, A. M. (2017). Dopamine and memory dedifferentiation in aging. Neurolmage. https://doi.org/10.1016/j.neuroimage.2015.03.031

Ajzen, I., \& Fishbein, M. (1980). Understanding attitudes and predicting social behaviour. In Englewood Cliffs. Prentice-Hall.

Ajzen, Icek. (1991). The theory of planned behavior. Organizational Behavior and Human Decision Processes. https://doi.org/10.1016/0749-5978(91)90020-T

Akoglu, H. (2018). User's guide to correlation coefficients. In Turkish Journal of Emergency Medicine. https://doi.org/10.1016/j.tjem.2018.08.001

Aldana, S. G., Sutton, L. D., Jacobson, B. H., \& Quirk, M. G. (1996). Relationships between leisure time physical activity and perceived stress. Perceptual and Motor Skills. https://doi.org/10.2466/pms.1996.82.1.315

Altman, D., \& Bland, J. (1995). Statistics notes: the normal distribution. BMJ, 310(6975), 298. https://doi.org/10.1136/bmj.310.6975.298

Amatriain-Fernández, S., Murillo-Rodríguez, E. S., Gronwald, T., Machado, S., \& Budde, H. (2020). Benefits of Physical Activity and Physical Exercise in the Time of Pandemic. Psychological Trauma: Theory, Research, Practice, and Policy, 12(1). https://doi.org/10.1037/tra0000643

American College of Sport Medicine. (2013). ACSM's guidelines for exercise testing and prescription. Lippincott Williams \& Wilkins.

American College of Sport Medicine. (2020). WHAT IS EXERCISE IS MEDICINE ${ }^{\circledR}$. https://www.exerciseismedicine.org/support_page.php/about-eim/

Anithakumari, D., Gayathri, S., \& Ramya, G. (2019). Effect of technology in sedentary lifestyle and its impact on the overall well being of the it employees in Chennai. International Journal of Recent Technology and Engineering. https://doi.org/10.35940/ijrte.B1088.0882S819

Arango, E. F., Patiño, F. A., Quintero, M. A., \& Arenas, M. M. (2011). Levels of physical activity, barriers, and stage of change in an urban population from a municipality in Colombia. Colombia Medica. https://doi.org/10.25100/cm.v42i3.882

Arigo, D., Pagoto, S., Carter-Harris, L., Lillie, S. E., \& Nebeker, C. (2018). Using social media for health research: Methodological and ethical considerations for recruitment and intervention delivery. Digital Health, 4. https://doi.org/https://doi.org/10.1177\%2F2055207618771757

Arlinghaus, K. R., \& Johnston, C. A. (2019). The Importance of Creating Habits and Routine. In American Journal of Lifestyle Medicine. https://doi.org/10.1177/1559827618818044

Atenstaedt, R. (2012). Word cloud analysis of the BJGP. In British Journal of General Practice. https://doi.org/10.3399/bjgp12X630142

Atlantis, E., Chow, C. M., Kirby, A., \& Fiatarone Singh, M. (2004). An effective exercise-based intervention for improving mental health and quality of life measures: A randomized controlled trial. Preventive Medicine. https://doi.org/10.1016/j.ypmed.2004.02.007

Attard, A. (2012). Antidepressants. Medicine, 40(12), 681-683. https://doi.org/https://doiorg.glos.idm.oclc.org/10.1016/j.mpmed.2012.09.007

Avni-Babad, D. (2011). Routine and feelings of safety, confidence, and well-being. British Journal of 
Psychology. https://doi.org/10.1348/000712610X513617

Bartle, \& Behrens. (2016). The Use of Technologies in Care Homes. Training Across the Health \& Social Care Spectrum. https://www.3spirituk.com/use-technologies-care-homes/

Basso, J. C., \& Suzuki, W. A. (2017). The Effects of Acute Exercise on Mood, Cognition, Neurophysiology, and Neurochemical Pathways: A Review. Brain Plasticity, 2(2), 127-152. https://doi.org/10.3233/bpl-160040

BBC. (2020, June 9). More than one in four UK workers now furloughed. https://www.bbc.co.uk/news/business-52977098

Bedard, A. C., Ickowicz, A., Logan, G. D., Hogg-Johnson, S., Schachar, R., \& Tannock, R. (2003). Selective inhibition in children with attention-deficit hyperactivity disorder off and on stimulant medication. Journal of Abnormal Child Psychology. https://doi.org/10.1023/A:1023285614844

Berger, R., \& Lahad, M. (2010). A safe place: Ways in which nature, play and creativity can help children cope with stress and crisis - establishing the kindergarten as a safe haven where children can develop resiliency. Early Child Development and Care. https://doi.org/10.1080/03004430802525013

Berger, R., \& McLeod, J. (2006). Incorporating Nature into Therapy: A Framework for Practice. Journal of Systemic Therapies. https://doi.org/10.1521/jsyt.2006.25.2.80

Bice, M. R., Ball, J. W., \& McClaran, S. (2016). Technology and physical activity motivation. International Journal of Sport and Exercise Psychology. https://doi.org/10.1080/1612197X.2015.1025811

Blumenthal, J. A., \& Ong, L. (2009). A commentary on “Exercise and Depression" (Mead et al., 2009): And the verdict is... Mental Health and Physical Activity. https://doi.org/10.1016/j.mhpa.2009.08.001

Bond, M. J., \& Feather, N. T. (1988). Some Correlates of Structure and Purpose in the Use of Time. Journal of Personality and Social Psychology. https://doi.org/10.1037/0022-3514.55.2.321

Boyd, J., McMillan, B., Easton, K., Delaney, B., \& Mitchell, C. (2020). Utility of the COM-B model in identifying facilitators and barriers to maintaining a healthy postnatal lifestyle following a diagnosis of gestational diabetes: A qualitative study. BMJ Open. https://doi.org/10.1136/bmjopen-2020-037318

Boyle, P. A., Buchman, A. S., Barnes, L. L., \& Bennett, D. A. (2010). Effect of a purpose in life on risk of incident Alzheimer disease and mild cognitive impairment in community-dwelling older persons. Archives of General Psychiatry. https://doi.org/10.1001/archgenpsychiatry.2009.208

Brand, R, \& Ekkekakis, P. (2018). Affective-Reflective Theory of physical inactivity and exercise: Foundations and preliminary evidence [Die Affective-Reflective Theory zur Erklärung von körperlicher Inaktivität und Sporttreiben: Grundlagen und erste Studienergebnisse]. German Journal of Exercise and Sport Research, 48, 48-58. https://doi.org/10.1007/s12662-017-0477-9

Brand, Ralf, \& Cheval, B. (2019). Theories to explain exercise motivation and physical inactivity: Ways of expanding our current theoretical perspective. Frontiers in Psychology. https://doi.org/10.3389/fpsyg.2019.01147

Brenner, I. K. M., Shek, P. N., \& Shephard, R. J. (1994). Infection in Athletes. In Sports Medicine: An International Journal of Applied Medicine and Science in Sport and Exercise. https://doi.org/10.2165/00007256-199417020-00002

British Heart Foundation. (2017). Physical Inactivity and Sedentary Behaviour Report 2017. 
https://www.bhf.org.uk/informationsupport/publications/statistics/physical-inactivity-report2017

Brooks, S. K., Webster, R. K., Smith, L. E., Woodland, L., Wessely, S., Greenberg, N., \& Rubin, G. J. (2020). The psychological impact of quarantine and how to reduce it: rapid review of the evidence. In The Lancet. https://doi.org/10.1016/S0140-6736(20)30460-8

Bruun-Pedersen, J. R., Serafin, S., \& Kofoed, L. B. (2016). Motivating elderly to exercise - recreational virtual environment for indoor biking. 2016 IEEE International Conference on Serious Games and Applications for Health. https://www.researchgate.net/publication/308990057_Motivating_elderly_to_exercise__recreational_virtual_environment_for_indoor_biking

Buckworth, J., \& Dishman, R. K. (2002). Determinants of exercise and physical activity. In In Buckworth, J. (ed.), Exercise psychology, Champaign, III., Human Kinetics, c2002, p.191-209.

Budde, H., Akko, D. P., Ainamani, H. E., Murillo-Rodríguez, E., \& Weierstall, R. (2018). The impact of an exercise training intervention on cortisol levels and post-traumatic stress disorder in juveniles from an Ugandan refugee settlement: Study protocol for a randomized control trial. Trials, 19(1), 364. https://doi.org/10.1186/s13063-018-2753-x

Budde, H., Voelcker-Rehage, C., Pietraßyk-Kendziorra, S., Ribeiro, P., \& Tidow, G. (2008). Acute coordinative exercise improves attentional performance in adolescents. Neuroscience Letters, 441(2), 219-223. https://doi.org/10.1016/j.neulet.2008.06.024

Burke, H. M., Davis, M. C., Otte, C., \& Mohr, D. C. (2005). Depression and cortisol responses to psychological stress: A meta-analysis. Psychoneuroendocrinology. https://doi.org/10.1016/j.psyneuen.2005.02.010

Cacioppo, J. T., \& Hawkley, L. C. (2009). Perceived social isolation and cognition. In Trends in Cognitive Sciences. https://doi.org/10.1016/j.tics.2009.06.005

Cameron, A. (2020). Coronavirus and homeworking in the UK: April 2020. https://www.ons.gov.uk/employmentandlabourmarket/peopleinwork/employmentandemploy eetypes/bulletins/coronavirusandhomeworkingintheuk/april2020

Carmeli, E. (2013). Physical Activity Reduces Stress and Anxiety. Journal of Aging Science, 2(1). https://doi.org/10.4172/2329-8847.1000e108

Caspersen, C. J., Powell, K. E., \& Christenson, G. M. (1985). Physical Activity, Exercise and Physical Fitness Definitions for Health-Related Research. Public Health Reports, 100(2), 126-131.

Centers for Disease Control and Prevention. (2014). State Indicator Report on Physical Activity. https://www.cdc.gov/physicalactivity/downloads/PA_State_Indicator_Report_2014.pdf

Chau, J. Y., Grunseit, A. C., Chey, T., Stamatakis, E., Brown, W. J., Matthews, C. E., Bauman, A. E., \& Van Der Ploeg, H. P. (2013). Daily sitting time and all-cause mortality: A meta-analysis. PLoS ONE, 8(11). https://doi.org/10.1371/journal.pone.0080000

Chau, J. Y., Reyes-Marcelino, G., Burnett, A. C., Bauman, A. E., \& Freeman, B. (2019). Hyping health effects: A news analysis of the "new smoking" and the role of sitting. In British Journal of Sports Medicine. https://doi.org/10.1136/bjsports-2018-099432

Chen, H. I., Lin, L. C., Yu, L., Liu, Y. F., Kuo, Y. M., Huang, A. M., Chuang, J. I., Wu, F. Sen, Liao, P. C., \& Jen, C. J. (2008). Treadmill exercise enhances passive avoidance learning in rats: The role of down-regulated serotonin system in the limbic system. Neurobiology of Learning and Memory. https://doi.org/10.1016/j.nlm.2007.08.004 
Chen, Y., \& Feeley, T. H. (2014). Social support, social strain, loneliness, and well-being among older adults: An analysis of the Health and Retirement Study*. Journal of Social and Personal Relationships. https://doi.org/10.1177/0265407513488728

Chennaoui, M., Grimaldi, B., Fillion, M. P., Bonnin, A., Drogou, C., Fillion, G., \& Guezennec, C. Y. (2000). Effects of physical training on functional activity of 5-HT(1B) receptors in rat central nervous system: Role of 5-HT-moduline. Naunyn-Schmiedeberg's Archives of Pharmacology. https://doi.org/10.1007/s002100000242

Cheval, B., Orsholits, D., Sieber, S., Courvoisier, D., Cullati, S., \& Boisgontier, M. P. (2020). Relationship Between Decline in Cognitive Resources and Physical Activity. Health Psychology. https://doi.org/10.1037/hea0000857

Chin Fatt, C. R., Jha, M. K., Cooper, C. M., Fonzo, G., South, C., Grannemann, B., Carmody, T., Greer, T. L., Kurian, B., Fava, M., McGrath, P. J., Adams, P., McInnis, M., Parsey, R. V., Weissman, M., Phillips, M. L., Etkin, A., \& Trivedi, M. H. (2020). Effect of intrinsic patterns of functional brain connectivity in moderating antidepressant. In American Journal of Psychiatry. https://doi.org/10.1176/APPI.AJP.2019.18070870

Church, T. S., Thomas, D. M., Tudor-Locke, C., Katzmarzyk, P. T., Earnest, C. P., Rodarte, R. Q., Martin, C. K., Blair, S. N., \& Bouchard, C. (2011). Trends over 5 decades in U.S. occupation-related physical activity and their associations with obesity. PLOS ONE, 6(5). https://doi.org/10.1371/journal.pone.0019657

Clark, D. (2020). Number of jobs furloughed under the job retention scheme in the United Kingdom between April 20 and August 2, 2020. https://www.statista.com/statistics/1116638/uknumber-of-people-on-furlough/

Commissaris, D. A. C. M., Huysmans, M. A., Mathiassen, S. E., Srinivasan, D., Koppes, L. L. J., \& Hendriksen, I. J. M. (2016). Interventions to reduce sedentary behavior and increase physical activity during productive work: A systematic review. In Scandinavian Journal of Work, Environment and Health. https://doi.org/10.5271/sjweh.3544

Conner, M. (2020). Theory of Planned Behaviour. In G. Tenenbaum \& R. C. Ekland (Eds.), Handbook of Sport Psychology (4th ed., pp. 3-36). John Wiley \& Sons.

Constandt, B., Thibaut, E., De Bosscher, V., Scheerder, J., Ricour, M., \& Willem, A. (2020). Exercising in times of lockdown: An analysis of the impact of COVID-19 on levels and patterns of exercise among adults in Belgium. International Journal of Environmental Research and Public Health. https://doi.org/10.3390/ijerph17114144

Cooney, G. M., Dwan, K., Greig, C. A., Lawlor, D. A., Rimer, J., Waugh, F. R., Mcmurdo, M., \& Mead, G. E. (2013). Exercise for depression. In Cochrane Database of Systematic Reviews. https://doi.org/10.1002/14651858.CD004366.pub6

Cooper, C. (2017). Cerebral blood perfusion as a biomarker to predict treatment outcomes in major depressive disorder. Neuropsychopharmacology.

Cooper, C., Lu, H., Almeida, J., Chase, H., Carmody, T., Fava, M., Jin, T., Kurian, B. T., McGrath, P. J., McInnis, M., Oquendo, M., Parsey, R. V, Weissman, M. M., Weyandt, S., Phillips, M. L., \& Trivedi, M. (2013). Cerebral blood flow differences in major depressive disorder using arterial spin labeling: Preliminary results from the embarc study. Neuropsychopharmacology.

Crawford, P., \& Crawford, J. O. (2021). Cabin Fever: Surviving Lockdown in the Coronavirus Pandemic.

Da Silva, M. A., Singh-Manoux, A., Brunner, E. J., Kaffashian, S., Shipley, M. J., Kivimäki, M., \& Nabi, H. (2012). Bidirectional association between physical activity and symptoms of anxiety and 
depression: The whitehall II study. European Journal of Epidemiology.

https://doi.org/10.1007/s10654-012-9692-8

Dancey, C., \& Reidy, J. (2011). Statistics without maths for psychology. Pearson education. In Book.

Davey, G. [Ed], Albery, I. P., Chandler, C., Field, A., Jones, D., Messer, D., Moore, S., \& Sterling, C. (2008). Complete psychology (2nd ed.). In Complete psychology (2nd ed.).

Deal, J. (2015). Always On, Never Done? Don't Blame the Smartphone. https://cclinnovation.org/wpcontent/uploads/2020/02/alwayson.pdf

Dear, J. ., \& Bateman, N. (2016). Antidepressants. Medicine, 44(3), 135-137. https://doi.org/https://doi-org.glos.idm.oclc.org/10.1016/j.mpmed.2015.12.027

Department for Transport. (2019). Analyses from the National Travel Survey. https://assets.publishing.service.gov.uk/government/uploads/system/uploads/attachment_dat a/file/775032/2019-nts-commissioned-analyses.pdf

Di Renzo, L., Gualtieri, P., Pivari, F., Soldati, L., Attinà, A., Cinelli, G., Cinelli, G., Leggeri, C., Caparello, G., Barrea, L., Scerbo, F., Esposito, E., \& De Lorenzo, A. (2020). Eating habits and lifestyle changes during COVID-19 lockdown: An Italian survey. Journal of Translational Medicine. https://doi.org/10.1186/s12967-020-02399-5

Diaz, K. M., Krupka, D. J., Chang, M. J., Peacock, J., Ma, Y., Goldsmith, J., Schwartz, J. E., \& Davidson, K. W. (2015). Fitbit $^{\circledR}$ : An accurate and reliable device for wireless physical activity tracking. International Journal of Cardiology. https://doi.org/10.1016/j.ijcard.2015.03.038

Donnelly, J. E., Hillman, C. H., Castelli, D., Etnier, J. L., Lee, S., Tomporowski, P., Lambourne, K., \& Szabo-Reed, A. N. (2016). Physical activity, fitness, cognitive function, and academic achievement in children: A systematic review. In Medicine and Science in Sports and Exercise. https://doi.org/10.1249/MSS.0000000000000901

Dunlop, B. W., \& Nemeroff, C. B. (2007). The role of dopamine in the pathophysiology of depression. In Archives of General Psychiatry. https://doi.org/10.1001/archpsyc.64.3.327

Eichorn, L., Bruner, K., Short, T., \& Abraham, S. (2018). Factors That Affect Exercise Habits of College Students. Journal of Education and Development, 2(1), 20-30. https://doi.org/10.20849/jed.v2i1.327

Ekkekakis, P. (2017). People have feelings! Exercise psychology in paradigmatic transition. Current Opinion in Psychology, 16, 84-88. https://doi.org/10.1016/j.copsyc.2017.03.018

Ekkekakis, P., Hargreaves, E. A., \& Parfitt, G. (2013). Invited Guest Editorial: Envisioning the next fifty years of research on the exercise-affect relationship. Psychology of Sport and Exercise. https://doi.org/10.1016/j.psychsport.2013.04.007

Ekkekakis, P., \& Murri, M. B. (2017). Exercise as antidepressant treatment: Time for the transition from trials to clinic? General Hospital Psychiatry, 49(1). https://doi.org/https://doi.org/10.1016/j.genhosppsych.2017.04.008

Ekkekakis, P., Zenko, Z., Ladwig, M. A., \& Hartman, M. E. (2018). Affect as a potential determinant of physical activity and exercise: Critical appraisal of an emerging research field. In Affective Determinants of Health Behavior (pp. 237-261). Oxford University Press. https://doi.org/10.1093/oso/9780190499037.003.0011

Ersche, K. D., Lim, T. V., Ward, L. H. E., Robbins, T. W., \& Stochl, J. (2017). Creature of Habit: A selfreport measure of habitual routines and automatic tendencies in everyday life. Personality and Individual Differences. https://doi.org/10.1016/j.paid.2017.04.024 
European Commission. (2014). Special Eurobarometer 412 - Sport and Physical Activity. https://doi.org/10.2766/73002

Evenson, K. R., Goto, M. M., \& Furberg, R. D. (2015). Systematic review of the validity and reliability of consumer-wearable activity trackers. In International Journal of Behavioral Nutrition and Physical Activity. https://doi.org/10.1186/s12966-015-0314-1

Faculty of Sport and Exercise Medicine. (2021). What is Moving Medicine? https://www.fsem.ac.uk/what-is-moving-medicine/

Faul, F., Erdfelder, E., Lang, A. G., \& Buchner, A. (2007). G*Power 3: A flexible statistical power analysis program for the social, behavioral, and biomedical sciences. Behavior Research Methods. https://doi.org/10.3758/BF03193146

Fernandes, J., Arida, R. M., \& Gomez-Pinilla, F. (2017). Physical exercise as an epigenetic modulator of brain plasticity and cognition. Neuroscience and Biobehavioral Reviews, 80, 443-456. https://doi.org/10.1016/j.neubiorev.2017.06.012

Field, T., Hernandez-Reif, M., Diego, M., Schanberg, S., \& Kuhn, C. (2005). Cortisol decreases and serotonin and dopamine increase following massage therapy. In International Journal of Neuroscience. https://doi.org/10.1080/00207450590956459

Fishbein, M., \& Ajzen, I. (2011). Predicting and changing behavior: The reasoned action approach. In Predicting and Changing Behavior: The Reasoned Action Approach. https://doi.org/10.4324/9780203838020

Fleshner, M. (2005). Physical activity and stress resistance: Sympathetic nervous system adaptations prevent stress-induced immunosuppression. In Exercise and Sport Sciences Reviews. https://doi.org/10.1097/00003677-200507000-00004

Fox, K. (2000). Physical Activity and Mental Health Promotion: The Natural Partnership. Journal of Public Mental Health. https://doi.org/10.1108/17465729200000002

Fox, K. R. (1999). The influence of physical activity on mental well-being. Public Health Nutrition. https://doi.org/10.1017/S1368980099000567

Franklin, B. A., Brinks, J., Berra, K., Lavie, C. J., Gordon, N. F., \& Sperling, L. S. (2018). Using Metabolic Equivalents in Clinical Practice. In American Journal of Cardiology. https://doi.org/10.1016/j.amjcard.2017.10.033

Friedenreich, C. M. (2001). Physical activity and cancer prevention: From observational to intervention research. In Cancer Epidemiology Biomarkers and Prevention.

Garmin. (2020a). The Global Pandemic and Active Lifestyles. https://www.garmin.com/en$\mathrm{GB} / \mathrm{blog} /$ the-global-pandemic-and-active-lifestyles/

Garmin. (2020b). The Impact of the Global Pandemic on Human Activity: A Global Perspective. https://www.garmin.com/en-GB/blog/the-impact-of-the-global-pandemic-on-human-activitya-global-perspective/

Gebhardt, W. A., Van Der Doef, M. P., \& Maes, S. (1999). Conflicting activities for exercise. Perceptual and Motor Skills. https://doi.org/10.2466/pms.1999.89.3f.1159

Germano, S. (2015). American inactivity level is highest since 2007, survey finds. Wall Street Journal. https://www.wsj.com/articles/american-inactivity-level-is-highest-since-2007-survey-finds1429796821

Gleeson, M., Bishop, N., Oliveira, M., \& Tauler, P. (2013). Influence of training load on upper 
respiratory tract infection incidence and antigen-stimulated cytokine production. Scandinavian Journal of Medicine and Science in Sports. https://doi.org/10.1111/j.1600-0838.2011.01422.x

Gökçe, E., Güneş, E., \& Nalçaci, E. (2019). Effect of exercise on major depressive disorder and schizophrenia: A BDNF focused approach. Noropsikiyatri Arsivi, 56(4), 302-310. https://doi.org/10.29399/npa.23369

Goldenberg, D. L., Burckhardt, C., \& Crofford, L. (2004). Management of fibromyalgia syndrome. In Journal of the American Medical Association. https://doi.org/10.1001/jama.292.19.2388

GOV.uk. (2019). Physical Activity - Active Lives Survey. https://www.ethnicity-factsfigures.service.gov.uk/health/diet-and-exercise/physical-activity/latest

Greenwood, B. N., \& Fleshner, M. (2008). Exercise, learned helplessness, and the stress-resistant brain. In NeuroMolecular Medicine. https://doi.org/10.1007/s12017-008-8029-y

Greenwood, B. N., \& Fleshner, M. (2011). Exercise, stress resistance, and central serotonergic systems. Exercise and Sport Sciences Reviews. https://doi.org/10.1097/JES.0b013e31821f7e45

Greenwood, B. N., Foley, T. E., Day, H. E. W., Campisi, J., Hammack, S. H., Campeau, S., Maier, S. F., \& Fleshner, M. (2003). Freewheel running prevents learned helplessness/behavioral depression: Role of dorsal raphe serotonergic neurons. Journal of Neuroscience. https://doi.org/10.1523/jneurosci.23-07-02889.2003

Greenwood, B. N., Strong, P. V., Dorey, A. A., \& Fleshner, M. (2007). Therapeutic Effects of Exercise: Wheel Running Reverses Stress-Induced Interference With Shuttle Box Escape. Behavioral Neuroscience. https://doi.org/10.1037/0735-7044.121.5.992

Gremaud, A. L., Carr, L. J., Simmering, J. E., Evans, N. J., Cremer, J. F., Segre, A. M., Polgreen, L. A., \& Polgreen, P. M. (2018). Gamifying accelerometer use increases physical activity levels of sedentary office workers. Journal of the American Heart Association, 7(13). https://doi.org/10.1161/JAHA.117.007735

Guiney, H., \& Machado, L. (2013). Benefits of regular aerobic exercise for executive functioning in healthy populations. Psychonomic Bulletin and Review, 20, 73-86. https://doi.org/10.3758/s13423-012-0345-4

Guinness World Records. (2020). Joe Wicks' PE with Joe smashes YouTube livestream record. https://www.guinnessworldrecords.com/news/2020/4/joe-wicks-pe-with-joe-smashesyoutube-livestream-record-614934\#: :text=A record-breaking number of,channel\%3A The Body Coach TV.\&text=955\%2C185 viewers tuned in to,live stream on YouTube'!

Guthold, R., Stevens, G. A., Riley, L. M., \& Bull, F. C. (2018). Worldwide trends in insufficient physical activity from 2001 to 2016: a pooled analysis of 358 population-based surveys with 1.9 million participants. The Lancet Global Health, 6(10). https://doi.org/10.1016/S2214-109X(18)30357-7

Harris, M. A. (2018). The relationship between physical inactivity and mental wellbeing: Findings from a gamification-based community-wide physical activity intervention. Health Psychology Open. https://doi.org/10.1177/2055102917753853

Hartig, T., \& Mang, M. (1991). Restorative effects of natural environment experiences. Environment and Behavior. https://doi.org/10.1177/0013916591231001

Healy, G. N., Wijndaele, K., Dunstan, D. W., Shaw, J. E., Salmon, J., Zimmet, P. Z., \& Owen, N. (2008). Objectively measured sedentary time, physical activity, and metabolic risk the Australian Diabetes, Obesity and Lifestyle Study (AusDiab). Diabetes Care. https://doi.org/10.2337/dc071795 
Heijnen, S., Hommel, B., Kibele, A., \& Colzato, L. S. (2016). Neuromodulation of aerobic exercise-A review. In Frontiers in Psychology. https://doi.org/10.3389/fpsyg.2015.01890

Heintzelman, S. J., \& King, L. A. (2019). Routines and Meaning in Life. Personality and Social Psychology Bulletin. https://doi.org/10.1177/0146167218795133

Herazo-Beltrán, Y., Pinillos, Y., Vidarte, J., Crissien, E., Suarez, D., \& García, R. (2017). Predictors of perceived barriers to physical activity in the general adult population: a cross-sectional study. Brazilian Journal of Physical Therapy. https://doi.org/10.1016/j.bjpt.2016.04.003

Heron, L., O'Neill, C., McAneney, H., Kee, F., \& Tully, M. A. (2019). Direct healthcare costs of sedentary behaviour in the UK. Journal of Epidemiology and Community Health. https://doi.org/10.1136/jech-2018-211758

HM Treasury. (2020). Official figures show that the furlough scheme has worked: saving jobs and helping more than half of employees back to work already. https://www.gov.uk/government/news/official-figures-show-that-the-furlough-scheme-hasworked-saving-jobs-and-helping-more-than-half-of-employees-back-to-work-already

Holmes, M. D., Chen, W. Y., Feskanich, D., Kroenke, C. H., \& Colditz, G. A. (2005). Physical activity and survival after breast cancer diagnosis. Journal of the American Medical Association. https://doi.org/10.1001/jama.293.20.2479

Howie, E., \& Pate, R. (2017). Physical activity and educational achievement: Dose-response relationships. In Physical Activity and Educational Achievement: Insights from Exercise Neuroscience (pp. 9-31). Routledge.

Howlett, N., Jones, A., Bain, L., \& Chater, A. (2017). How effective is community physical activity promotion in areas of deprivation for inactive adults with cardiovascular disease risk and/or mental health concerns? Study protocol for a pragmatic observational evaluation of the "Active Herts" physical activ. BMJ Open. https://doi.org/10.1136/bmjopen-2017-017783

Hsieh, H.-F., \& Shannon, S. E. (2005). Three Approaches to Qualitative Content Analysis BACKGROUND ON THE DEVELOPMENT OF CONTENT ANALYSIS. QUALITATIVE HEALTH RESEARCH.

Huang, Y., \& Zhao, N. (2020). Generalized anxiety disorder, depressive symptoms and sleep quality during COVID-19 outbreak in China: a web-based cross-sectional survey. Psychiatry Research. https://doi.org/10.1016/j.psychres.2020.112954

Ingram, J., Maciejewski, G., \& Hand, C. J. (2020). Changes in Diet, Sleep, and Physical Activity Are Associated With Differences in Negative Mood During COVID-19 Lockdown. Frontiers in Psychology. https://doi.org/10.3389/fpsyg.2020.588604

Japan, M. (2019). Published the effect measurement results of the in-house practice project "Work Life Choice Challenge 2019 Summer" centered on "4 days a week \& 3 days a week." https://news.microsoft.com/ja-jp/2019/10/31/191031-published-the-results-of-measuringthe-effectiveness-of-our-work-life-choice-challenge-summer-2019/

Jayakody, K., Gunadasa, S., \& Hosker, C. (2014). Exercise for anxiety disorders: Systematic review. In British Journal of Sports Medicine. https://doi.org/10.1136/bjsports-2012-091287

Jetté, M., Sidney, K., \& Blümchen, G. (1990). Metabolic equivalents (METS) in exercise testing, exercise prescription, and evaluation of functional capacity. Clinical Cardiology. https://doi.org/10.1002/clc.4960130809

Johns, G. (2011). Attendance Dynamics at Work: The Antecedents and Correlates of Presenteeism, 
Absenteeism, and Productivity Loss. Journal of Occupational Health Psychology. https://doi.org/10.1037/a0025153

Jun, S. Y., Kim, J., Choi, H., Kim, J. S., Lim, S. H., Sul, B., \& Hong, B. Y. (2019). Physical Activity of Workers in a Hospital. International Journal of Environmental Research and Public Health, 16(4), 532. https://doi.org/10.3390/ijerph16040532.

Kaminska, M. S., Miller, A., Rotter, I., Szylinska, A., \& Grochans, E. (2018). The effectiveness of virtual reality training in reducing the risk of falls among elderly people. Clinical Interventions in Aging, 13, 2329-2338. https://doi.org/https://doi.org/10.2147/cia.s183502

Kandola, A., Ashdown-Franks, G., Hendrikse, J., Sabiston, C. M., \& Stubbs, B. (2019). Physical activity and depression: Towards understanding the antidepressant mechanisms of physical activity. In Neuroscience and Biobehavioral Reviews. https://doi.org/10.1016/j.neubiorev.2019.09.040

Kaplan, S. (1995). The restorative benefits of nature: Toward an integrative framework. Journal of Environmental Psychology. https://doi.org/10.1016/0272-4944(95)90001-2

Keane, L., \& Loades, M. (2017). Review: Low self-esteem and internalizing disorders in young people - a systematic review. In Child and Adolescent Mental Health. https://doi.org/10.1111/camh.12204

Kleinman, Z. (2019). Microsoft four-day work week "boosts productivity." BBC News. https://www.bbc.co.uk/news/technology-50287391

Kodz, J., Kersley, B., \& Strebler, T. (1998). Breaking the Long Hours Culture. In Institute of Employment Studies Report 352.

Kohll, A. (2019). Why We Pay Our Employees To Exercise At Work. Forbes. https://www.forbes.com/sites/alankohll/2019/01/09/why-we-pay-our-employees-to-exerciseat-work/?sh=67d3e26428d2

Kondracki, N., \& Wellman, D. (2012). Content analysis: Introduction. How to Design and Evaluate Research in Education.

Koščak Tivadar, B. (2017). Physical activity improves cognition: possible explanations. In Biogerontology. https://doi.org/10.1007/s10522-017-9708-6

Kriska, A. M., Knowler, W. C., LaPorte, R. E., Drash, A. L., Wing, R. R., Blair, S. N., Bennett, P. H., \& Kuller, L. H. (1990). Development of questionnaire to examine relationship of physical activity and diabetes in Pima Indians. Diabetes Care. https://doi.org/10.2337/diacare.13.4.401

Krithikadatta, J. (2014). Normal Distribution. Journal of Conservative Dentistry. https://doi.org/10.4103/0972-0707.124171

Kun, A., Sadun, R., Shaer, O., \& Teodorovicz, T. (2020). Where did the commute time go? Harvard Business Review. https://hbr.org/2020/12/where-did-the-commute-time-go

Kvam, S., Kleppe, C. L., Nordhus, I. H., \& Hovland, A. (2016). Exercise as a treatment for depression: A meta-analysis. In Journal of Affective Disorders. https://doi.org/10.1016/j.jad.2016.03.063

Kwak, L., Berrigan, D., van Domelen, D., Sjostrom, M., \& Hagstromer, M. (2015). Examining differences in physical activity levels by employment status and/or job activity level: Genderspecific comparisons between the United States and Sweden. Journal of Science and Medicine in Sport, 19(6), 482-487. https://doi.org/https://doi.org/10.1016/j.jsams.2015.05.008

Labott, S. M., Johnson, T. P., Fendrich, M., \& Feeny, N. C. (2013). Emotional Risks to Respondents in Survey Research: Some Empirical Evidence. Journal of Empirical Research on Human Research 
Ethics. https://doi.org/10.1525/jer.2013.8.4.53

Lachman, M. E., Neupert, S. D., Bertrand, R., \& Jette, A. M. (2006). The effects of strength training on memory in older adults. Journal of Aging and Physical Activity. https://doi.org/10.1123/japa.14.1.59

Lakens, D. (2013). Calculating and reporting effect sizes to facilitate cumulative science: a practical primer for t-tests and ANOVAs. Frontiers in Psychology, 4(863). https://doi.org/10.3389/fpsyg.2013.00863

Landers, D. M., \& Arent, S. M. (2007). Chapter 21 Physical ACtivity and Mental Health. In Handbook of Sport Psychology.

Larson, R. B. (2019). Controlling Social Desirability Bias. International Journal of Market Research, 61(5), 534-547. https://doi.org/https://doi.org/10.1177\%2F1470785318805305

Latkin, C. A., Edwards, C., Davey-Rothwell, M. A., \& Tobin, K. E. (2017). The relationship between social desirability bias and self-reports of health, substance use, and social network factors among urban substance users in Baltimore, Maryland. Addictive Behaviors. https://doi.org/10.1016/j.addbeh.2017.05.005

Lawton, J., Ahmad, N., Hanna, L., Douglas, M., \& Hallowell, N. (2006). “I can't do any serious exercise": Barriers to physical activity amongst people of Pakistani and Indian origin with Type 2 diabetes. Health Education Research. https://doi.org/10.1093/her/cyh042

Leslie A. Perlow, \& Jessica L. Porter. (2009). Making Time Off Predictable and Required. Harvard Business Review.

Lin, T. W., \& Kuo, Y. M. (2013). Exercise benefits brain function: The monoamine connection. In Brain Sciences. https://doi.org/10.3390/brainsci3010039

Lista, I., \& Sorrentino, G. (2010). Biological mechanisms of physical activity in preventing cognitive decline. Cellular and Molecular Neurobiology, 30(4), 493-503. https://doi.org/10.1007/s10571009-9488-x

Lockhart, S. N., \& DeCarli, C. (2014). Structural Imaging Measures of Brain Aging. In Neuropsychology Review. https://doi.org/10.1007/s11065-014-9268-3

López-Bueno, R., Calatayud, J., Ezzatvar, Y., Casajús, J. A., Smith, L., Andersen, L. L., \& López-Sánchez, G. F. (2020). Association Between Current Physical Activity and Current Perceived Anxiety and Mood in the Initial Phase of COVID-19 Confinement. Frontiers in Psychiatry. https://doi.org/10.3389/fpsyt.2020.00729

Lord Edward Stanley. (n.d.). QUOTE.

Ludyga, S., Gerber, M., Brand, S., Holsboer-Trachsler, E., \& Pühse, U. (2016). Acute effects of moderate aerobic exercise on specific aspects of executive function in different age and fitness groups: A meta-analysis. Psychophysiology, 53(11), 1611-1626. https://doi.org/10.1111/psyp.12736

Ma, J. K., Mare, L. Le, \& Gurd, B. J. (2015). Four minutes of in-class high-intensity interval activity improves selective attention in 9- to 11-year olds. Applied Physiology, Nutrition and Metabolism. https://doi.org/10.1139/apnm-2014-0309

Maass, A., Düzel, S., Goerke, M., Becke, A., Sobieray, U., Neumann, K., Lövden, M., Lindenberger, U., Bäckman, L., Braun-Dullaeus, R., Ahrens, D., Heinze, H. J., Müller, N. G., \& Düzel, E. (2015). Vascular hippocampal plasticity after aerobic exercise in older adults. Molecular Psychiatry. https://doi.org/10.1038/mp.2014.114 
Macpherson, H., Teo, W. P., Schneider, L. A., \& Smith, A. E. (2017). A life-long approach to physical activity for brain health. Frontiers in Aging Neuroscience.

https://doi.org/10.3389/fnagi.2017.00147

Maher, C., Lewis, L., Katzmarzyk, P. T., Dumuid, D., Cassidy, L., \& Olds, T. (2016). The associations between physical activity, sedentary behaviour and academic performance. Journal of Science and Medicine in Sport, 19(12), 1004-1009. https://doi.org/10.1016/j.jsams.2016.02.010

Malhi, G. S., Bassett, D., Boyce, P., Bryant, R., Fitzgerald, P. B., Fritz, K., Hopwood, M., Lyndon, B., Mulder, R., Murray, G., Porter, R., \& Singh, A. B. (2015). Royal Australian and New Zealand College of Psychiatrists clinical practice guidelines for mood disorders. Australian and New Zealand Journal of Psychiatry, 49(12), 1087-1206. https://doi.org/10.1177/0004867415617657

Mammen, G., \& Faulkner, G. (2013). Physical Activity and the Prevention of Depression. American Journal of Preventive Medicine. https://doi.org/10.1016/j.amepre.2013.08.001

Mandolesi, L., Polverino, A., Montuori, S., Foti, F., Ferraioli, G., Sorrentino, P., \& Sorrentino, G. (2018). Effects of physical exercise on cognitive functioning and wellbeing: Biological and psychological benefits. Frontiers in Psychology, 9, 509. https://doi.org/10.3389/fpsyg.2018.00509

Martela, F., \& Steger, M. F. (2016). The three meanings of meaning in life: Distinguishing coherence, purpose, and significance. Journal of Positive Psychology. https://doi.org/10.1080/17439760.2015.1137623

Martinsen, E. W., Hoffart, A., \& Solberg, Y. (1989). Aerobic and non-aerobic forms of exercise in the treatment of anxiety disorders. Stress Medicine. https://doi.org/10.1002/smi.2460050209

Maslow, A. H. (1968). Health as transcendence of environment. Pastoral Psychology. https://doi.org/10.1007/BF01835090

McCauley, C. D., Van Velsor, E., \& Ruderman, M. N. (2004). Our view of leadership development. In Handbook of Leadership Development.

McClune, D. W., Kostka, B., Delahay, R. J., Montgomery, W. I., Marks, N. J., \& Scantlebury, D. M. (2015). Winter is coming: Seasonal variation in resting metabolic rate of the European badger (Meles meles). PLoS ONE. https://doi.org/10.1371/journal.pone.0135920

McDonagh, L. K., Saunders, J. M., Cassell, J., Curtis, T., Bastaki, H., Hartney, T., \& Rait, G. (2018). Application of the COM-B model to barriers and facilitators to chlamydia testing in general practice for young people and primary care practitioners: A systematic review. In Implementation Science. https://doi.org/10.1186/s13012-018-0821-y

McMichael, A. J., \& Hetzel, B. S. (1975). Mental health problems among university students, and their relationship to academic failure and withdrawal. The Medical Journal of Australia. https://doi.org/10.5694/j.1326-5377.1975.tb111533.x

Menotti, A., Puddu, P. E., Lanti, M., Maiani, G., Catasta, G., \& Fidanza, A. A. (2014). Lifestyle habits and mortality from all and specific causes of death: 40-year follow-up in the italian rural areas of the seven countries study. Journal of Nutrition, Health and Aging. https://doi.org/10.1007/s12603-013-0392-1

Michie, S., van Stralen, M. M., \& West, R. (2011). The behaviour change wheel: A new method for characterising and designing behaviour change interventions. Implementation Science. https://doi.org/10.1186/1748-5908-6-42

Mingo, I., \& Montecolle, S. (2014). Subjective and Objective Aspects of Free Time: The Italian Case. 
Journal of Happiness Studies. https://doi.org/10.1007/s10902-013-9429-8

Ministry of Housing. Communities and Local Government. (2020). New Guidance on Spending Time Outdoors. https://www.gov.uk/government/news/new-guidance-on-spending-time-outdoors

MITCHELL, H. H. (1962). The Maintenance Requirement of Energy: The Basal Metabolism. In Comparative Nutrition of Man and Domestic Animals. https://doi.org/10.1016/b978-0-12395551-7.50007-6

Moore, G. E. (2004). The role of exercise prescription in chronic disease. In British Journal of Sports Medicine. https://doi.org/10.1136/bjsm.2003.010314

Moore, J. B., Mitchell, N. G., Beets, M. W., \& Bartholomew, J. B. (2012). Physical self-esteem in older adults: $\mathrm{A}$ test of the indirect effect of physical activity. Sport, Exercise, and Performance Psychology. https://doi.org/10.1037/a0028636

Motion. (2021). Motion Project.

https://www.enactussheffield.org/motion/?fbclid=IwAROTgUj6DptjX2ljPwHagALivVoKywjy2ljxp zWALIm50xyd3xs-gHeYIIw

Moving Medicine. (2021). Moving Medicine - Homepage. https://movingmedicine.ac.uk/

Müller-Riemenschneider, F., Reinhold, T., Nocon, M., \& Willich, S. N. (2008). Long-term effectiveness of interventions promoting physical activity: A systematic review. In Preventive Medicine. https://doi.org/10.1016/j.ypmed.2008.07.006

Naor, L., \& Mayseless, O. (2020). The therapeutic value of experiencing spirituality in nature. Spirituality in Clinical Practice. https://doi.org/10.1037/scp0000204

Nazlieva, N., Mavilidi, M. F., Baars, M., \& Paas, F. (2020). Establishing a scientific consensus on the cognitive benefits of physical activity. International Journal of Environmental Research and Public Health. https://doi.org/10.3390/ijerph17010029

NCCMH, \& NICE. (2010). Depression: The Nice Guideline on the Treatment and Management of Depression in Adults. In Economist.

Network, S. B. R. (2012). Standardized use of the terms "sedentary" and "sedentary behaviours." Applied Physiology, Nutrition, and Metabolism. https://doi.org/10.1371/journal.pone.0004515

Newman, M. A., Pettee, K. K., Storti, K. L., Richardson, C. R., Kuller, L. H., \& Kriska, A. M. (2009). Monthly variation in physical activity levels in postmenopausal women. Medicine and Science in Sports and Exercise. https://doi.org/10.1249/MSS.0b013e3181864c05

NHS. (2013). Health Survey - England 2012.

NHS. (2018). Overview - Seasonal affective disorder (SAD). https://www.nhs.uk/mentalhealth/conditions/seasonal-affective-disorder-sad/overview/

NHS. (2019a). Does prolonged sitting really kill 70,000 people a year in the UK? https://www.nhs.uk/news/lifestyle-and-exercise/does-prolonged-sitting-really-kill-70000people-year-uk/\#: :text=UK sedentary patterns were identified,of adults at the weekend.

NHS. (2019b). Exercise. https://www.nhs.uk/live-well/exercise/

NHS. (2020). Couch to 5k: Week by Week. https://www.nhs.uk/live-well/exercise/couch-to-5k-weekby-week/

NICE. (2004). Management of depression in primary and secondary care. In Depression. https://doi.org/CG23 
Nieman, D. C., Henson, D. A., Gusewitch, G., Warren, B. J., Dotson, R. C., Butterworth, D. E., \& Nehlsen-Cannarella, S. L. (1993). Physical activity and immune function in elderly women. Medicine and Science in Sports and Exercise. https://doi.org/10.1249/00005768-19930700000011

Nieman, D. C., \& Wentz, L. M. (2019). The compelling link between physical activity and the body's defense system. In Journal of Sport and Health Science.

https://doi.org/10.1016/j.jshs.2018.09.009

Nuffield Health. (2020). Almost three quarters of British women don't feel safe exercising outdoors in the dark. https://www.nuffieldhealth.com/article/almost-three-quarters-of-british-womendont-feel-safe-exercising-outdoors-in-the-dark

Office for National Statistics. (2020a). Coronavirus and key workers in the UK. https://www.ons.gov.uk/employmentandlabourmarket/peopleinwork/earningsandworkinghou $\mathrm{rs} /$ articles/coronavirusandkeyworkersintheuk/2020-05-15

Office for National Statistics. (2020b). Employment in the UK: August 2020. https://www.ons.gov.uk/employmentandlabourmarket/peopleinwork/employmentandemploy eetypes/bulletins/employmentintheuk/august2020\#: :text=there were 28.02 million employees,fewer than the previous quarter

Orchard, C. (2015). The Business Benefits of a Healthy Workforce. Harvard School of Public Health. https://www.hsph.harvard.edu/ecpe/the-business-benefits-of-a-healthy-workforce/

Owen, N., Sparling, P. B., Healy, G. N., Dunstan, D. W., \& Matthews, C. E. (2010a). Sedentary behavior: Emerging evidence for a new health risk. Mayo Clinic Proceedings, 85(12), 11381141. https://doi.org/10.4065/mcp.2010.0444

Owen, N., Sparling, P. B., Healy, G. N., Dunstan, D. W., \& Matthews, C. E. (2010b). Sedentary Behavior: Emerging Evidence for a New Health Risk. Mayo Clinic Proceedings. https://doi.org/10.4065/mcp.2010.0444

Ozamiz-Etxebarria, N., Idoiaga Mondragon, N., Dosil Santamaría, M., \& Picaza Gorrotxategi, M. (2020). Psychological Symptoms During the Two Stages of Lockdown in Response to the COVID19 Outbreak: An Investigation in a Sample of Citizens in Northern Spain. Frontiers in Psychology. https://doi.org/10.3389/fpsyg.2020.01491

Parkrun. (2020). Parkrun: Our Story. https://www.parkrun.com/about/our-story/

Parry, S., \& Straker, L. (2013). The contribution of office work to sedentary behaviour associated risk. BMC Public Health. https://doi.org/10.1186/1471-2458-13-296

Paths for All. (2020). Step Count Challenge. https://www.pathsforall.org.uk/step-count-challenge

Patterson, R., McNamara, E., Tainio, M., de Sá, T. H., Smith, A. D., Sharp, S. J., Edwards, P., Woodcock, J., Brage, S., \& Wijndaele, K. (2018). Sedentary behaviour and risk of all-cause, cardiovascular and cancer mortality, and incident type 2 diabetes: a systematic review and dose response meta-analysis. European Journal of Epidemiology, 33, 811-829. https://doi.org/10.1007/s10654-018-0380-1

Paulhus, D. L. (1984). Two-component models of socially desirable responding. Journal of Personality and Social Psychology. https://doi.org/10.1037/0022-3514.46.3.598

Pearce, P. Z. (2008). Exercise is medicine ${ }^{\mathrm{TM}}$. In Current Sports Medicine Reports. https://doi.org/10.1097/01.CSMR.0000319712.63793.5f

Pettee Gabriel, K., McClain, J. J., Schmid, K. K., Storti, K. L., \& Ainsworth, B. E. (2011). Reliability and 
convergent validity of the past-week Modifiable Activity Questionnaire. In Public Health Nutrition. https://doi.org/10.1017/S1368980010002612

Pettee, K. K., Kriska, A. M., Johnson, B. D., Conroy, M. B., Mackey, R. H., Orchard, T. J., \& Kuller, L. H. (2007). The relationship between physical activity and lipoprotein subclasses in postmenopausal women: The influence of hormone therapy. Menopause. https://doi.org/10.1097/01.gme.0000229573.29258.d5

Pickett, K., Yardley, L., \& Kendrick, T. (2012). Physical activity and depression: A multiple mediation analysis. Mental Health and Physical Activity. https://doi.org/10.1016/j.mhpa.2012.10.001

Pierce, G., Beske, S., Lawson, B., Southall, K., Benay, F., Donato, A., \& Seals, D. (2008). Weight Loss Alone Improves Conduit and Resistance Artery Endothelial Function in Young and Older Overweight/Obese Adults. Hypertension, 52(1), 72-79. https://doi.org/https://dx.doi.org/10.1161\%2FHYPERTENSIONAHA.108.111427

Pierce, M., Hope, H., Ford, T., Hatch, S., Hotopf, M., John, A., Kontopantelis, E., Webb, R., Wessely, S., McManus, S., \& Abel, K. M. (2020). Mental health before and during the COVID-19 pandemic: a longitudinal probability sample survey of the UK population. The Lancet Psychiatry. https://doi.org/10.1016/S2215-0366(20)30308-4

Poirier, P., Giles, T. D., Bray, G. A., Hong, Y., Stern, J. S., Pi-Sunyer, F. X., \& Eckel, R. H. (2006). Obesity and cardiovascular disease: Pathophysiology, evaluation, and effect of weight loss: An update of the 1997 American Heart Association Scientific Statement on obesity and heart disease from the Obesity Committee of the Council on Nutrition, Physical. In Circulation. https://doi.org/10.1161/CIRCULATIONAHA.106.171016

Potter, W. J., \& Levine-Donnerstein, D. (1999). Rethinking validity and reliability in content analysis. Journal of Applied Communication Research. https://doi.org/10.1080/00909889909365539

Power, J. (2019). The Influence of Task Difficulty on Engagement, Performance and Self-Efficacy. In Explorations in Technology Education Research: Helping Teachers Develop Research Informed Practice. Springer.

Prochaska, J. O., \& DiClemente, C. C. (1992). Stages of change in the modification of problem behaviors. In Progress in behavior modification.

Public Health England. (2019). Physical activity: applying All Our Health. https://www.gov.uk/government/publications/physical-activity-applying-all-ourhealth/physical-activity-applying-all-our-health

Puig-Ribera, A., Martínez-Lemos, I., Giné-Garriga, M., González-Suárez, Á. M., Bort-Roig, J., Fortuño, J., Muñoz-Ortiz, L., Mckenna, J., \& Gilson, N. D. (2015). Self-reported sitting time and physical activity: Interactive associations with mental well-being and productivity in office employees. BMC Public Health. https://doi.org/10.1186/s12889-015-1447-5

Rhodes, R. E., Martin, A. D., Taunton, J. E., Rhodes, E. C., Donnelly, M., \& Elliot, J. (1999). Factors associated with exercise adherence among older adults. An individual perspective. In Sports Medicine. https://doi.org/10.2165/00007256-199928060-00003

Richards, M., Hardy, R., \& Wadsworth, M. E. J. (2003). Does active leisure protect cognition? Evidence from a national birth cohort. Social Science and Medicine. https://doi.org/10.1016/S0277-9536(02)00075-8

Robertson, M., Duffy, F., Newman, E., Bravo, C. P., Ates, H. H., \& Sharpe, H. (2020). Exploring changes in body image, eating and exercise during the COVID-19 lockdown: A UK survey. Appetite, 159. https://doi.org/https://doi.org/10.1016/j.appet.2020.105062 
Rodgers, W. M., Markland, D., Selzler, A. M., Murray, T. C., \& Wilson, P. M. (2014). Distinguishing perceived competence and self-efficacy: An example from exercise. Research Quarterly for Exercise and Sport. https://doi.org/10.1080/02701367.2014.961050

Roepke, A. M., Jayawickreme, E., \& Riffle, O. M. (2014). Meaning and Health: A Systematic Review. In Applied Research in Quality of Life. https://doi.org/10.1007/s11482-013-9288-9

Rovio, S., Spulber, G., Nieminen, L. J., Niskanen, E., Winblad, B., Tuomilehto, J., Nissinen, A., Soininen, H., \& Kivipelto, M. (2010). The effect of midlife physical activity on structural brain changes in the elderly. Neurobiology of Aging. https://doi.org/10.1016/j.neurobiolaging.2008.10.007

RSPB. (2020). Recovering together: a report of public opinion on the role and importance of nature during and in our recovery from the Coronavirus crisis in the UK.

https://www.rspb.org.uk/globalassets/downloads/recovering-together-report/summaryreport---recovering-together_-uk_-final.pdf

Ryan, R. M., \& Deci, E. L. (2000). Self-determination theory and the facilitation of intrinsic motivation, social development, and well-being. American Psychologist, 55, 68-78. https://doi.org/10.1037/0003-066X.55.1.68

Ryan, R. M., Williams, G. C., Patrick, H., \& Deci, E. L. (2009). Self-determination theory and physical activity: the dynamics of motivation in development and wellness. Hellenic Journal of Psychology, 6(2), 107-124. https://doi.org/10.1080/17509840701827437

Sacheli, M. A., Neva, J. L., Lakhani, B., Murray, D. K., Vafai, N., Shahinfard, E., English, C., McCormick, S., Dinelle, K., Neilson, N., McKenzie, J., Schulzer, M., McKenzie, D. C., Appel-Cresswell, S., McKeown, M. J., Boyd, L. A., Sossi, V., \& Stoessl, A. J. (2019). Exercise increases caudate dopamine release and ventral striatal activation in Parkinson's disease. Movement Disorders. https://doi.org/10.1002/mds.27865

Sallis, R. E. (2009). Exercise is medicine and physicians need to prescribe it! In British Journal of Sports Medicine. https://doi.org/10.1136/bjsm.2008.054825

Scarapicchia, T. M. F., Amireault, S., Faulkner, G., \& Sabiston, C. M. (2017). Social support and physical activity participation among healthy adults: A systematic review of prospective studies. In International Review of Sport and Exercise Psychology. https://doi.org/10.1080/1750984X.2016.1183222

Schnohr, P., Kristensen, T. S., Prescott, E., \& Scharling, H. (2005). Stress and life dissatisfaction are inversely associated with jogging and other types of physical activity in leisure time - The Copenhagen City Heart Study. Scandinavian Journal of Medicine and Science in Sports. https://doi.org/10.1111/j.1600-0838.2004.00394.x

Schuch, F. B., Vancampfort, D., Firth, J., Rosenbaum, S., Ward, P. B., Silva, E. S., Hallgren, M., De Leon, A. P., Dunn, A. L., Deslandes, A. C., Fleck, M. P., Carvalho, A. F., \& Stubbs, B. (2018). Physical activity and incident depression: A meta-analysis of prospective cohort studies. American Journal of Psychiatry. https://doi.org/10.1176/appi.ajp.2018.17111194

Sharma, S., \& Agarwala, S. (2014). Self-Esteem and Collective Self-Esteem as Predictors of Depression. Journal of Behavioural Sciences.

Sharma, S., \& Agarwala, S. (2015). Self-Esteem and Collective Self-Esteem Among Adolescents: An Interventional Approach. Psychological Thought. https://doi.org/10.5964/psyct.v8i1.121

Shephard, R. J., \& Shek, P. N. (1994). Potential impact of physical activity and sport on the immune system - a brief review. In British Journal of Sports Medicine. 
https://doi.org/10.1136/bjsm.28.4.247

Singh, S., Roy, D., Sinha, K., Parveen, S., Sharma, G., \& Joshi, G. (2020). Impact of COVID-19 and lockdown on mental health of children and adolescents: A narrative review with recommendations. In Psychiatry Research. https://doi.org/10.1016/j.psychres.2020.113429

Sloan, L. (2017). Who Tweets in the United Kingdom? Profiling the Twitter Population Using the British Social Attitudes Survey 2015. Social Media \& Society, 1(11). https://doi.org/: $10.1177 / 2056305117698981$

Smith, P. J., Potter, G. G., McLaren, M. E., \& Blumenthal, J. A. (2013). Impact of aerobic exercise on neurobehavioral outcomes. Mental Health and Physical Activity. https://doi.org/10.1016/j.mhpa.2013.06.008

Smits, J. A. J., \& Otto, M. W. (2013). Exercise for Mood and Anxiety Disorders: Therapist Guide. In Journal of Chemical Information and Modeling.

Sonstroem, R. J., \& Morgan, W. P. (1989). Exercise and self-esteem: Rationale and model. Medicine and Science in Sports and Exercise. https://doi.org/10.1249/00005768-198906000-00018

Sport England. (2020). Coronavirus - Research. https://www.sportengland.org/know-youraudience/demographic-knowledge/coronavirus?section=research

Srivastav, A. K., Sharma, N., \& Samuel, A. J. (2020). Impact of Coronavirus disease-19 (COVID-19) lockdown on physical activity and energy expenditure among physiotherapy professionals and students using web-based open E-survey sent through WhatsApp, Facebook and Instagram messengers: Impact of COVID-19 lock. Clinical Epidemiology and Global Health. https://doi.org/10.1016/j.cegh.2020.07.003

Steger, M. F., \& Kashdan, T. B. (2009). Depression and Everyday Social Activity, Belonging, and WellBeing. Journal of Counseling Psychology. https://doi.org/10.1037/a0015416

Stevenson, L. M., \& McKenzie, D. C. (1992). Physicians' Exercise Habits: Most believe in exercise but don't do enough. Canadian Family Physician Medecin de Famille Canadien.

Steventon, J. J., Foster, C., Furby, H., Helme, D., Wise, R. G., \& Murphy, K. (2020). Hippocampal Blood Flow Is Increased After 20 min of Moderate-Intensity Exercise. Cerebral Cortex, 30(2), 525-533. https://doi.org/10.1093/cercor/bhz104

Stewart-Brown, S., Platt, S., Tennant, A., Maheswaran, H., Parkinson, J., Weich, S., Tennant, R., Taggart, F., \& Clarke, A. (2011). The Warwick-Edinburgh Mental Well-being Scale (WEMWBS): a valid and reliable tool for measuring mental well-being in diverse populations and projects. Journal of Epidemiology \& Community Health. https://doi.org/10.1136/jech.2011.143586.86

Stewart-Brown, Sarah, Tennant, A., Tennant, R., Platt, S., Parkinson, J., \& Weich, S. (2009). Internal construct validity of the Warwick-Edinburgh Mental Well-Being Scale (WEMWBS): A Rasch analysis using data from the Scottish Health Education Population Survey. Health and Quality of Life Outcomes. https://doi.org/10.1186/1477-7525-7-15

Stillman, T. F., Lambert, N. M., Fincham, F. D., \& Baumeister, R. F. (2011). Meaning as magnetic force: Evidence that meaning in life promotes interpersonal appeal. Social Psychological and Personality Science. https://doi.org/10.1177/1948550610378382

Stonebridge, N. (2020). Springtime in Lockdown. Social Bridges - COVID19 Research. https://www.youtube.com/watch?v=oAFTsQKazQ4\&ab_channel=socialBRIDGES

Strazdins, L., Broom, D. H., Banwell, C., McDonald, T., \& Skeat, H. (2011). Time limits? Reflecting and responding to time barriers for healthy, active living in Australia. Health Promotion 
International, 26(1), 46-54. https://doi.org/10.1093/heapro/daq060

Ströhle, A. (2009). Physical activity, exercise, depression and anxiety disorders. In Journal of Neural Transmission. https://doi.org/10.1007/s00702-008-0092-x

Ströhle, A. (2019). Sports psychiatry: mental health and mental disorders in athletes and exercise treatment of mental disorders. In European Archives of Psychiatry and Clinical Neuroscience. https://doi.org/10.1007/s00406-018-0891-5

Stults-Kolehmainen, M. A., \& Sinha, R. (2014). The effects of stress on physical activity and exercise. In Sports Medicine. https://doi.org/10.1007/s40279-013-0090-5

Sun, Y., Li, Y., Bao, Y., Meng, S., Sun, Y., Schumann, G., Kosten, T., Strang, J., Lu, L., \& Shi, J. (2020). Brief Report: Increased Addictive Internet and Substance Use Behavior During the COVID-19 Pandemic in China. American Journal on Addictions. https://doi.org/10.1111/ajad.13066

Sushames, A., Edwards, A., Thompson, F., McDermott, R., \& Gebel, K. (2016). Validity and reliability of fitbit flex for step count, moderate to vigorous physical activity and activity energy expenditure. PLOS ONE. https://doi.org/10.1371/journal.pone.0161224

Sustrans. (2019). Physical Activity and Health - facts and figures. https://www.sustrans.org.uk/policy-evidence/the-impact-of-our-work/related-academicresearch-and-statistics/physical-activity\#cmsanchor1

Takacs, J., Pollock, C. L., Guenther, J. R., Bahar, M., Napier, C., \& Hunt, M. A. (2014). Validation of the Fitbit One activity monitor device during treadmill walking. Journal of Science and Medicine in Sport. https://doi.org/10.1016/j.jsams.2013.10.241

Tankovska, H. (2021a). Age distribution of Linkedln users in the United Kingdom (UK) in April 2021. https://www.statista.com/statistics/278322/age-distribution-of-linkedin-users-in-greatbritain/\#: :text=LinkedIn users\%3A age distribution in the United Kingdom 2021\&text=In April 2021\%2C Linkedln had, 35 to 54 years old.

Tankovska, H. (2021b). Distribution of Facebook users in the United Kingdom (UK) as of April 2021, by age group and gender. https://www.statista.com/statistics/1030057/facebook-users-unitedkingdom-age-gender/

Tannahill, A. (2008). Beyond evidence - To ethics: A decision-making framework for health promotion, public health and health improvement. In Health Promotion International. https://doi.org/10.1093/heapro/dan032

Taylor-Piliae, R. E., Newell, K. A., Cherin, R., Lee, M. J., King, A. C., \& Haskell, W. L. (2010). Effects of Tai Chi and Western exercise on physical and cognitive functioning in healthy communitydwelling older adults. Journal of Aging and Physical Activity. https://doi.org/10.1123/japa.18.3.261

Teixeira, P. J., Carraça, E. V., Markland, D., Silva, M. N., \& Ryan, R. M. (2012). Exercise, physical activity, and self-determination theory: A systematic review. International Journal of Behavioral Nutrition and Physical Activity, 9, 78. https://doi.org/10.1186/1479-5868-9-78

Tennant, R., Hiller, L., Fishwick, R., Platt, S., Joseph, S., Weich, S., Parkinson, J., Secker, J., \& StewartBrown, S. (2007). The Warwick-Edinburgh Mental Well-Being Scale. Health and Quality Of.

Thivel, D., Tremblay, A., Genin, P. M., Panahi, S., Rivière, D., \& Duclos, M. (2018). Physical Activity, Inactivity, and Sedentary Behaviors: Definitions and Implications in Occupational Health. Frontiers in Public Health. https://doi.org/10.3389/fpubh.2018.00288

Thorp, A. A., Healy, G. N., Winkler, E., Clark, B. K., Gardiner, P. A., Owen, N., \& Dunstan, D. W. (2012). 
Prolonged sedentary time and physical activity in workplace and non-work contexts: A crosssectional study of office, customer service and call centre employees. International Journal of Behavioral Nutrition and Physical Activity. https://doi.org/10.1186/1479-5868-9-128

Thune, I., \& Furberg, A. S. (2001). Physical activity and cancer risk: Dose-response and cancer, all sites and site-specific. Medicine and Science in Sports and Exercise. https://doi.org/10.1097/00005768-200106001-00025

Tine, M. T., \& Butler, A. G. (2012). Acute aerobic exercise impacts selective attention: An exceptional boost in lower-income children. Educational Psychology. https://doi.org/10.1080/01443410.2012.723612

Tourangeau, R., \& Yan, T. (2007). Sensitive Questions in Surveys. Psychological Bulletin. https://doi.org/10.1037/0033-2909.133.5.859

Tremblay, M. S., Aubert, S., Barnes, J. D., Saunders, T. J., Carson, V., Latimer-Cheung, A. E., Chastin, S. F. M., Altenburg, T. M., Chinapaw, M. J. M., Aminian, S., Arundell, L., Hinkley, T., Hnatiuk, J., Atkin, A. J., Belanger, K., Chaput, J. P., Gunnell, K., Larouche, R., Manyanga, T., ... Wondergem, R. (2017). Sedentary Behavior Research Network (SBRN) - Terminology Consensus Project process and outcome. International Journal of Behavioral Nutrition and Physical Activity. https://doi.org/10.1186/s12966-017-0525-8

Trumpeter, N. N. (2015). The role of self-efficacy in mediating the effect of physical activity on adolescent depression. ProQuest Dissertations and Theses.

U.S. Department of Health and Human Services. (2017). Facts \& Statistics - Physical Activity. https://www.hhs.gov/fitness/resource-center/facts-and-statistics/index.html\#footnote-3

Ulrich, R. S., Simons, R. F., Losito, B. D., Fiorito, E., Miles, M. A., \& Zelson, M. (1991). Stress recovery during exposure to natural and urban environments. Journal of Environmental Psychology. https://doi.org/10.1016/S0272-4944(05)80184-7

Väänänen, J.-M., Marttunen, M., Helminen, M., \& Kaltiala-Heino, R. (2014). Low perceived social support predicts later depression but not social phobia in middle adolescence. Health Psychology and Behavioral Medicine. https://doi.org/10.1080/21642850.2014.966716

Van Cauwenberghe, E., Gubbels, J., De Bourdeaudhuij, I., \& Cardon, G. (2011). Feasibility and validity of accelerometer measurements to assess physical activity in toddlers. International Journal of Behavioral Nutrition and Physical Activity. https://doi.org/10.1186/1479-5868-8-67

van de Mortel, T. F. (2008). Faking it: Social desirability response bias in selfreport research. Australian Journal of Advanced Nursing.

van der Ploeg, H. P., \& Hillsdon, M. (2017). Is sedentary behaviour just physical inactivity by another name? International Journal of Behavioral Nutrition and Physical Activity, 14(142). https://doi.org/10.1186/s12966-017-0601-0

Van Uffelen, J. G. Z., Wong, J., Chau, J. Y., Van Der Ploeg, H. P., Riphagen, I., Gilson, N. D., Burton, N. W., Healy, G. N., Thorp, A. A., Clark, B. K., Gardiner, P. A., Dunstan, D. W., Bauman, A., Owen, N., \& Brown, W. J. (2010). Occupational sitting and health risks: A systematic review. American Journal of Preventive Medicine, 39(4), 379-388. https://doi.org/10.1016/j.amepre.2010.05.024

Verity, A. (2020). Coronavirus: More than 9 million expected to be furloughed. BBC News. https://www.bbc.co.uk/news/business-52209790

Vidoni, E. D., Johnson, D. K., Morris, J. K., Van Sciver, A., Greer, C. S., Billinger, S. A., Donnelly, J. E., \& Burns, J. M. (2015). Dose-response of aerobic exercise on cognition: A community-based, pilot 
randomized controlled trial. PLOS ONE. https://doi.org/10.1371/journal.pone.0131647

Vitality Health, \& Financial Times. (2019). Health at Work: Britain's Healthiest Workplace. https://www.vitality.co.uk/media-online/britains-healthiest-workplace/pdf/2019/health-atwork-2019_uk.pdf

Voelcker-Rehage, C., \& Niemann, C. (2013). Structural and functional brain changes related to different types of physical activity across the life span. In Neuroscience and Biobehavioral Reviews. https://doi.org/10.1016/j.neubiorev.2013.01.028

Voss, M. W., Chaddock, L., Kim, J. S., VanPatter, M., Pontifex, M. B., Raine, L. B., Cohen, N. J., Hillman, C. H., \& Kramer, A. F. (2011). Aerobic fitness is associated with greater efficiency of the network underlying cognitive control in preadolescent children. Neuroscience, 199, 166-176. https://doi.org/10.1016/j.neuroscience.2011.10.009

Vučcković, M. G., Li, Q., Fisher, B., Nacca, A., Leahy, R. M., Walsh, J. P., Mukherjee, J., Williams, C., Jakowec, M. W., \& Petzinger, G. M. (2010). Exercise elevates dopamine D2 receptor in a mouse model of Parkinson's disease: In vivo imaging with [18F]fallypride. Movement Disorders. https://doi.org/10.1002/mds.23407

Wahid, A., Manek, N., Nichols, M., Kelly, P., Foster, C., Webster, P., Kaur, A., Friedemann Smith, C., Wilkins, E., Rayner, M., Roberts, N., \& Scarborough, P. (2016). Quantifying the Association Between Physical Activity and Cardiovascular Disease and Diabetes: A Systematic Review and Meta-Analysis. Journal of the American Heart Association. https://doi.org/10.1161/JAHA.115.002495

Warburton, D. E. R., \& Bredin, S. S. D. (2017). Health benefits of physical activity: A systematic review of current systematic reviews. Current Opinion in Cardiology, 32(5), 541-556. https://doi.org/10.1097/HCO.0000000000000437

Warburton, D. E. R., Nicol, C. W., \& Bredin, S. S. D. (2006). Health benefits of physical activity: The evidence. In CMAJ. https://doi.org/10.1503/cmaj.051351

Wegner, M., Amatriain-Fernández, S., Kaulitzky, A., Murillo-Rodríguez, E., Machado, S., \& Budde, H. (2020). Systematic Review of Meta-Analyses: Exercise Effects on Depression in Children and Adolescents. Frontiers in Psychiatry, 11(81). https://doi.org/10.3389/fpsyt.2020.00081

West, R. (2007). The PRIME theory of motivation as a possible foundation for the treatment of addiction. In Addiction treatment: Science and policy for the twenty-first century.

West, R., \& Brown, J. (2013). A synthetic theory of motivation. In Theory of Addiction. https://doi.org/10.1002/9781118484890.ch8

West, R., \& Michie, S. (2020). A brief introduction to the COM-B Model of behaviour and the PRIME Theory of motivation. Qeios. https://doi.org/10.32388/ww04e6

Whitbourne, S. B., Neupert, S. D., \& Lachman, M. E. (2008). Daily physical activity: Relation to everyday memory in adulthood. Journal of Applied Gerontology. https://doi.org/10.1177/0733464807312175

White, R. L., Babic, M. J., Parker, P. D., Lubans, D. R., Astell-Burt, T., \& Lonsdale, C. (2017). DomainSpecific Physical Activity and Mental Health: A Meta-analysis. In American Journal of Preventive Medicine. https://doi.org/10.1016/j.amepre.2016.12.008

Wiklund, P. (2016). The role of physical activity and exercise in obesity and weight management: Time for critical appraisal. In Journal of Sport and Health Science. https://doi.org/10.1016/j.jshs.2016.04.001 
World Health Organization. (2002). Physical inactivity a leading cause of disease and disability, warns WHO. https://www.who.int/mediacentre/news/releases/release23/en/

World Health Organization. (2008). Physical Inactivity: A Global Public Health Problem. https://www.who.int/dietphysicalactivity/factsheet_inactivity/en/

World Health Organization. (2010). Global Recommendations on Physical Activity for Health. https://www.who.int/dietphysicalactivity/global-PA-recs-2010.pdf

World Health Organization. (2013). Global action plan for the prevention and control of noncommunicable diseases 2013-2020. World Health Organization. https://doi.org/978 924 1506236

World Health Organization. (2018a). Global Action Plan on Physical Activity 2018-2030: More active people for a healthier world. https://www.who.int/publications/i/item/9789241514187

World Health Organization. (2018b). Physical Activity. Fact Sheets. https://www.who.int/newsroom/fact-sheets/detail/physical-activity

World Health Organization. (2018c). WHO launches ACTIVE: a toolkit for countries to increase physical activity and reduce noncommunicable diseases.

https://www.who.int/ncds/prevention/physical-activity/active-toolkit/en/

World Health Organization. (2020). Webinar: WHO 2020 Guidelines on physical activity and sedentary behaviour. Webinar: WHO 2020 Guidelines on Physical Activity and Sedentary Behaviour. https://www.who.int/news-room/events/detail/2020/11/26/defaultcalendar/webinar-who-2020-guidelines-on-physical-activity-and-sedentary-behaviour

World Health Organization (WHO). (2020). WHO guidelines on physical activity and sedentary behaviour. https://www.who.int/publications/i/item/9789240015128

Wu, S., Feng, X., \& Sun, X. (2020). Development and evaluation of the health belief model scale for exercise. International Journal of Nursing Sciences, IN PRESS.

https://doi.org/https://doi.org/10.1016/j.ijnss.2020.07.006

Zhang, H., \& Shaw, R. (2020). Identifying research trends and gaps in the context of covid-19. International Journal of Environmental Research and Public Health. https://doi.org/10.3390/ijerph17103370

Zubala, A., MacGillivray, S., Frost, H., Kroll, T., Skelton, D. A., Gavine, A., Gray, N. M., Toma, M., \& Morris, J. (2017). Promotion of physical activity interventions for community dwelling older adults: A systematic review of reviews. PLOS ONE, 12(7).

https://doi.org/10.1371/journal.pone.0180902 


\section{Appendix:}

Appendix 1 - Participant Information Sheet

Appendix 2 - Participant Consent Form

Appendix 3 - Participant Unique Identifier Formulation Protocol

Appendix 4 - Demographic Questions List

Appendix 5 - Warwick-Edinburgh Mental Wellbeing Scale

Appendix 6 - Past-Week Modifiable Activity Questionnaire (Template)

Appendix 7 - Questionnaire Structure

Appendix 8 - SPSS Output

Appendix 9 - A Table demonstrating the significances of the tests of differences between Work Statuses and their impact on Mental Wellbeing

Appendix 10 - A Table demonstrating the significances of the tests of differences between types of accessible Open Spaces and their impact on Mental Wellbeing

Appendix 11 - A Table demonstrating the significances of the tests of differences between Work Statuses and their impact on METhrs/week difference scores

Appendix 12 - A Table demonstrating the significances of the tests of differences between types of accessible Open Spaces and their impact on METhrs/week difference scores

Appendix 13 - A Table demonstrating the significances of the tests of differences between Work Statuses and their impact on time spent engaging in physical activity difference scores

Appendix 14 - A Table demonstrating the significances of the tests of differences between types of accessible Open Spaces and their impact on time spent engaging in physical activity difference scores 


\title{
Appendix 1: Participant Information Sheet
}

\author{
Name of Principal Investigator:
}

Sam Warne

\section{Title of Research:}

Active Lockdown: Exploring the effect of Government enforced lockdown on physical activity habits and the corresponding relationship with wellbeing.

\section{Aim of research:}

You are being asked to participate in a study exploring physical activity levels and mental wellbeing during the 2020 Coronavirus pandemic Government enforced lockdown.

\section{Description of procedure:}

You will be asked to complete a series of demographic based questions, upon completion of which, you will be asked to answer a number of questions about your wellbeing. Please answer these based on your current mood, thoughts and feelings.

You will then be asked to complete another questionnaire, where you'll be asked to input any physical activity that you have done for 10 minutes or more at a time, as well as how long for (you do not need to have done the activity on more than one day, as long as you have done it at least once for 10 minutes or more). Please first do this as a reflection, based on an average week before the coronavirus pandemic.

After this, you'll be asked whether you own an activity tracker such as a Fitbit, Apple Watch or Garmin Watch. Those that do will take Path A through the survey, with the addition of a couple more questions. If possible, and Path $A$ is taken, you'll then be asked to input 3 pieces of data - Number of Steps, Total Distance and Number of Active Hours, which are accessible via the related app or profile. Please also base this on an average pre-Coronavirus week - ideally the same week as discussed beforehand. Those who do not own such technology are still eligible to participate, and will take Path $B$ through the study, skipping these data input questions.

At this point, you will be asked to do the same task again, however this time based on an average week during the coronavirus pandemic. As before, please note any activity that you have done for 10 minutes or more.

For those on Path A, you'll once again be asked for the Number of Steps, Total Distance and Number of Active Hours, this time based on an average week during the Coronavirus pandemic lockdown.

The final stage will be a simple question asking about your physical activity habit aspirations after the lockdown is lifted. Upon completion of this, the research is 
complete, and you will see the final debrief form, where you will be invited to volunteer for a potential follow-up study - this is optional.

\section{Description of risks:}

Research such as this has been conducted worldwide with no known negative effects however if you feel that talking around self-reflections and discussion of your personal habits, physical activity levels and mental wellbeing may result in negative outcomes then please do not take part. If you do feel any ill-effects as a result of your participation, then you can contact the support services provided in the debrief form at the end of the study. You can also contact your GP. Please note, you can also stop participating at any time by simply closing the window.

\section{Data collection and storage:}

The data collected from yourself includes a score from your responses to the wellbeing questions, as well as scores from the activity data provided (both by questionnaire and activity tracker. All data collected is completely anonymous and your data will be allocated a unique identifier in the format $A B C 123$, created using the first three letters of your mother's maiden name and the first three digits of your Date of Birth (This will be created on an upcoming page). No name or contact details will be taken, and your data isn't trackable back to yourself once collected, unless you opt to leave your email address for contact regarding future research.

The data is due to be stored in a password-locked computer, and will be kept until 31st September 2021. In line with BPS Ethical Guidelines, you are reminded that you are free to withdraw from the research, by contacting the email address provided, at any time until the given date on the debrief form. If you do choose to withdraw, any data collected from yourself will be destroyed.

\section{Contact information:}

If you have any questions regarding the research, please contact the researcher, Sam Warne, in the first instance

If you have questions you wish to ask to someone other than the researcher, please contact Dr Steven Baker , or the chair of the University of Gloucestershire Research Ethics Panel, Dr Rachel Sumner

This research has been approved by the Psychological Sciences Research Ethics Panel, and adheres to British Psychological Society guidelines also.

To read more about the university privacy policy for research participants please follow this link: https://www.glos.ac.uk/docs/download/Privacy-notices/Research-ParticipantsPrivacy-Notice.pdf

Advice: When participating in this research, open the link in a Chrome/Safari tab, not as a pop-up on a secondary app. This helps to make it easier to access activity tracker data, and means answered questions may not be lost in case of an accident. 


\section{Appendix 2: Participant Consent Form}

\section{Consent Form}

\section{Active Lockdown: Exploring the effect of Government enforced lockdown on physical activity habits and the corresponding relationship with wellbeing}

This study is investigating the influence of the 2020 COVID-19 pandemic Government enforced lockdown on physical activity levels and mental wellbeing.

Your data will be stored anonymously, although should you choose to provide your email address for contact regarding follow-up research, this will also be stored with your data. To enable the retrieval of your data should you wish to withdraw, we will provide a unique identifier that will be used to label materials relating to your participation in this study. You will need to provide your identifier should you wish to withdraw from the study, which you can do so via email within two weeks of your participation. Any requests to withdraw data after this time may not be actionable as the data may already have been entered for analysis. Your (anonymized) data will be used as part of a wider research project which will be written up for publication in academic journals - your contact email address will not be publicised, and will be permanently deleted after any correspondence.

Should you wish to contact anyone about this research, please contact Sam Warne (Researcher) on in the first instance, or the research supervisor (Dr Steve Baker; Sumner; ) or the ethics chair (Dr Rachel

Please tick the boxes to acknowledge that you agree to the statements below:

- I have read the information sheet provided and understand what I am required to do in order to take part in this study.

- I have been advised of my rights as a participant and understand that I can withdraw my data from this research project at any time up to two weeks after my participation.

- I have had the opportunity to ask questions before consenting to participant in the study and am satisfied with the information provided either through the information sheet, or from adequately answered questions to the researcher.

- I confirm that I am over 18 years old; that I consent to allow the answers I provided to be included in the analysis and reporting of the study, including potential publication; and that there is no reason why I consider myself unable to take part

- By checking this box, I am consenting to taking part in the research and am confirming that I understand all of the above-mentioned ethical rights. 


\section{Appendix 3: Participant Unique Identifier Formulation}

Using the space below, please create your unique identifier.

To do this, you are asked to use the first three letters of your mother's maiden name, followed by the first three digits of your date of birth (in the format DD/MM), to create an identifier in the format ABC123. For example, if your mother's maiden name was Smith, and your birthday was April 27th, your identifier should read SMI270.

Please enter your unique identifier in the space below: 


\section{Appendix 4: List of Demographic Questions}

- Age

- Gender

- Work Status Pre-Covid19

- Work Status During-COVID19

- Are you isolating alone during lockdown?

- Including yourself, how many are living in your household during lockdown?

- Are you exercising alone during the COVID19 lockdown?

- Do you have access to an open space during lockdown?

$\circ$ Which of the following best describes this space?

- Do you have Carer responsibilities during lockdown?

- Do you feel as though you have more spare time during COVID19 lockdown than you did before? 


\section{Appendix 5: Warwick-Edinburgh Mental Wellbeing Scale}

*All statements rated using a 5-point Likert Scale, where: $1=$ None of the time $/ 2=$ Rarely $/ 3=$ Some of the time $/ 4=$ Often $/ 5=$ All of the Time *

- I've been feeling optimistic about the future

- I've been feeling useful

- I've been feeling relaxed

- I've been feeling interested in other people

- I've had energy to spare

- I've been dealing with problems well

- I've been thinking clearly

- I've been feeling good about myself

- I've been feeling close to other people

- I've been feeling confident

- I've been able to make up my own mind about things

- I've been feeling loved

- I've been interested in new things

- I've been feeling cheerful 


\section{Appendix 6: Past-Week Modifiable Activity Questionnaire}

\begin{tabular}{|c|c|c|c|c|c|c|c|}
\hline \multirow[t]{2}{*}{ Activity } & \multicolumn{7}{|c|}{ Total \# Minutes per Day } \\
\hline & 芺 & $\stackrel{z}{0}$ & $\stackrel{S}{S}$ & $\stackrel{9}{3}$ & $\underset{\mid P}{P}$ & $\overrightarrow{\underline{\alpha}}$ & 范 \\
\hline \multicolumn{8}{|l|}{$\square$ Aerobic Dance/Step Aerobics } \\
\hline \multicolumn{8}{|l|}{$\square$ American Football } \\
\hline \multicolumn{8}{|l|}{$\square$ Badminton } \\
\hline \multicolumn{8}{|l|}{$\square$ Basketball } \\
\hline \multicolumn{8}{|l|}{$\square$ Bicycling (indoor, outdoor) } \\
\hline \multicolumn{8}{|l|}{$\square$ Bowling } \\
\hline \multicolumn{8}{|l|}{$\square$ Calisthenics/Toning Exercises } \\
\hline \multicolumn{8}{|l|}{$\square$ Cricket } \\
\hline \multicolumn{8}{|l|}{$\square$ Dancing (square, line, ballroom) } \\
\hline \multicolumn{8}{|l|}{$\square$ Elliptical Trainer } \\
\hline \multicolumn{8}{|l|}{$\square$ Fencing } \\
\hline \multicolumn{8}{|l|}{$\square$ Fishing } \\
\hline \multicolumn{8}{|l|}{$\square$ Football } \\
\hline \multicolumn{8}{|l|}{$\square$ Gardening } \\
\hline \multicolumn{8}{|l|}{$\square$ Golf } \\
\hline \multicolumn{8}{|l|}{$\square$ Gymnastics } \\
\hline \multicolumn{8}{|l|}{$\square$ Hiking } \\
\hline \multicolumn{8}{|l|}{$\square$ Horse Riding } \\
\hline \multicolumn{8}{|l|}{$\square$ Jogging (outdoor, indoor) } \\
\hline \multicolumn{8}{|l|}{$\square$ Jumping Rope } \\
\hline \multicolumn{8}{|l|}{$\square$ Martial Arts (karate, judo) } \\
\hline \multicolumn{8}{|l|}{$\square$ Pilates } \\
\hline \multicolumn{8}{|l|}{$\square$ Rock Climbing } \\
\hline$\square$ Rounders & & & & & & & \\
\hline$\square$ Rugby & & & & & & & \\
\hline$\square$ Scuba Diving & & & & & & & \\
\hline$\square$ Skating (roller, ice, blading) & & & & & & & \\
\hline$\square$ Skiing & & & & & & & \\
\hline$\square$ Squash & & & & & & & \\
\hline$\square$ Stairmaster & & & & & & & \\
\hline$\square$ Strength/Weight Training & & & & & & & \\
\hline$\square$ Swimming (laps, snorkeling) & & & & & & & \\
\hline$\square$ Tai Chi & & & & & & & \\
\hline$\square$ Tennis & & & & & & & \\
\hline$\square$ Volleyball & & & & & & & \\
\hline$\square$ Walking for Exercise (outdoor, in & & & & & & & \\
\hline$\square$ Water Aerobics & & & & & & & \\
\hline$\square$ Yoga & & & & & & & \\
\hline$\square$ Other & & & & & & & \\
\hline
\end{tabular}




\section{Appendix 7: Questionnaire Structure}

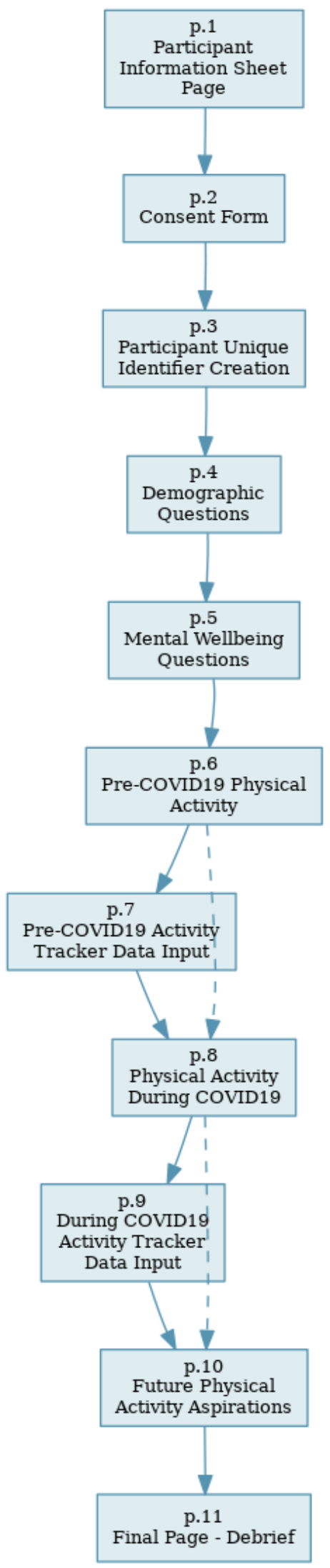




\section{Appendix 8: SPSS Output}

\section{Statistics}

\begin{tabular}{|c|c|c|c|c|c|c|c|c|c|c|c|c|}
\hline & & WEM.ASRZs & PM.ASRZs & DMASRZs & PT.ASRZs & DT.ASRZs & WEM.ASSZ & Pre.SASS.Zs & $\begin{array}{c}\text { During.Steps. } \\
\text { ASS.Zs }\end{array}$ & WEM.ADZ & Pre.Dist.ADZ & DurDist.ADZ \\
\hline \multirow[t]{2}{*}{$N$} & Valid & 199 & 199 & 199 & 199 & 199 & 48 & 48 & 48 & 43 & 43 & 43 \\
\hline & Missing & 0 & 0 & 0 & 0 & 0 & 151 & 151 & 151 & 156 & 156 & 156 \\
\hline
\end{tabular}

\section{Statistics}

WEMASRZS PMASRZS DMASRZS PTASRZS DTASRZS WEMASSZ PreSASSZs During.Steps.

\begin{tabular}{|c|c|c|c|c|c|c|c|c|c|c|c|c|}
\hline & & WEM.ASRZs & PM.ASRZs & DMASRZs & PT.ASRZs & DT.ASRZs & WEM.ASSZ & Pre.SASS.Zs & ASS.Zs & WEM.ADZ & Pre.Dist.ADZ & DurDist.ADZ \\
\hline \multirow[t]{2}{*}{$N$} & Valid & 198 & 194 & 193 & 194 & 193 & 48 & 47 & 47 & 43 & 43 & 42 \\
\hline & Missing & 1 & 5 & 6 & 5 & 6 & 151 & 152 & 152 & 156 & 156 & 157 \\
\hline
\end{tabular}

WEM.ASRZs

\begin{tabular}{|c|c|c|c|c|c|}
\hline & & Frequency & Percent & Valid Percent & $\begin{array}{c}\text { Cumulative } \\
\text { Percent }\end{array}$ \\
\hline \multirow[t]{35}{*}{ Valid } & -3.3698 & 1 & .5 & .5 & .5 \\
\hline & -2.2906 & 3 & 1.5 & 1.5 & 2.0 \\
\hline & -2.1557 & 3 & 1.5 & 1.5 & 3.5 \\
\hline & -1.8859 & 1 & .5 & .5 & 4.0 \\
\hline & -1.7510 & 4 & 2.0 & 2.0 & 6.0 \\
\hline & -1.6161 & 2 & 1.0 & 1.0 & 7.0 \\
\hline & -1.4812 & 4 & 2.0 & 2.0 & 9.0 \\
\hline & -1.3463 & 4 & 2.0 & 2.0 & 11.1 \\
\hline & -1.2114 & 5 & 2.5 & 2.5 & 13.6 \\
\hline & -1.0765 & 8 & 4.0 & 4.0 & 17.6 \\
\hline & -.9416 & 7 & 3.5 & 3.5 & 21.1 \\
\hline & -.8067 & 2 & 1.0 & 1.0 & 22.1 \\
\hline & -.6718 & 5 & 2.5 & 2.5 & 24.6 \\
\hline & -.5369 & 9 & 4.5 & 4.5 & 29.1 \\
\hline & -.4020 & 8 & 4.0 & 4.0 & 33.2 \\
\hline & -.2671 & 12 & 6.0 & 6.0 & 39.2 \\
\hline & -.1322 & 9 & 4.5 & 4.5 & 43.7 \\
\hline & .0027 & 11 & 5.5 & 5.5 & 49.2 \\
\hline & .1376 & 9 & 4.5 & 4.5 & 53.8 \\
\hline & .2725 & 15 & 7.5 & 7.5 & 61.3 \\
\hline & .4074 & 12 & 6.0 & 6.0 & 67.3 \\
\hline & .5423 & 11 & 5.5 & 5.5 & 72.9 \\
\hline & .6772 & 7 & 3.5 & 3.5 & 76.4 \\
\hline & .8121 & 10 & 5.0 & 5.0 & 81.4 \\
\hline & .9470 & 11 & 5.5 & 5.5 & 86.9 \\
\hline & 1.0819 & 4 & 2.0 & 2.0 & 88.9 \\
\hline & 1.2168 & 4 & 2.0 & 2.0 & 91.0 \\
\hline & 1.3517 & 4 & 2.0 & 2.0 & 93.0 \\
\hline & 1.4866 & 4 & 2.0 & 2.0 & 95.0 \\
\hline & 1.6215 & 2 & 1.0 & 1.0 & 96.0 \\
\hline & 1.7564 & 3 & 1.5 & 1.5 & 97.5 \\
\hline & 1.8913 & 1 & .5 & .5 & 98.0 \\
\hline & 2.0262 & 3 & 1.5 & 1.5 & 99.5 \\
\hline & 2.2961 & 1 & .5 & .5 & 100.0 \\
\hline & Total & 199 & 100.0 & 100.0 & \\
\hline
\end{tabular}

WEM.ASRZs

\begin{tabular}{|c|c|c|c|c|c|}
\hline & & Frequency & Percent & Valid Percent & $\begin{array}{c}\text { Cumulative } \\
\text { Percent }\end{array}$ \\
\hline \multirow[t]{34}{*}{ Valid } & -2.2906 & 3 & 1.5 & 1.5 & 1.5 \\
\hline & -2.1557 & 3 & 1.5 & 1.5 & 3.0 \\
\hline & -1.8859 & 1 & .5 & .5 & 3.5 \\
\hline & -1.7510 & 4 & 2.0 & 2.0 & 5.6 \\
\hline & -1.6161 & 2 & 1.0 & 1.0 & 6.6 \\
\hline & -1.4812 & 4 & 2.0 & 2.0 & 8.6 \\
\hline & -1.3463 & 4 & 2.0 & 2.0 & 10.6 \\
\hline & -1.2114 & 5 & 2.5 & 2.5 & 13.1 \\
\hline & -1.0765 & 8 & 4.0 & 4.0 & 17.2 \\
\hline & -.9416 & 7 & 3.5 & 3.5 & 20.7 \\
\hline & -.8067 & 2 & 1.0 & 1.0 & 21.7 \\
\hline & -.6718 & 5 & 2.5 & 2.5 & 24.2 \\
\hline & -.5369 & 9 & 4.5 & 4.5 & 28.8 \\
\hline & -.4020 & 8 & 4.0 & 4.0 & 32.8 \\
\hline & -.2671 & 12 & 6.0 & 6.1 & 38.9 \\
\hline & -.1322 & 9 & 4.5 & 4.5 & 43.4 \\
\hline & .0027 & 11 & 5.5 & 5.6 & 49.0 \\
\hline & .1376 & 9 & 4.5 & 4.5 & 53.5 \\
\hline & .2725 & 15 & 7.5 & 7.6 & 61.1 \\
\hline & .4074 & 12 & 6.0 & 6.1 & 67.2 \\
\hline & .5423 & 11 & 5.5 & 5.6 & 72.7 \\
\hline & .6772 & 7 & 3.5 & 3.5 & 76.3 \\
\hline & .8121 & 10 & 5.0 & 5.1 & 81.3 \\
\hline & .9470 & 11 & 5.5 & 5.6 & 86.9 \\
\hline & 1.0819 & 4 & 2.0 & 2.0 & 88.9 \\
\hline & 1.2168 & 4 & 2.0 & 2.0 & 90.9 \\
\hline & 1.3517 & 4 & 2.0 & 2.0 & 92.9 \\
\hline & 1.4866 & 4 & 2.0 & 2.0 & 94.9 \\
\hline & 1.6215 & 2 & 1.0 & 1.0 & 96.0 \\
\hline & 1.7564 & 3 & 1.5 & 1.5 & 97.5 \\
\hline & 1.8913 & 1 & .5 & .5 & 98.0 \\
\hline & 2.0262 & 3 & 1.5 & 1.5 & 99.5 \\
\hline & 2.2961 & 1 & .5 & .5 & 100.0 \\
\hline & Total & 198 & 99.5 & 100.0 & \\
\hline Missing & System & 1 & .5 & & \\
\hline Total & & 199 & 100.0 & & \\
\hline
\end{tabular}




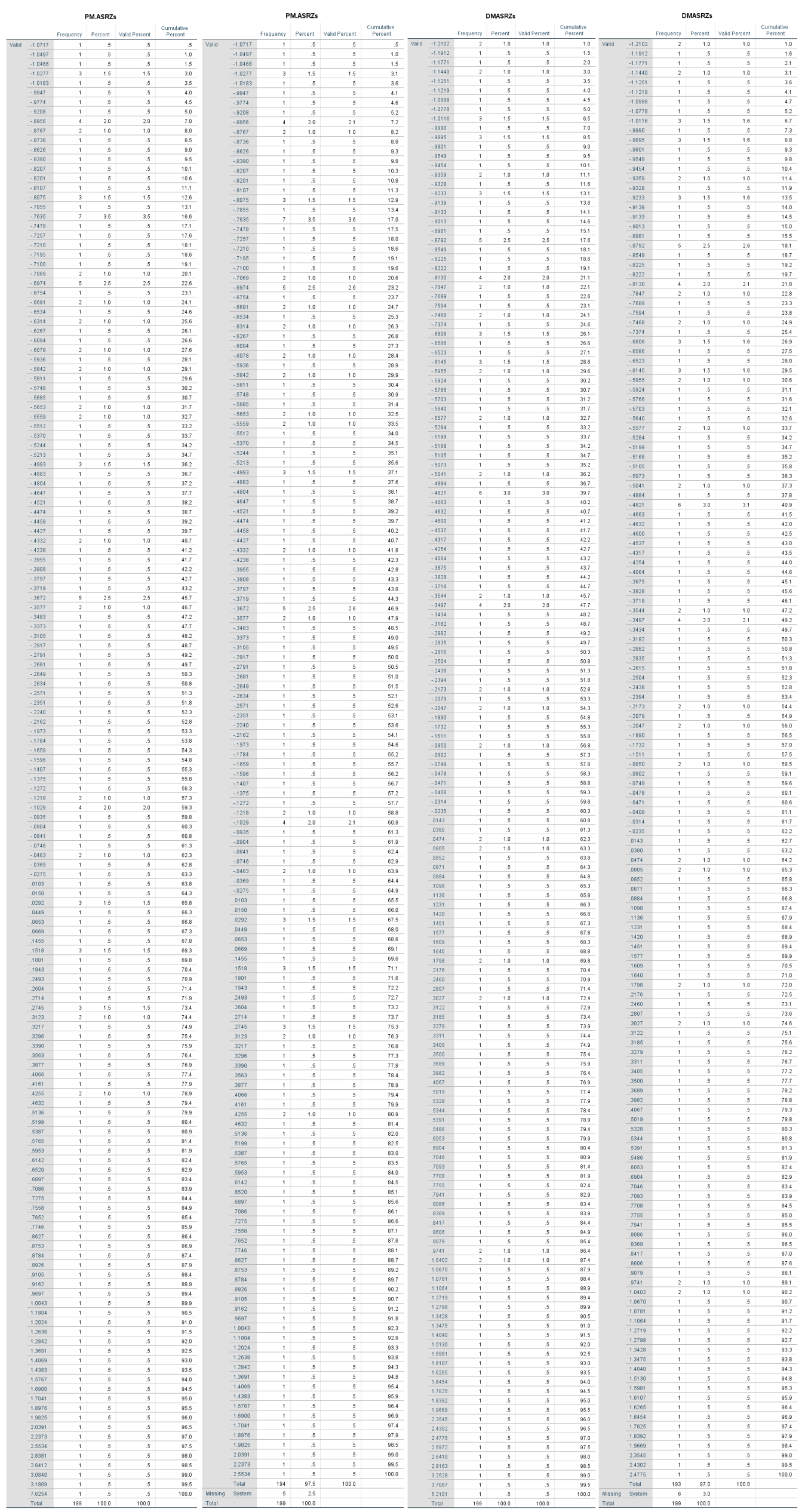




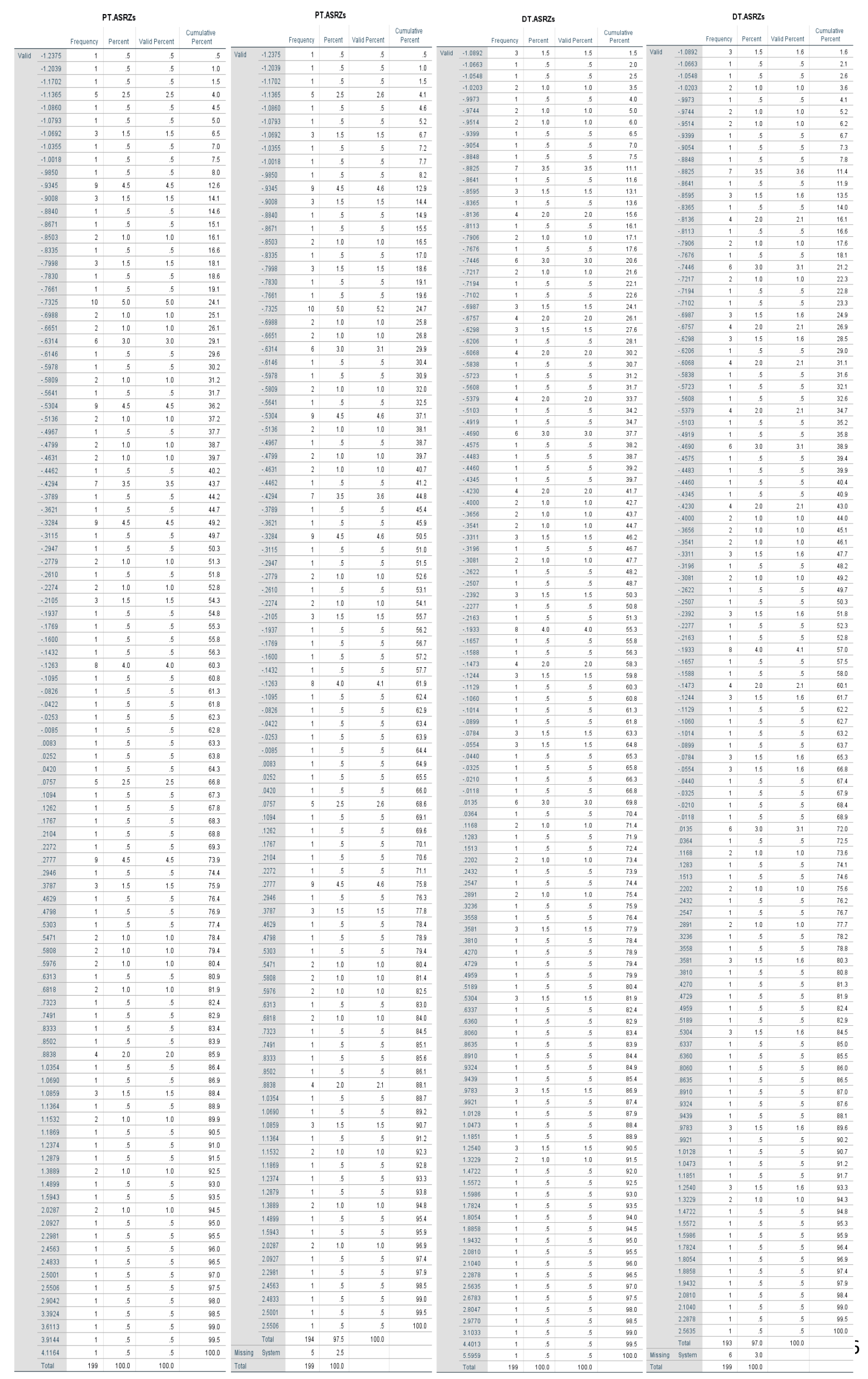


Pre.SASS.Zs

\begin{tabular}{|c|c|c|c|c|c|}
\hline & & Frequency & Percent & Valid Percent & $\begin{array}{c}\text { Cumulative } \\
\text { Percent }\end{array}$ \\
\hline \multirow[t]{49}{*}{ Valid } & -1.5606 & 1 & .5 & 2.1 & 2.1 \\
\hline & -1.3416 & 1 & .5 & 2.1 & 4.2 \\
\hline & -1.2597 & 1 & .5 & 2.1 & 6.3 \\
\hline & -1.1734 & 1 & .5 & 2.1 & 8.3 \\
\hline & -1.1220 & 1 & .5 & 2.1 & 10.4 \\
\hline & -1.0917 & 1 & .5 & 2.1 & 12.5 \\
\hline & -1.0833 & 1 & .5 & 2.1 & 14.6 \\
\hline & -1.0352 & 1 & .5 & 2.1 & 16.7 \\
\hline & -.8512 & 1 & .5 & 2.1 & 18.8 \\
\hline & -.8152 & 1 & .5 & 2.1 & 20.8 \\
\hline & -.7558 & 1 & .5 & 2.1 & 22.9 \\
\hline & -.7445 & 1 & .5 & 2.1 & 25.0 \\
\hline & -.7399 & 1 & .5 & 2.1 & 27.1 \\
\hline & -.6466 & 1 & .5 & 2.1 & 29.2 \\
\hline & -.6437 & 1 & .5 & 2.1 & 31.3 \\
\hline & -.6341 & 1 & .5 & 2.1 & 33.3 \\
\hline & -.6159 & 1 & .5 & 2.1 & 35.4 \\
\hline & -.5999 & 1 & .5 & 2.1 & 37.5 \\
\hline & -.5365 & 1 & .5 & 2.1 & 39.6 \\
\hline & -.4619 & 1 & .5 & 2.1 & 41.7 \\
\hline & -.4263 & 1 & .5 & 2.1 & 43.8 \\
\hline & -.2864 & 1 & .5 & 2.1 & 45.8 \\
\hline & -.1722 & 1 & .5 & 2.1 & 47.9 \\
\hline & -.0891 & 1 & .5 & 2.1 & 50.0 \\
\hline & -.0476 & 1 & .5 & 2.1 & 52.1 \\
\hline & -.0405 & 1 & .5 & 2.1 & 54.2 \\
\hline & .0496 & 1 & .5 & 2.1 & 56.3 \\
\hline & .1647 & 1 & .5 & 2.1 & 58.3 \\
\hline & .1940 & 1 & .5 & 2.1 & 60.4 \\
\hline & .2516 & 1 & .5 & 2.1 & 62.5 \\
\hline & .2761 & 1 & .5 & 2.1 & 64.6 \\
\hline & .4347 & 1 & .5 & 2.1 & 66.7 \\
\hline & .4473 & 1 & .5 & 2.1 & 68.8 \\
\hline & .4559 & 1 & .5 & 2.1 & 70.8 \\
\hline & .4875 & 1 & .5 & 2.1 & 72.9 \\
\hline & .5210 & 1 & .5 & 2.1 & 75.0 \\
\hline & .5316 & 1 & .5 & 2.1 & 77.1 \\
\hline & .6302 & 1 & .5 & 2.1 & 79.2 \\
\hline & .7581 & 1 & .5 & 2.1 & 81.3 \\
\hline & .8815 & 1 & .5 & 2.1 & 83.3 \\
\hline & 1.0145 & 1 & .5 & 2.1 & 85.4 \\
\hline & 1.0335 & 1 & .5 & 2.1 & 87.5 \\
\hline & 1.1756 & 1 & .5 & 2.1 & 89.6 \\
\hline & 1.1957 & 1 & .5 & 2.1 & 91.7 \\
\hline & 1.4090 & 1 & .5 & 2.1 & 93.8 \\
\hline & 1.4352 & 1 & .5 & 2.1 & 95.8 \\
\hline & 1.6563 & 1 & .5 & 2.1 & 97.9 \\
\hline & 3.7711 & 1 & .5 & 2.1 & 100.0 \\
\hline & Total & 48 & 24.1 & 100.0 & \\
\hline Missing & System & 151 & 75.9 & & \\
\hline Total & & 199 & 100.0 & & \\
\hline
\end{tabular}

Pre.SASS.Zs

\begin{tabular}{|c|c|c|c|c|c|}
\hline & & Frequency & Percent & Valid Percent & $\begin{array}{c}\text { Cumulative } \\
\text { Percent }\end{array}$ \\
\hline \multirow[t]{48}{*}{ Valid } & -1.5606 & 1 & .5 & 2.1 & 2.1 \\
\hline & -1.3416 & 1 & .5 & 2.1 & 4.3 \\
\hline & -1.2597 & 1 & .5 & 2.1 & 6.4 \\
\hline & -1.1734 & 1 & .5 & 2.1 & 8.5 \\
\hline & -1.1220 & 1 & .5 & 2.1 & 10.6 \\
\hline & -1.0917 & 1 & .5 & 2.1 & 12.8 \\
\hline & -1.0833 & 1 & .5 & 2.1 & 14.9 \\
\hline & -1.0352 & 1 & .5 & 2.1 & 17.0 \\
\hline & -.8512 & 1 & .5 & 2.1 & 19.1 \\
\hline & -.8152 & 1 & .5 & 2.1 & 21.3 \\
\hline & -.7558 & 1 & .5 & 2.1 & 23.4 \\
\hline & -.7445 & 1 & .5 & 2.1 & 25.5 \\
\hline & -.7399 & 1 & .5 & 2.1 & 27.7 \\
\hline & -.6466 & 1 & .5 & 2.1 & 29.8 \\
\hline & -.6437 & 1 & .5 & 2.1 & 31.9 \\
\hline & -.6341 & 1 & .5 & 2.1 & 34.0 \\
\hline & -.6159 & 1 & .5 & 2.1 & 36.2 \\
\hline & -.5999 & 1 & .5 & 2.1 & 38.3 \\
\hline & -.5365 & 1 & .5 & 2.1 & 40.4 \\
\hline & -.4619 & 1 & .5 & 2.1 & 42.6 \\
\hline & -.4263 & 1 & .5 & 2.1 & 44.7 \\
\hline & -.2864 & 1 & .5 & 2.1 & 46.8 \\
\hline & -.1722 & 1 & .5 & 2.1 & 48.9 \\
\hline & -.0891 & 1 & .5 & 2.1 & 51.1 \\
\hline & -.0476 & 1 & .5 & 2.1 & 53.2 \\
\hline & -.0405 & 1 & .5 & 2.1 & 55.3 \\
\hline & .0496 & 1 & .5 & 2.1 & 57.4 \\
\hline & .1647 & 1 & .5 & 2.1 & 59.6 \\
\hline & .1940 & 1 & .5 & 2.1 & 61.7 \\
\hline & .2516 & 1 & .5 & 2.1 & 63.8 \\
\hline & .2761 & 1 & .5 & 2.1 & 66.0 \\
\hline & .4347 & 1 & .5 & 2.1 & 68.1 \\
\hline & .4473 & 1 & .5 & 2.1 & 70.2 \\
\hline & .4559 & 1 & .5 & 2.1 & 72.3 \\
\hline & .4875 & 1 & .5 & 2.1 & 74.5 \\
\hline & .5210 & 1 & .5 & 2.1 & 76.6 \\
\hline & .5316 & 1 & .5 & 2.1 & 78.7 \\
\hline & .6302 & 1 & .5 & 2.1 & 80.9 \\
\hline & .7581 & 1 & .5 & 2.1 & 83.0 \\
\hline & .8815 & 1 & .5 & 2.1 & 85.1 \\
\hline & 1.0145 & 1 & .5 & 2.1 & 87.2 \\
\hline & 1.0335 & 1 & .5 & 2.1 & 89.4 \\
\hline & 1.1756 & 1 & .5 & 2.1 & 91.5 \\
\hline & 1.1957 & 1 & .5 & 2.1 & 93.6 \\
\hline & 1.4090 & 1 & .5 & 2.1 & 95.7 \\
\hline & 1.4352 & 1 & .5 & 2.1 & 97.9 \\
\hline & 1.6563 & 1 & .5 & 2.1 & 100.0 \\
\hline & Total & 47 & 23.6 & 100.0 & \\
\hline Missing & System & 152 & 76.4 & & \\
\hline Total & & 199 & 100.0 & & \\
\hline
\end{tabular}


During.Steps.ASS.Zs

\begin{tabular}{|c|c|c|c|c|c|}
\hline & & Frequency & Percent & Valid Percent & $\begin{array}{c}\text { Cumulative } \\
\text { Percent }\end{array}$ \\
\hline \multirow[t]{49}{*}{ Valid } & -.7710 & 1 & .5 & 2.1 & 2.1 \\
\hline & -.7359 & 1 & .5 & 2.1 & 4.2 \\
\hline & -.7083 & 1 & .5 & 2.1 & 6.3 \\
\hline & -.6782 & 1 & .5 & 2.1 & 8.3 \\
\hline & -.6607 & 1 & .5 & 2.1 & 10.4 \\
\hline & -.6205 & 1 & .5 & 2.1 & 12.5 \\
\hline & -.6039 & 1 & .5 & 2.1 & 14.6 \\
\hline & -.5766 & 1 & .5 & 2.1 & 16.7 \\
\hline & -.5639 & 1 & .5 & 2.1 & 18.8 \\
\hline & -.5104 & 1 & .5 & 2.1 & 20.8 \\
\hline & -.4811 & 1 & .5 & 2.1 & 22.9 \\
\hline & -.4083 & 1 & .5 & 2.1 & 25.0 \\
\hline & -.4073 & 1 & .5 & 2.1 & 27.1 \\
\hline & -.3698 & 1 & .5 & 2.1 & 29.2 \\
\hline & -.3656 & 1 & .5 & 2.1 & 31.3 \\
\hline & -.3463 & 1 & .5 & 2.1 & 33.3 \\
\hline & -.3406 & 1 & .5 & 2.1 & 35.4 \\
\hline & -.3172 & 1 & .5 & 2.1 & 37.5 \\
\hline & -.3034 & 1 & .5 & 2.1 & 39.6 \\
\hline & -.2911 & 1 & .5 & 2.1 & 41.7 \\
\hline & -.2809 & 1 & .5 & 2.1 & 43.8 \\
\hline & -.2749 & 1 & .5 & 2.1 & 45.8 \\
\hline & -.2305 & 1 & .5 & 2.1 & 47.9 \\
\hline & -.2280 & 1 & .5 & 2.1 & 50.0 \\
\hline & -.2171 & 1 & .5 & 2.1 & 52.1 \\
\hline & -.1868 & 1 & .5 & 2.1 & 54.2 \\
\hline & -.1221 & 1 & .5 & 2.1 & 56.3 \\
\hline & -.0961 & 1 & .5 & 2.1 & 58.3 \\
\hline & -.0861 & 1 & .5 & 2.1 & 60.4 \\
\hline & .0332 & 1 & .5 & 2.1 & 62.5 \\
\hline & .0333 & 1 & .5 & 2.1 & 64.6 \\
\hline & .0509 & 1 & .5 & 2.1 & 66.7 \\
\hline & .0697 & 1 & .5 & 2.1 & 68.8 \\
\hline & .0801 & 1 & .5 & 2.1 & 70.8 \\
\hline & .2251 & 1 & .5 & 2.1 & 72.9 \\
\hline & .2927 & 1 & .5 & 2.1 & 75.0 \\
\hline & .3444 & 1 & .5 & 2.1 & 77.1 \\
\hline & .3462 & 1 & .5 & 2.1 & 79.2 \\
\hline & .3505 & 1 & .5 & 2.1 & 81.3 \\
\hline & .3559 & 1 & .5 & 2.1 & 83.3 \\
\hline & .3573 & 1 & .5 & 2.1 & 85.4 \\
\hline & .4446 & 1 & .5 & 2.1 & 87.5 \\
\hline & .4566 & 1 & .5 & 2.1 & 89.6 \\
\hline & .4763 & 1 & .5 & 2.1 & 91.7 \\
\hline & .4962 & 1 & .5 & 2.1 & 93.8 \\
\hline & .5128 & 1 & .5 & 2.1 & 95.8 \\
\hline & .6294 & 1 & .5 & 2.1 & 97.9 \\
\hline & 6.2272 & 1 & .5 & 2.1 & 100.0 \\
\hline & Total & 48 & 24.1 & 100.0 & \\
\hline Missing & System & 151 & 75.9 & & \\
\hline Total & & 199 & 100.0 & & \\
\hline
\end{tabular}

During.Steps.ASS.Zs

\begin{tabular}{|c|c|c|c|c|c|}
\hline & & Frequency & Percent & Valid Percent & $\begin{array}{c}\text { Cumulative } \\
\text { Percent }\end{array}$ \\
\hline \multirow[t]{48}{*}{ Valid } & -.7710 & 1 & .5 & 2.1 & 2.1 \\
\hline & -.7359 & 1 & .5 & 2.1 & 4.3 \\
\hline & -.7083 & 1 & .5 & 2.1 & 6.4 \\
\hline & -.6782 & 1 & .5 & 2.1 & 8.5 \\
\hline & -.6607 & 1 & .5 & 2.1 & 10.6 \\
\hline & -.6205 & 1 & .5 & 2.1 & 12.8 \\
\hline & -.6039 & 1 & .5 & 2.1 & 14.9 \\
\hline & -.5766 & 1 & .5 & 2.1 & 17.0 \\
\hline & -.5639 & 1 & .5 & 2.1 & 19.1 \\
\hline & -.5104 & 1 & .5 & 2.1 & 21.3 \\
\hline & -.4811 & 1 & .5 & 2.1 & 23.4 \\
\hline & -.4083 & 1 & .5 & 2.1 & 25.5 \\
\hline & -.4073 & 1 & .5 & 2.1 & 27.7 \\
\hline & -.3698 & 1 & .5 & 2.1 & 29.8 \\
\hline & -.3656 & 1 & .5 & 2.1 & 31.9 \\
\hline & -.3463 & 1 & .5 & 2.1 & 34.0 \\
\hline & -.3406 & 1 & .5 & 2.1 & 36.2 \\
\hline & -.3172 & 1 & .5 & 2.1 & 38.3 \\
\hline & -.3034 & 1 & .5 & 2.1 & 40.4 \\
\hline & -.2911 & 1 & .5 & 2.1 & 42.6 \\
\hline & -.2809 & 1 & .5 & 2.1 & 44.7 \\
\hline & -.2749 & 1 & .5 & 2.1 & 46.8 \\
\hline & -.2305 & 1 & .5 & 2.1 & 48.9 \\
\hline & -.2280 & 1 & .5 & 2.1 & 51.1 \\
\hline & -.2171 & 1 & .5 & 2.1 & 53.2 \\
\hline & -.1868 & 1 & .5 & 2.1 & 55.3 \\
\hline & -.1221 & 1 & .5 & 2.1 & 57.4 \\
\hline & -.0961 & 1 & .5 & 2.1 & 59.6 \\
\hline & -.0861 & 1 & .5 & 2.1 & 61.7 \\
\hline & .0332 & 1 & .5 & 2.1 & 63.8 \\
\hline & .0333 & 1 & .5 & 2.1 & 66.0 \\
\hline & .0509 & 1 & .5 & 2.1 & 68.1 \\
\hline & .0697 & 1 & .5 & 2.1 & 70.2 \\
\hline & .0801 & 1 & .5 & 2.1 & 72.3 \\
\hline & .2251 & 1 & .5 & 2.1 & 74.5 \\
\hline & .2927 & 1 & .5 & 2.1 & 76.6 \\
\hline & .3444 & 1 & .5 & 2.1 & 78.7 \\
\hline & .3462 & 1 & .5 & 2.1 & 80.9 \\
\hline & .3505 & 1 & .5 & 2.1 & 83.0 \\
\hline & .3559 & 1 & .5 & 2.1 & 85.1 \\
\hline & .3573 & 1 & .5 & 2.1 & 87.2 \\
\hline & .4446 & 1 & .5 & 2.1 & 89.4 \\
\hline & .4566 & 1 & .5 & 2.1 & 91.5 \\
\hline & .4763 & 1 & .5 & 2.1 & 93.6 \\
\hline & .4962 & 1 & .5 & 2.1 & 95.7 \\
\hline & .5128 & 1 & .5 & 2.1 & 97.9 \\
\hline & .6294 & 1 & .5 & 2.1 & 100.0 \\
\hline & Total & 47 & 23.6 & 100.0 & \\
\hline Missing & System & 152 & 76.4 & & \\
\hline Total & & 199 & 100.0 & & \\
\hline
\end{tabular}


Pre.Dist.ADZ

\begin{tabular}{|c|c|c|c|c|c|}
\hline & & Frequency & Percent & Valid Percent & $\begin{array}{c}\text { Cumulative } \\
\text { Percent }\end{array}$ \\
\hline \multirow[t]{43}{*}{ Valid } & -1.9092 & 1 & .5 & 2.3 & 2.3 \\
\hline & -1.8372 & 1 & .5 & 2.3 & 4.7 \\
\hline & -1.4695 & 1 & .5 & 2.3 & 7.0 \\
\hline & -1.3818 & 1 & .5 & 2.3 & 9.3 \\
\hline & -1.3674 & 1 & .5 & 2.3 & 11.6 \\
\hline & -1.2733 & 1 & .5 & 2.3 & 14.0 \\
\hline & -1.0221 & 2 & 1.0 & 4.7 & 18.6 \\
\hline & -.9250 & 1 & .5 & 2.3 & 20.9 \\
\hline & -.9223 & 1 & .5 & 2.3 & 23.3 \\
\hline & -.7833 & 1 & .5 & 2.3 & 25.6 \\
\hline & -.7325 & 1 & .5 & 2.3 & 27.9 \\
\hline & -.6300 & 1 & .5 & 2.3 & 30.2 \\
\hline & -.5660 & 1 & .5 & 2.3 & 32.6 \\
\hline & -.4719 & 1 & .5 & 2.3 & 34.9 \\
\hline & -.3993 & 1 & .5 & 2.3 & 37.2 \\
\hline & -.3206 & 1 & .5 & 2.3 & 39.5 \\
\hline & -.2475 & 1 & .5 & 2.3 & 41.9 \\
\hline & -.2118 & 1 & .5 & 2.3 & 44.2 \\
\hline & -.1534 & 1 & .5 & 2.3 & 46.5 \\
\hline & -.0086 & 1 & .5 & 2.3 & 48.8 \\
\hline & .1488 & 1 & .5 & 2.3 & 51.2 \\
\hline & .2086 & 1 & .5 & 2.3 & 53.5 \\
\hline & .2593 & 1 & .5 & 2.3 & 55.8 \\
\hline & .2648 & 1 & .5 & 2.3 & 58.1 \\
\hline & .2882 & 1 & .5 & 2.3 & 60.5 \\
\hline & .3736 & 1 & .5 & 2.3 & 62.8 \\
\hline & .4026 & 1 & .5 & 2.3 & 65.1 \\
\hline & .4267 & 1 & .5 & 2.3 & 67.4 \\
\hline & .4343 & 1 & .5 & 2.3 & 69.8 \\
\hline & .5705 & 1 & .5 & 2.3 & 72.1 \\
\hline & .5713 & 1 & .5 & 2.3 & 74.4 \\
\hline & .6798 & 1 & .5 & 2.3 & 76.7 \\
\hline & .7347 & 1 & .5 & 2.3 & 79.1 \\
\hline & .7848 & 1 & .5 & 2.3 & 81.4 \\
\hline & .7999 & 1 & .5 & 2.3 & 83.7 \\
\hline & 1.1135 & 1 & .5 & 2.3 & 86.0 \\
\hline & 1.1515 & 1 & .5 & 2.3 & 88.4 \\
\hline & 1.4051 & 1 & .5 & 2.3 & 90.7 \\
\hline & 1.4349 & 1 & .5 & 2.3 & 93.0 \\
\hline & 1.6371 & 1 & .5 & 2.3 & 95.3 \\
\hline & 1.7216 & 1 & .5 & 2.3 & 97.7 \\
\hline & 2.2432 & 1 & .5 & 2.3 & 100.0 \\
\hline & Total & 43 & 21.6 & 100.0 & \\
\hline Missing & System & 156 & 78.4 & & \\
\hline Total & & 199 & 100.0 & & \\
\hline
\end{tabular}

Pre.Dist.ADZ

\begin{tabular}{|c|c|c|c|c|c|}
\hline & & Frequency & Percent & Valid Percent & $\begin{array}{c}\text { Cumulative } \\
\text { Percent }\end{array}$ \\
\hline \multirow[t]{43}{*}{ Valid } & -1.9092 & 1 & .5 & 2.3 & 2.3 \\
\hline & -1.8372 & 1 & .5 & 2.3 & 4.7 \\
\hline & -1.4695 & 1 & .5 & 2.3 & 7.0 \\
\hline & -1.3818 & 1 & .5 & 2.3 & 9.3 \\
\hline & -1.3674 & 1 & .5 & 2.3 & 11.6 \\
\hline & -1.2733 & 1 & .5 & 2.3 & 14.0 \\
\hline & -1.0221 & 2 & 1.0 & 4.7 & 18.6 \\
\hline & -.9250 & 1 & .5 & 2.3 & 20.9 \\
\hline & -.9223 & 1 & .5 & 2.3 & 23.3 \\
\hline & -.7833 & 1 & .5 & 2.3 & 25.6 \\
\hline & -.7325 & 1 & .5 & 2.3 & 27.9 \\
\hline & -.6300 & 1 & .5 & 2.3 & 30.2 \\
\hline & -.5660 & 1 & .5 & 2.3 & 32.6 \\
\hline & -.4719 & 1 & .5 & 2.3 & 34.9 \\
\hline & -.3993 & 1 & .5 & 2.3 & 37.2 \\
\hline & -.3206 & 1 & .5 & 2.3 & 39.5 \\
\hline & -.2475 & 1 & .5 & 2.3 & 41.9 \\
\hline & -.2118 & 1 & .5 & 2.3 & 44.2 \\
\hline & -.1534 & 1 & .5 & 2.3 & 46.5 \\
\hline & -.0086 & 1 & .5 & 2.3 & 48.8 \\
\hline & .1488 & 1 & .5 & 2.3 & 51.2 \\
\hline & .2086 & 1 & .5 & 2.3 & 53.5 \\
\hline & .2593 & 1 & .5 & 2.3 & 55.8 \\
\hline & .2648 & 1 & .5 & 2.3 & 58.1 \\
\hline & .2882 & 1 & .5 & 2.3 & 60.5 \\
\hline & .3736 & 1 & .5 & 2.3 & 62.8 \\
\hline & .4026 & 1 & .5 & 2.3 & 65.1 \\
\hline & .4267 & 1 & .5 & 2.3 & 67.4 \\
\hline & .4343 & 1 & .5 & 2.3 & 69.8 \\
\hline & .5705 & 1 & .5 & 2.3 & 72.1 \\
\hline & .5713 & 1 & .5 & 2.3 & 74.4 \\
\hline & .6798 & 1 & .5 & 2.3 & 76.7 \\
\hline & .7347 & 1 & .5 & 2.3 & 79.1 \\
\hline & .7848 & 1 & .5 & 2.3 & 81.4 \\
\hline & .7999 & 1 & .5 & 2.3 & 83.7 \\
\hline & 1.1135 & 1 & .5 & 2.3 & 86.0 \\
\hline & 1.1515 & 1 & .5 & 2.3 & 88.4 \\
\hline & 1.4051 & 1 & .5 & 2.3 & 90.7 \\
\hline & 1.4349 & 1 & .5 & 2.3 & 93.0 \\
\hline & 1.6371 & 1 & .5 & 2.3 & 95.3 \\
\hline & 1.7216 & 1 & .5 & 2.3 & 97.7 \\
\hline & 2.2432 & 1 & .5 & 2.3 & 100.0 \\
\hline & Total & 43 & 21.6 & 100.0 & \\
\hline Missing & System & 156 & 78.4 & & \\
\hline Total & & 199 & 100.0 & & \\
\hline
\end{tabular}


DurDist.ADZ

\begin{tabular}{|c|c|c|c|c|c|}
\hline & & Frequency & Percent & Valid Percent & $\begin{array}{c}\text { Cumulative } \\
\text { Percent }\end{array}$ \\
\hline \multirow[t]{43}{*}{ Valid } & -1.9064 & 1 & .5 & 2.3 & 2.3 \\
\hline & -1.5352 & 1 & .5 & 2.3 & 4.7 \\
\hline & -1.4496 & 1 & .5 & 2.3 & 7.0 \\
\hline & -1.3355 & 1 & .5 & 2.3 & 9.3 \\
\hline & -1.2194 & 1 & .5 & 2.3 & 11.6 \\
\hline & -1.0778 & 1 & .5 & 2.3 & 14.0 \\
\hline & -1.0196 & 1 & .5 & 2.3 & 16.3 \\
\hline & -1.0050 & 1 & .5 & 2.3 & 18.6 \\
\hline & -.9366 & 1 & .5 & 2.3 & 20.9 \\
\hline & -.7508 & 1 & .5 & 2.3 & 23.3 \\
\hline & -.7141 & 1 & .5 & 2.3 & 25.6 \\
\hline & -.7085 & 1 & .5 & 2.3 & 27.9 \\
\hline & -.6949 & 1 & .5 & 2.3 & 30.2 \\
\hline & -.6911 & 1 & .5 & 2.3 & 32.6 \\
\hline & -.5727 & 1 & .5 & 2.3 & 34.9 \\
\hline & -.5570 & 1 & .5 & 2.3 & 37.2 \\
\hline & -.5273 & 1 & .5 & 2.3 & 39.5 \\
\hline & -.5111 & 1 & .5 & 2.3 & 41.9 \\
\hline & -.4108 & 1 & .5 & 2.3 & 44.2 \\
\hline & -.1907 & 1 & .5 & 2.3 & 46.5 \\
\hline & -.1389 & 1 & .5 & 2.3 & 48.8 \\
\hline & -.0643 & 1 & .5 & 2.3 & 51.2 \\
\hline & -.0241 & 1 & .5 & 2.3 & 53.5 \\
\hline & .2742 & 1 & .5 & 2.3 & 55.8 \\
\hline & .3444 & 1 & .5 & 2.3 & 58.1 \\
\hline & .3542 & 1 & .5 & 2.3 & 60.5 \\
\hline & .4775 & 2 & 1.0 & 4.7 & 65.1 \\
\hline & .5740 & 1 & .5 & 2.3 & 67.4 \\
\hline & .6008 & 1 & .5 & 2.3 & 69.8 \\
\hline & .6119 & 1 & .5 & 2.3 & 72.1 \\
\hline & .6162 & 1 & .5 & 2.3 & 74.4 \\
\hline & .6950 & 1 & .5 & 2.3 & 76.7 \\
\hline & .7283 & 1 & .5 & 2.3 & 79.1 \\
\hline & .8967 & 1 & .5 & 2.3 & 81.4 \\
\hline & .9091 & 1 & .5 & 2.3 & 83.7 \\
\hline & .9447 & 1 & .5 & 2.3 & 86.0 \\
\hline & 1.0680 & 1 & .5 & 2.3 & 88.4 \\
\hline & 1.2789 & 1 & .5 & 2.3 & 90.7 \\
\hline & 1.2900 & 1 & .5 & 2.3 & 93.0 \\
\hline & 1.4022 & 1 & .5 & 2.3 & 95.3 \\
\hline & 1.8424 & 1 & .5 & 2.3 & 97.7 \\
\hline & 2.6549 & 1 & .5 & 2.3 & 100.0 \\
\hline & Total & 43 & 21.6 & 100.0 & \\
\hline Missing & System & 156 & 78.4 & & \\
\hline Total & & 199 & 100.0 & & \\
\hline
\end{tabular}

DurDist.ADZ

\begin{tabular}{|c|c|c|c|c|c|}
\hline \\
\hline & & Frequency & Percent & Valid Percent & $\begin{array}{c}\text { Cumulative } \\
\text { Percent }\end{array}$ \\
\hline \multirow[t]{42}{*}{ Valid } & -1.9064 & 1 & .5 & 2.4 & 2.4 \\
\hline & -1.5352 & 1 & .5 & 2.4 & 4.8 \\
\hline & -1.4496 & 1 & .5 & 2.4 & 7.1 \\
\hline & -1.3355 & 1 & .5 & 2.4 & 9.5 \\
\hline & -1.2194 & 1 & .5 & 2.4 & 11.9 \\
\hline & -1.0778 & 1 & .5 & 2.4 & 14.3 \\
\hline & -1.0196 & 1 & .5 & 2.4 & 16.7 \\
\hline & -1.0050 & 1 & .5 & 2.4 & 19.0 \\
\hline & -.9366 & 1 & .5 & 2.4 & 21.4 \\
\hline & -.7508 & 1 & .5 & 2.4 & 23.8 \\
\hline & -.7141 & 1 & .5 & 2.4 & 26.2 \\
\hline & -.7085 & 1 & .5 & 2.4 & 28.6 \\
\hline & -.6949 & 1 & .5 & 2.4 & 31.0 \\
\hline & -.6911 & 1 & .5 & 2.4 & 33.3 \\
\hline & -.5727 & 1 & .5 & 2.4 & 35.7 \\
\hline & -.5570 & 1 & .5 & 2.4 & 38.1 \\
\hline & -.5273 & 1 & .5 & 2.4 & 40.5 \\
\hline & -.5111 & 1 & .5 & 2.4 & 42.9 \\
\hline & -.4108 & 1 & .5 & 2.4 & 45.2 \\
\hline & -.1907 & 1 & .5 & 2.4 & 47.6 \\
\hline & -.1389 & 1 & .5 & 2.4 & 50.0 \\
\hline & -.0643 & 1 & .5 & 2.4 & 52.4 \\
\hline & -.0241 & 1 & .5 & 2.4 & 54.8 \\
\hline & .2742 & 1 & .5 & 2.4 & 57.1 \\
\hline & .3444 & 1 & .5 & 2.4 & 59.5 \\
\hline & .3542 & 1 & .5 & 2.4 & 61.9 \\
\hline & .4775 & 2 & 1.0 & 4.8 & 66.7 \\
\hline & .5740 & 1 & .5 & 2.4 & 69.0 \\
\hline & .6008 & 1 & .5 & 2.4 & 71.4 \\
\hline & .6119 & 1 & .5 & 2.4 & 73.8 \\
\hline & .6162 & 1 & .5 & 2.4 & 76.2 \\
\hline & .6950 & 1 & .5 & 2.4 & 78.6 \\
\hline & .7283 & 1 & .5 & 2.4 & 81.0 \\
\hline & .8967 & 1 & .5 & 2.4 & 83.3 \\
\hline & .9091 & 1 & .5 & 2.4 & 85.7 \\
\hline & .9447 & 1 & .5 & 2.4 & 88.1 \\
\hline & 1.0680 & 1 & .5 & 2.4 & 90.5 \\
\hline & 1.2789 & 1 & .5 & 2.4 & 92.9 \\
\hline & 1.2900 & 1 & .5 & 2.4 & 95.2 \\
\hline & 1.4022 & 1 & .5 & 2.4 & 97.6 \\
\hline & 1.8424 & 1 & .5 & 2.4 & 100.0 \\
\hline & Total & 42 & 21.1 & 100.0 & \\
\hline Missing & System & 157 & 78.9 & & \\
\hline Total & & 199 & 100.0 & & \\
\hline
\end{tabular}


Correlations

\begin{tabular}{ll|r|r} 
& & WEM.All.SR & DM.ASR \\
\hline \multirow{2}{*}{ WEM.All.SR } & Pearson Correlation & 1 & $.248^{\star \star}$ \\
\cline { 2 - 4 } & Sig. (1-tailed) & & .000 \\
\cline { 2 - 4 } & $\mathrm{N}$ & 198 & 192 \\
\hline \multirow{2}{*}{ DM.ASR } & Pearson Correlation & $.248^{\star \star}$ & 1 \\
\cline { 2 - 4 } & Sig. (1-tailed) & .000 & \\
\cline { 2 - 4 } & $\mathrm{N}$ & 192 & 193 \\
\hline
\end{tabular}

**. Correlation is significant at the 0.01 level (1-tailed).
Correlations

\begin{tabular}{llr|r} 
& & WEM.All.SR & \multicolumn{1}{c}{ DT.ASR } \\
\hline \multirow{2}{*}{ WEM.All.SR } & Pearson Correlation & 1 & $.263^{\star \star}$ \\
\cline { 2 - 4 } & Sig. (1-tailed) & & .000 \\
\cline { 2 - 4 } & $\mathrm{N}$ & 198 & 192 \\
\hline \multirow{2}{*}{ DT.ASR } & Pearson Correlation & $.263^{\star \star}$ & 1 \\
\cline { 2 - 4 } & Sig. (1-tailed) & .000 & \\
\cline { 2 - 4 } & $\mathrm{N}$ & 192 & 193 \\
\hline
\end{tabular}

${ }^{\star *}$. Correlation is significant at the 0.01 level (1-tailed).

\section{Correlations}

\begin{tabular}{|c|c|c|c|c|c|c|c|}
\hline & \multicolumn{4}{|c|}{ Correlations } \\
\hline & & WEM.ASS & ASS & & & WEM.AD & DurDist.AD \\
\hline \multirow[t]{2}{*}{ WEM.ASS } & Pearson Correlation & 1 & .065 & \multirow[t]{2}{*}{ WEM.AD } & Pearson Correlation & 1 & .051 \\
\hline & $\mathrm{N}$ & 48 & 47 & & $N$ & 43 & 42 \\
\hline \multirow[t]{2}{*}{ During.Steps.ASS } & Pearson Correlation & .065 & 1 & \multirow[t]{2}{*}{ DurDist.AD } & Pearson Correlation & .051 & 1 \\
\hline & $\mathrm{N}$ & 47 & 47 & & $N$ & 42 & 42 \\
\hline
\end{tabular}

Within-Subjects Factors

\begin{tabular}{lll} 
Measure & COVID & $\begin{array}{c}\text { Dependent } \\
\text { Variable }\end{array}$ \\
\hline METS & 1 & PM.ASR \\
\cline { 2 - 3 } & 2 & DM.ASR \\
\hline Time & 1 & PT.ASR \\
\cline { 2 - 3 } & 2 & DT.ASR \\
\hline
\end{tabular}

Descriptive Statistics

\begin{tabular}{l|r|r|r} 
& \multicolumn{1}{c|}{ Mean } & Std. Deviation & \multicolumn{1}{l}{ N } \\
\hline PM.ASR & 27.5134 & 18.70428 & 188 \\
\hline DM.ASR & 30.2505 & 20.61371 & 188 \\
\hline PT.ASR & 360.1596 & 232.80727 & 188 \\
\hline DT.ASR & 447.3245 & 327.99391 & 188 \\
\hline
\end{tabular}

\begin{tabular}{ll|r|r|r|r} 
& \multicolumn{7}{c}{ Estimates } \\
Measure & CoVID & Mean & Std. Error & Lower Bound & Upper Bound \\
\hline METS & 1 & 27.513 & 1.364 & 24.822 & 30.205 \\
\cline { 2 - 7 } & 2 & 30.250 & 1.503 & 27.285 & 33.216 \\
\hline Time & 1 & 360.160 & 16.979 & 326.664 & 393.655 \\
\cline { 2 - 7 } & 2 & 447.324 & 23.921 & 400.134 & 494.515 \\
\hline
\end{tabular}

Univariate Tests

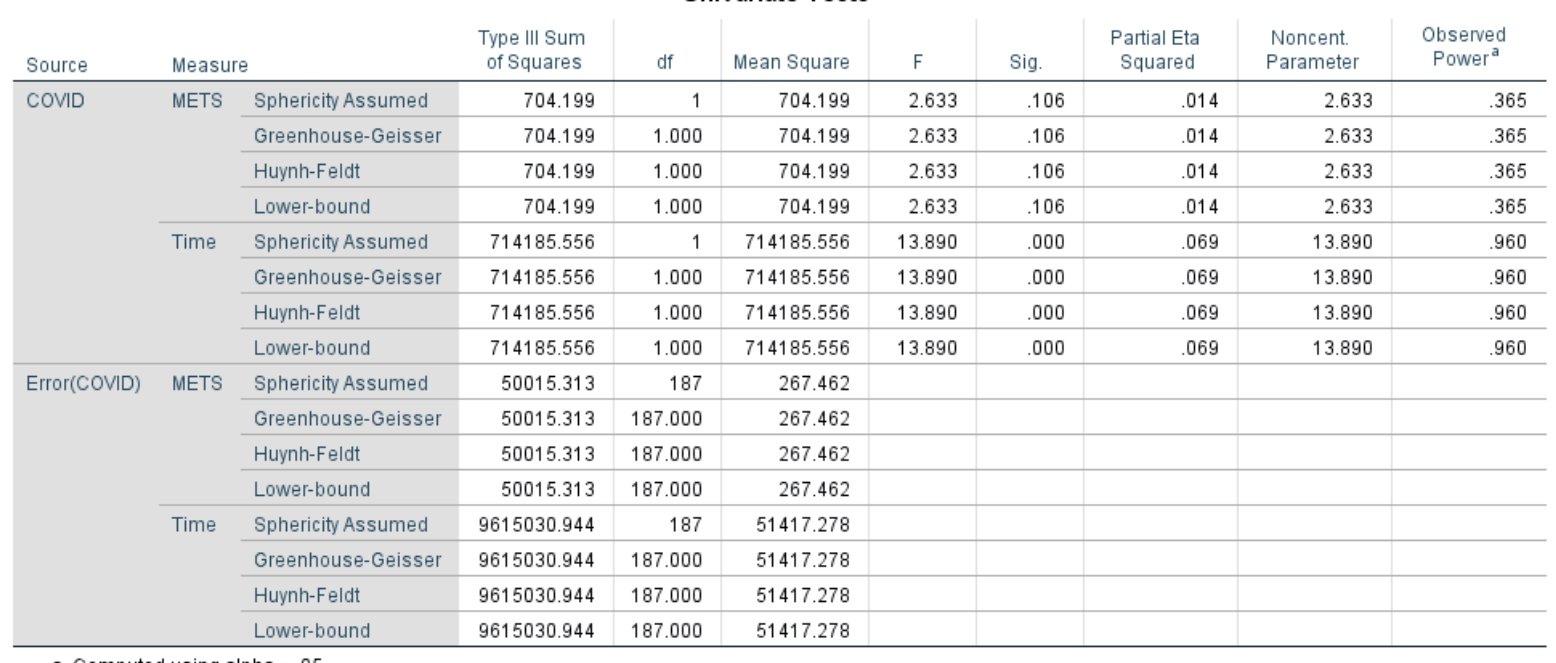

a. Computed using alpha $=.05$ 
Within-Subjects Factors

Dependent

\begin{tabular}{|c|c|c|}
\hline Measure & COVID & Variable \\
\hline \multirow[t]{2}{*}{ Steps } & 1 & Pre.Step.ASs \\
\hline & 2 & $\begin{array}{l}\text { During Steps. } \\
\text { ASS }\end{array}$ \\
\hline \multirow[t]{2}{*}{ Dist } & 1 & Pre.Dist.AD \\
\hline & 2 & DurDist.AD \\
\hline
\end{tabular}

Descriptive Statistics

Mean Std. Deviation

\begin{tabular}{|l|r|r|r|}
\hline Pre.Step.ASS & 69928.2500 & 31885.30962 & 40 \\
\hline During.Steps.ASS & 67395.4250 & 31811.96667 & 40 \\
\hline Pre.Dist.AD & 51.0041 & 22.35907 & 40 \\
\hline DurDist.AD & 54.1508 & 24.37801 & 40 \\
\hline
\end{tabular}

Estimates

95\% Confidence Interval

\begin{tabular}{ll|r|r|r|r|} 
& & & & \multicolumn{2}{c}{$95 \%$ Confidence Interval } \\
Measure & CovID & Mean & Std. Error & Lower Bound & Upper Bound \\
\hline Steps & 1 & 69928.250 & 5041.510 & 59730.833 & 80125.667 \\
\cline { 2 - 7 } & 2 & 67395.425 & 5029.914 & 57221.464 & 77569.386 \\
\hline \multirow{2}{*}{ Dist } & 1 & 51.004 & 3.535 & 43.853 & 58.155 \\
\cline { 2 - 7 } & 2 & 54.151 & 3.855 & 46.354 & 61.947 \\
\hline
\end{tabular}

Univariate Tests

\begin{tabular}{|c|c|c|c|c|c|c|c|c|c|c|}
\hline \\
\hline Source & \multicolumn{2}{|c|}{ Measure } & $\begin{array}{l}\text { Type III Sum } \\
\text { of Squares }\end{array}$ & df & Mean Square & $\mathrm{F}$ & Sig. & $\begin{array}{c}\text { Partial Eta } \\
\text { Squared }\end{array}$ & $\begin{array}{l}\text { Noncent. } \\
\text { Parameter }\end{array}$ & $\begin{array}{l}\text { Observed } \\
\text { Power }^{\mathrm{a}}\end{array}$ \\
\hline \multirow[t]{6}{*}{ COVID } & \multirow[t]{4}{*}{ Steps } & Sphericity Assumed & 128304049.6 & 1 & 128304049.6 & .267 & .608 & .007 & .267 & .080 \\
\hline & & Greenhouse-Geisser & 128304049.6 & 1.000 & 128304049.6 & .267 & .608 & .007 & .267 & .080 \\
\hline & & Huynh-Feldt & 128304049.6 & 1.000 & 128304049.6 & .267 & .608 & .007 & .267 & .080 \\
\hline & & Lower-bound & 128304049.6 & 1.000 & 128304049.6 & .267 & .608 & .007 & .267 & .080 \\
\hline & \multirow[t]{2}{*}{ Dist } & Sphericity Assumed & 198.033 & 1 & 198.033 & .562 & .458 & .014 & .562 & .113 \\
\hline & & Lower-bound & 198.033 & 1.000 & 198.033 & .562 & .458 & .014 & .562 & .113 \\
\hline \multirow[t]{5}{*}{ Error(COVID) } & \multirow[t]{4}{*}{ Steps } & Sphericity Assumed & $1.873 \mathrm{E}+10$ & 39 & 480142707.9 & & & & & \\
\hline & & Greenhouse-Geisser & $1.873 \mathrm{E}+10$ & 39.000 & 480142707.9 & & & & & \\
\hline & & Huynh-Feldt & $1.873 \mathrm{E}+10$ & 39.000 & 480142707.9 & & & & & \\
\hline & & Lower-bound & $1.873 \mathrm{E}+10$ & 39.000 & 480142707.9 & & & & & \\
\hline & Dist & Lower-bound & 13736.896 & 39.000 & 352.228 & & & & & \\
\hline
\end{tabular}

a. Computed using alpha $=.05$ 


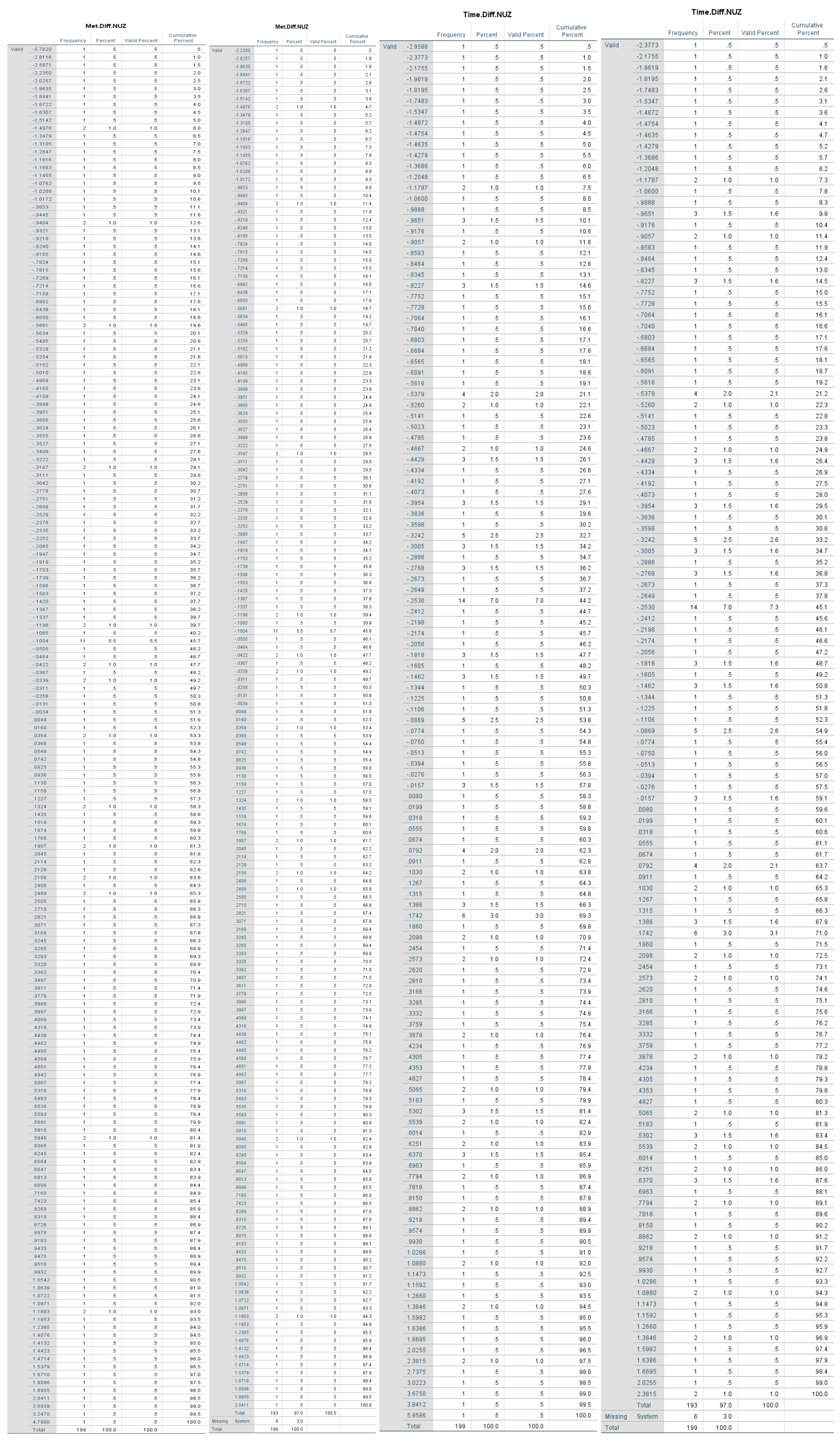




\begin{tabular}{|c|c|c|c|c|c|}
\hline \multicolumn{6}{|c|}{ Group Statistics } \\
\hline & ST.NUSR & $\mathrm{N}$ & Mean & Std. Deviation & $\begin{array}{l}\text { Std. Error } \\
\text { Mean }\end{array}$ \\
\hline \multirow[t]{2}{*}{ MDNUSR } & No & 62 & -2.4519 & 23.61862 & 2.99957 \\
\hline & Yes & 121 & 5.5271 & 22.82088 & 2.07463 \\
\hline \multirow[t]{2}{*}{ TDNUSR } & No & 63 & -3.3175 & 319.26730 & 40.22390 \\
\hline & Yes & 119 & 116.8908 & 311.74788 & 28.57788 \\
\hline
\end{tabular}

\begin{tabular}{|c|c|c|c|c|c|c|c|c|c|c|}
\hline \multicolumn{11}{|c|}{ Independent Samples Test } \\
\hline & & \multicolumn{2}{|c|}{$\begin{array}{l}\text { Levene's Test for Equality of } \\
\text { Variances }\end{array}$} & \multicolumn{7}{|c|}{ t-test for Equality of Means } \\
\hline & & \multirow[b]{2}{*}{$\mathrm{F}$} & \multirow[b]{2}{*}{ Sig. } & \multirow[b]{2}{*}{$t$} & \multirow[b]{2}{*}{ df } & \multirow[b]{2}{*}{ Sig. (2-tailed) } & \multirow{2}{*}{$\begin{array}{c}\text { Mean } \\
\text { Difference }\end{array}$} & \multirow{2}{*}{$\begin{array}{l}\text { Std. Error } \\
\text { Difference }\end{array}$} & \multicolumn{2}{|c|}{$\begin{array}{l}95 \% \text { Confidence Interval of the } \\
\text { Difference }\end{array}$} \\
\hline & & & & & & & & & Lower & Upper \\
\hline \multirow[t]{2}{*}{ MDNUSR } & $\begin{array}{l}\text { Equal variances } \\
\text { assumed }\end{array}$ & .002 & .962 & -2.212 & 181 & .028 & -7.97902 & 3.60673 & -15.09566 & -.86237 \\
\hline & $\begin{array}{l}\text { Equal variances not } \\
\text { assumed }\end{array}$ & & & -2.188 & 119.427 & .031 & -7.97902 & 3.64712 & -15.20041 & -.75762 \\
\hline \multirow[t]{2}{*}{ TDNUSR } & $\begin{array}{l}\text { Equal variances } \\
\text { assumed }\end{array}$ & .149 & .700 & -2.454 & 180 & .015 & -120.20822 & 48.97977 & -216.85661 & -23.55982 \\
\hline & $\begin{array}{l}\text { Equal variances not } \\
\text { assumed }\end{array}$ & & & -2.436 & 123.813 & .016 & -120.20822 & 49.34225 & -217.87180 & -22.54464 \\
\hline
\end{tabular}

\begin{tabular}{|c|c|c|c|c|c|c|c|c|c|c|c|}
\hline \multicolumn{6}{|c|}{ Group Statistics } & \multicolumn{6}{|c|}{ Group Statistics } \\
\hline & ST.NU.S & $\mathrm{N}$ & Mean & Std. Deviation & $\begin{array}{l}\text { Std. Error } \\
\text { Mean }\end{array}$ & & ST.NU.D & $\mathrm{N}$ & Mean & Std. Deviation & $\begin{array}{l}\text { Std. Error } \\
\text { Mean }\end{array}$ \\
\hline \multirow[t]{2}{*}{ Step.Diff.NUS } & No & 9 & -19067.78 & 25206.536 & 8402.179 & \multirow[t]{2}{*}{ DistDiff.NUD } & No & 8 & -10.9855 & 14.04109 & 4.96428 \\
\hline & Yes & 32 & -2373.38 & 42658.448 & 7541.019 & & Yes & 30 & 8.1847 & 30.39589 & 5.54950 \\
\hline
\end{tabular}

\begin{tabular}{|c|c|c|c|c|c|c|c|c|c|c|}
\hline \multicolumn{11}{|c|}{ Independent Samples Test } \\
\hline & & \multicolumn{2}{|c|}{$\begin{array}{l}\text { Levene's Test for Equality of } \\
\text { Variances }\end{array}$} & \multicolumn{7}{|c|}{ t-test for Equality of Means } \\
\hline & & \multirow[b]{2}{*}{$\mathrm{F}$} & \multirow[b]{2}{*}{ Sig. } & \multirow[b]{2}{*}{$\mathrm{t}$} & \multirow[b]{2}{*}{ df } & \multirow[b]{2}{*}{ Sig. (2-tailed) } & \multirow{2}{*}{$\begin{array}{l}\text { Mean } \\
\text { Difference }\end{array}$} & \multirow{2}{*}{$\begin{array}{l}\text { Std. Error } \\
\text { Difference }\end{array}$} & \multicolumn{2}{|c|}{$\begin{array}{l}\text { 95\% Confidence Interval of the } \\
\text { Difference }\end{array}$} \\
\hline & & & & & & & & & Lower & Upper \\
\hline \multirow[t]{2}{*}{ Step.Diff.NUS } & $\begin{array}{l}\text { Equal variances } \\
\text { assumed }\end{array}$ & .513 & .478 & -1.114 & 39 & .272 & -16694.403 & 14982.465 & -46999.298 & 13610.493 \\
\hline & $\begin{array}{l}\text { Equal variances not } \\
\text { assumed }\end{array}$ & & & -1.479 & 22.339 & .153 & -16694.403 & 11289.977 & -40087.819 & 6699.014 \\
\hline
\end{tabular}

\section{Independent Samples Test}

\begin{tabular}{|c|c|c|c|c|c|c|c|c|c|c|}
\hline & & \multicolumn{2}{|c|}{$\begin{array}{c}\text { Levene's Test for Equality of } \\
\text { Variances }\end{array}$} & \multicolumn{7}{|c|}{ t-test for Equality of Means } \\
\hline & & \multirow[b]{2}{*}{$\mathrm{F}$} & \multirow[b]{2}{*}{ Sig. } & \multirow[b]{2}{*}{$t$} & \multirow[b]{2}{*}{ df } & \multirow[b]{2}{*}{ Sig. (2-tailed) } & \multirow{2}{*}{$\begin{array}{c}\text { Mean } \\
\text { Difference }\end{array}$} & \multirow{2}{*}{$\begin{array}{l}\text { Std. Error } \\
\text { Difference }\end{array}$} & \multicolumn{2}{|c|}{$\begin{array}{l}\text { 95\% Confidence Interval of the } \\
\text { Difference }\end{array}$} \\
\hline & & & & & & & & & Lower & Upper \\
\hline \multirow[t]{2}{*}{ DistDiff.NUD } & $\begin{array}{l}\text { Equal variances } \\
\text { assumed }\end{array}$ & 2.325 & .136 & -1.722 & 36 & .094 & -19.17013 & 11.13153 & -41.74592 & 3.40567 \\
\hline & $\begin{array}{l}\text { Equal variances not } \\
\text { assumed }\end{array}$ & & & -2.575 & 25.729 & .016 & -19.17013 & 7.44587 & -34.48320 & -3.85705 \\
\hline
\end{tabular}




\begin{tabular}{|c|c|c|c|c|c|}
\hline \multicolumn{6}{|c|}{ WEM.FUSRZ } \\
\hline & & Frequency & Percent & Valid Percent & $\begin{array}{c}\text { Cumulative } \\
\text { Percent }\end{array}$ \\
\hline \multirow[t]{20}{*}{ Valid } & -2.2200 & 1 & .5 & 3.2 & 3.2 \\
\hline & -1.7731 & 1 & .5 & 3.2 & 6.5 \\
\hline & -1.2145 & 2 & 1.0 & 6.5 & 12.9 \\
\hline & -.8794 & 1 & .5 & 3.2 & 16.1 \\
\hline & -.7676 & 4 & 2.0 & 12.9 & 29.0 \\
\hline & -6559 & 1 & .5 & 3.2 & 32.3 \\
\hline & -.5442 & 1 & .5 & 3.2 & 35.5 \\
\hline & -.4325 & 1 & .5 & 3.2 & 38.7 \\
\hline & -.3208 & 3 & 1.5 & 9.7 & 48.4 \\
\hline & .1261 & 1 & .5 & 3.2 & 51.6 \\
\hline & .3496 & 3 & 1.5 & 9.7 & 61.3 \\
\hline & .4613 & 1 & .5 & 3.2 & 64.5 \\
\hline & .5730 & 2 & 1.0 & 6.5 & 71.0 \\
\hline & .6847 & 2 & 1.0 & 6.5 & 77.4 \\
\hline & .9082 & 2 & 1.0 & 6.5 & 83.9 \\
\hline & 1.0199 & 2 & 1.0 & 6.5 & 90.3 \\
\hline & 1.1316 & 1 & .5 & 3.2 & 93.5 \\
\hline & 1.6903 & 1 & .5 & 3.2 & 96.8 \\
\hline & 2.1371 & 1 & .5 & 3.2 & 100.0 \\
\hline & Total & 31 & 15.6 & 100.0 & \\
\hline Missing & System & 168 & 84.4 & & \\
\hline Total & & 199 & 100.0 & & \\
\hline
\end{tabular}
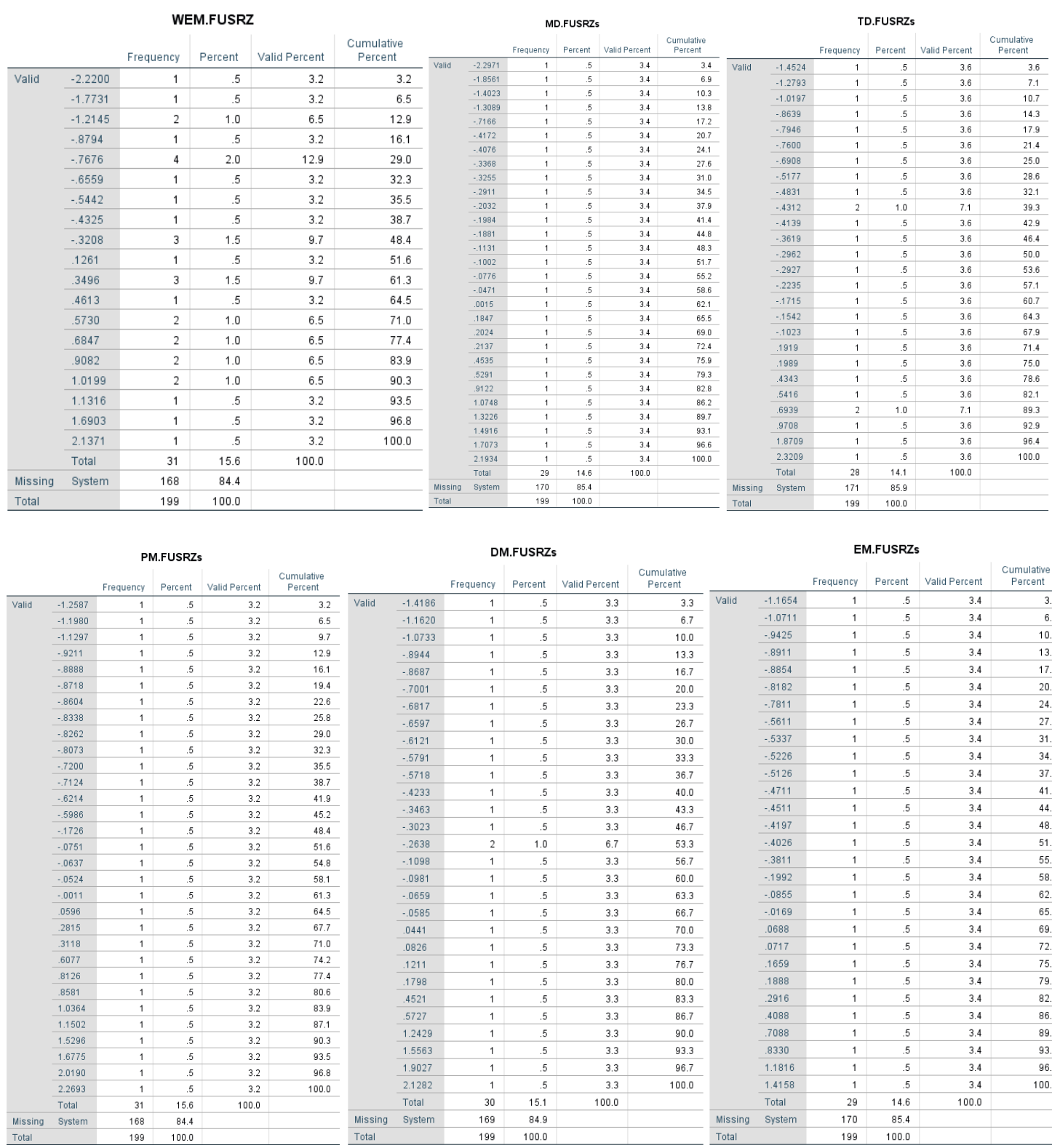

DM.FUSRZs

EM.FUSRZs

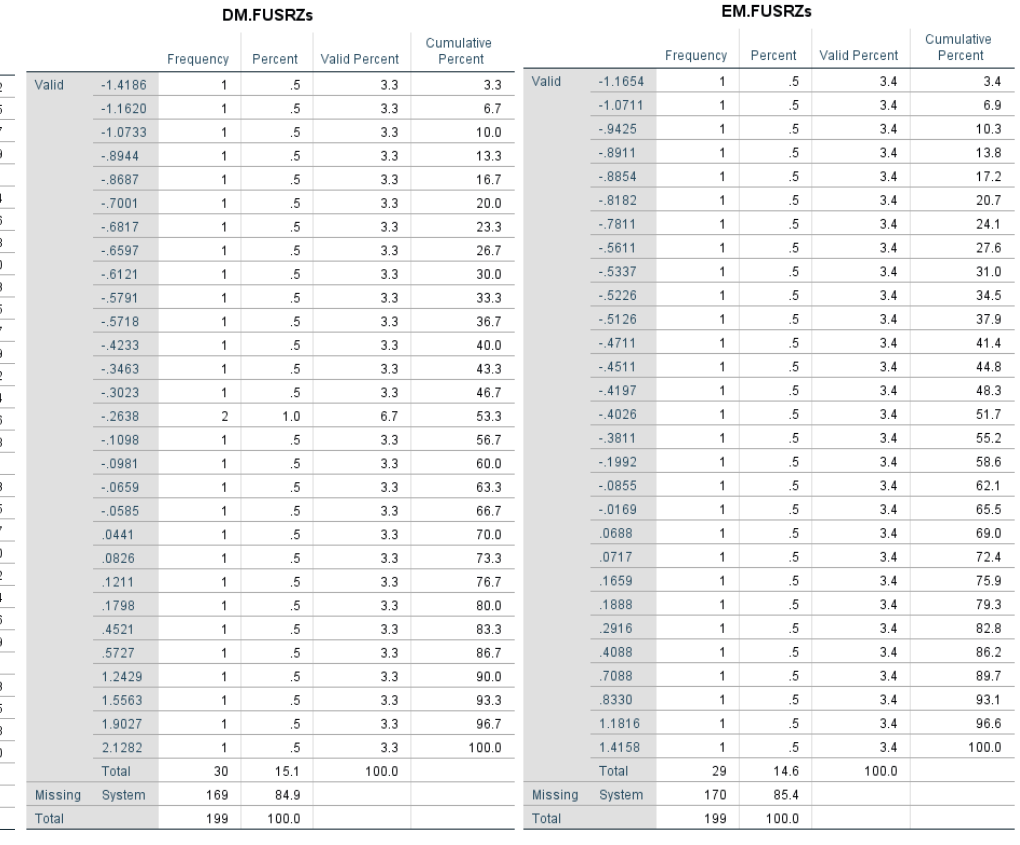

PT.FUSRZs

DT.FUSRZs

ET.FUSRZs

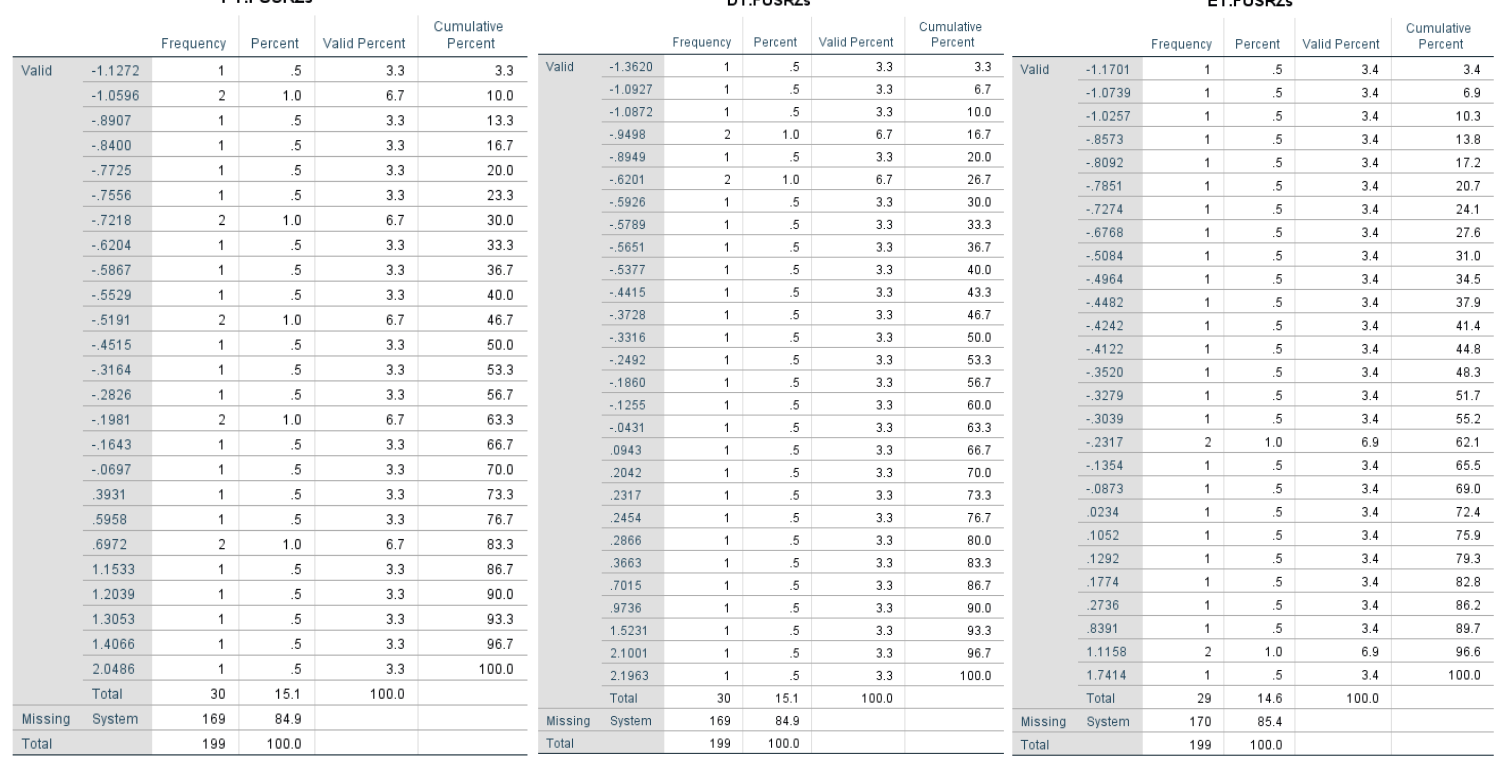




\section{Correlations}

\begin{tabular}{llr|r} 
& & WEM.FU.SR & EM.FUSR \\
\hline \multirow{2}{*}{ WEM.FU.SR } & Pearson Correlation & 1 & .161 \\
\cline { 2 - 4 } & Sig. (1-tailed) & & .202 \\
\cline { 2 - 4 } & $\mathrm{N}$ & 31 & 29 \\
\hline \multirow{2}{*}{ EM.FUSR } & Pearson Correlation & .161 & 1 \\
\cline { 2 - 4 } & Sig. (1-tailed) & .202 & \\
\cline { 2 - 4 } & $\mathrm{N}$ & 29 & 29 \\
\hline
\end{tabular}

\section{Correlations}

\begin{tabular}{llr|r} 
& & WEM.FU.SR & ET.FUSR \\
\hline \multirow{2}{*}{ WEM.FU.SR } & Pearson Correlation & 1 & .143 \\
\cline { 2 - 4 } & Sig. (1-tailed) & & .229 \\
\cline { 2 - 4 } & $\mathrm{N}$ & 31 & 29 \\
\hline \multirow{2}{*}{ ET.FUSR } & Pearson Correlation & .143 & 1 \\
\cline { 2 - 4 } & Sig. (1-tailed) & .229 & \\
\cline { 2 - 4 } & $\mathrm{N}$ & 29 & 29 \\
\hline
\end{tabular}

Within-Subjects Factors

\begin{tabular}{lll} 
Measure & COVID & $\begin{array}{c}\text { Dependent } \\
\text { Variable }\end{array}$ \\
\hline MET & 1 & PM.FUSR \\
\cline { 2 - 3 } & 2 & DM.FUSR \\
\cline { 2 - 3 } & 3 & EM.FUSR \\
\hline Time & 1 & PT.FUSR \\
\cline { 2 - 3 } & 2 & DT.FUSR \\
\cline { 2 - 3 } & 3 & ET.FUSR \\
\hline
\end{tabular}

Descriptive Statistics

\begin{tabular}{|l|r|r|r} 
& \multicolumn{1}{c|}{ Mean } & Std. Deviation & \multicolumn{1}{l}{ N } \\
\hline PM.FUSR & 28.8356 & 20.55969 & 29 \\
\hline DM.FUSR & 30.2555 & 17.89584 & 29 \\
\hline EM.FUSR & 30.6819 & 19.18654 & 29 \\
\hline PT.FUSR & 349.4138 & 242.58055 & 29 \\
\hline DT.FUSR & 465.7241 & 288.83199 & 29 \\
\hline ET.FUSR & 436.5517 & 287.22360 & 29 \\
\hline
\end{tabular}

29

\begin{tabular}{ll|r|r|r|r} 
& \multicolumn{5}{c}{ Estimates } \\
Measure & CoVID & Mean & Std. Error & Lower Bound & Upper Bound \\
\hline MET & 1 & 28.836 & 3.818 & 21.015 & 36.656 \\
\cline { 2 - 7 } & 2 & 30.255 & 3.323 & 23.448 & 37.063 \\
\hline \multirow{2}{*}{ Time } & 3 & 30.682 & 3.563 & 23.384 & 37.980 \\
\hline & 1 & 349.414 & 45.046 & 257.141 & 441.686 \\
\hline & 2 & 465.724 & 53.635 & 355.858 & 575.590 \\
\hline
\end{tabular}

\section{Univariate Tests}

\begin{tabular}{|c|c|c|c|c|c|c|c|c|c|c|}
\hline Source & Meas: & & $\begin{array}{l}\text { Type III Sum } \\
\text { of Squares }\end{array}$ & df & Mean Square & $\mathrm{F}$ & Sig. & $\begin{array}{c}\text { Partial Eta } \\
\text { Squared }\end{array}$ & $\begin{array}{l}\text { Noncent. } \\
\text { Parameter }\end{array}$ & $\begin{array}{l}\text { Observed } \\
\text { Power }^{\mathrm{a}}\end{array}$ \\
\hline \multirow[t]{8}{*}{ COVID } & \multirow[t]{4}{*}{ MET } & Sphericity Assumed & 54.196 & 2 & 27.098 & .144 & .867 & .005 & .287 & .071 \\
\hline & & Greenhouse-Geisser & 54.196 & 1.720 & 31.508 & .144 & .836 & .005 & .247 & .070 \\
\hline & & Huynh-Feldt & 54.196 & 1.822 & 29.745 & .144 & .848 & .005 & .262 & .070 \\
\hline & & Lower-bound & 54.196 & 1.000 & 54.196 & .144 & .708 & .005 & .144 & .065 \\
\hline & \multirow[t]{4}{*}{ Time } & Sphericity Assumed & 212397.402 & 2 & 106198.701 & 3.994 & .024 & .125 & 7.988 & .692 \\
\hline & & Greenhouse-Geisser & 212397.402 & 1.984 & 107052.032 & 3.994 & .024 & .125 & 7.925 & .689 \\
\hline & & Huynh-Feldt & 212397.402 & 2.000 & 106198.701 & 3.994 & .024 & .125 & 7.988 & .692 \\
\hline & & Lower-bound & 212397.402 & 1.000 & 212397.402 & 3.994 & .055 & .125 & 3.994 & .488 \\
\hline \multirow[t]{8}{*}{ Error(COVID) } & \multirow[t]{4}{*}{ MET } & Sphericity Assumed & 10569.302 & 56 & 188.738 & & & & & \\
\hline & & Greenhouse-Geisser & 10569.302 & 48.162 & 219.451 & & & & & \\
\hline & & Huynh-Feldt & 10569.302 & 51.017 & 207.174 & & & & & \\
\hline & & Lower-bound & 10569.302 & 28.000 & 377.475 & & & & & \\
\hline & \multirow[t]{4}{*}{ Time } & Sphericity Assumed & 1488935.931 & 56 & 26588.142 & & & & & \\
\hline & & Greenhouse-Geisser & 1488935.931 & 55.554 & 26801.783 & & & & & \\
\hline & & Huynh-Feldt & 1488935.931 & 56.000 & 26588.142 & & & & & \\
\hline & & Lower-bound & 1488935.931 & 28.000 & 53176.283 & & & & & \\
\hline
\end{tabular}

a. Computed using alpha $=.05$

Pairwise Comparisons

\begin{tabular}{|c|c|c|c|c|c|c|c|}
\hline \multirow[b]{2}{*}{ Measure } & \multirow[b]{2}{*}{ (I) COVID } & \multirow[b]{2}{*}{ (J) COVID } & \multirow{2}{*}{$\begin{array}{c}\text { Mean } \\
\text { Difference (I- } \\
\text { J) }\end{array}$} & \multirow[b]{2}{*}{ Std. Error } & \multirow[b]{2}{*}{ Sig. ${ }^{\text {b }}$} & \multicolumn{2}{|c|}{$\begin{array}{l}\text { 95\% Confidence Interval for } \\
\text { Difference }^{\mathrm{b}}\end{array}$} \\
\hline & & & & & & Lower Bound & Upper Bound \\
\hline \multirow[t]{6}{*}{ MET } & \multirow[t]{2}{*}{1} & 2 & -1.420 & 3.862 & .716 & -9.331 & 6.492 \\
\hline & & 3 & -1.846 & 4.038 & .651 & -10.118 & 6.425 \\
\hline & \multirow[t]{2}{*}{2} & 1 & 1.420 & 3.862 & .716 & -6.492 & 9.331 \\
\hline & & 3 & -.426 & 2.798 & .880 & -6.157 & 5.304 \\
\hline & \multirow[t]{2}{*}{3} & 1 & 1.846 & 4.038 & .651 & -6.425 & 10.118 \\
\hline & & 2 & .426 & 2.798 & .880 & -5.304 & 6.157 \\
\hline \multirow[t]{6}{*}{ Time } & \multirow[t]{2}{*}{1} & 2 & $-116.310^{x}$ & 42.860 & .011 & -204.105 & -28.516 \\
\hline & & 3 & -87.138 & 44.433 & .060 & -178.156 & 3.880 \\
\hline & \multirow[t]{2}{*}{2} & 1 & $116.310^{*}$ & 42.860 & .011 & 28.516 & 204.105 \\
\hline & & 3 & 29.172 & 41.106 & .484 & -55.029 & 113.374 \\
\hline & \multirow[t]{2}{*}{3} & 1 & 87.138 & 44.433 & .060 & -3.880 & 178.156 \\
\hline & & 2 & -29.172 & 41.106 & .484 & -113.374 & 55.029 \\
\hline
\end{tabular}

Based on estimated marginal means

*. The mean difference is significant at the .05 level.

b. Adjustment for multiple comparisons: Least Significant Difference (equivalent to no adjustments). 


\section{Group Statistics}

\begin{tabular}{llr|r|r|r} 
& ST.FUSR & N & \multicolumn{1}{c}{ Mean } & Std. Deviation & \multicolumn{1}{c}{$\begin{array}{c}\text { Std. Error } \\
\text { Mean }\end{array}$} \\
\hline \multirow{2}{*}{ MetDiff.FUSR } & No & 14 & 1.9185 & 17.70177 & 4.73100 \\
\cline { 2 - 7 } & Yes & 15 & 8.9428 & 31.99826 & 8.26191 \\
\hline \multirow{2}{*}{ TimeDiff.FUSR } & No & 14 & 66.7143 & 236.50904 & 63.20970 \\
\cline { 2 - 7 } & Yes & 14 & 134.1429 & 261.47801 & 69.88294 \\
\hline
\end{tabular}

\begin{tabular}{|c|c|c|c|c|c|c|c|c|c|c|}
\hline \multicolumn{11}{|c|}{ Independent Samples Test } \\
\hline & & \multicolumn{2}{|c|}{$\begin{array}{l}\text { Levene's Test for Equality of } \\
\text { Variances }\end{array}$} & \multicolumn{7}{|c|}{ t-test for Equality of Means } \\
\hline & & \multirow[b]{2}{*}{$\mathrm{F}$} & \multirow[b]{2}{*}{ Sig. } & \multirow[b]{2}{*}{$t$} & \multirow[b]{2}{*}{ df } & \multirow[b]{2}{*}{ Sig. (2-tailed) } & \multirow{2}{*}{$\begin{array}{c}\text { Mean } \\
\text { Difference }\end{array}$} & \multirow{2}{*}{$\begin{array}{l}\text { Std. Error } \\
\text { Difference }\end{array}$} & \multicolumn{2}{|c|}{$\begin{array}{l}\text { 95\% Confidence Interval of the } \\
\text { Difference }\end{array}$} \\
\hline & & & & & & & & & Lower & Upper \\
\hline \multirow[t]{2}{*}{ MetDiff.FUSR } & $\begin{array}{l}\text { Equal variances } \\
\text { assumed }\end{array}$ & 6.409 & .017 & -.724 & 27 & .475 & -7.02433 & 9.70311 & -26.93347 & 12.88482 \\
\hline & $\begin{array}{l}\text { Equal variances not } \\
\text { assumed }\end{array}$ & & & -.738 & 22.125 & .468 & -7.02433 & 9.52059 & -26.76236 & 12.71371 \\
\hline \multirow[t]{2}{*}{ TimeDiff.FUSR } & $\begin{array}{l}\text { Equal variances } \\
\text { assumed }\end{array}$ & 2.136 & .156 & -.716 & 26 & .481 & -67.42857 & 94.22893 & -261.11891 & 126.26177 \\
\hline & $\begin{array}{l}\text { Equal variances not } \\
\text { assumed }\end{array}$ & & & -.716 & 25.742 & .481 & -67.42857 & 94.22893 & -261.21327 & 126.35613 \\
\hline
\end{tabular}
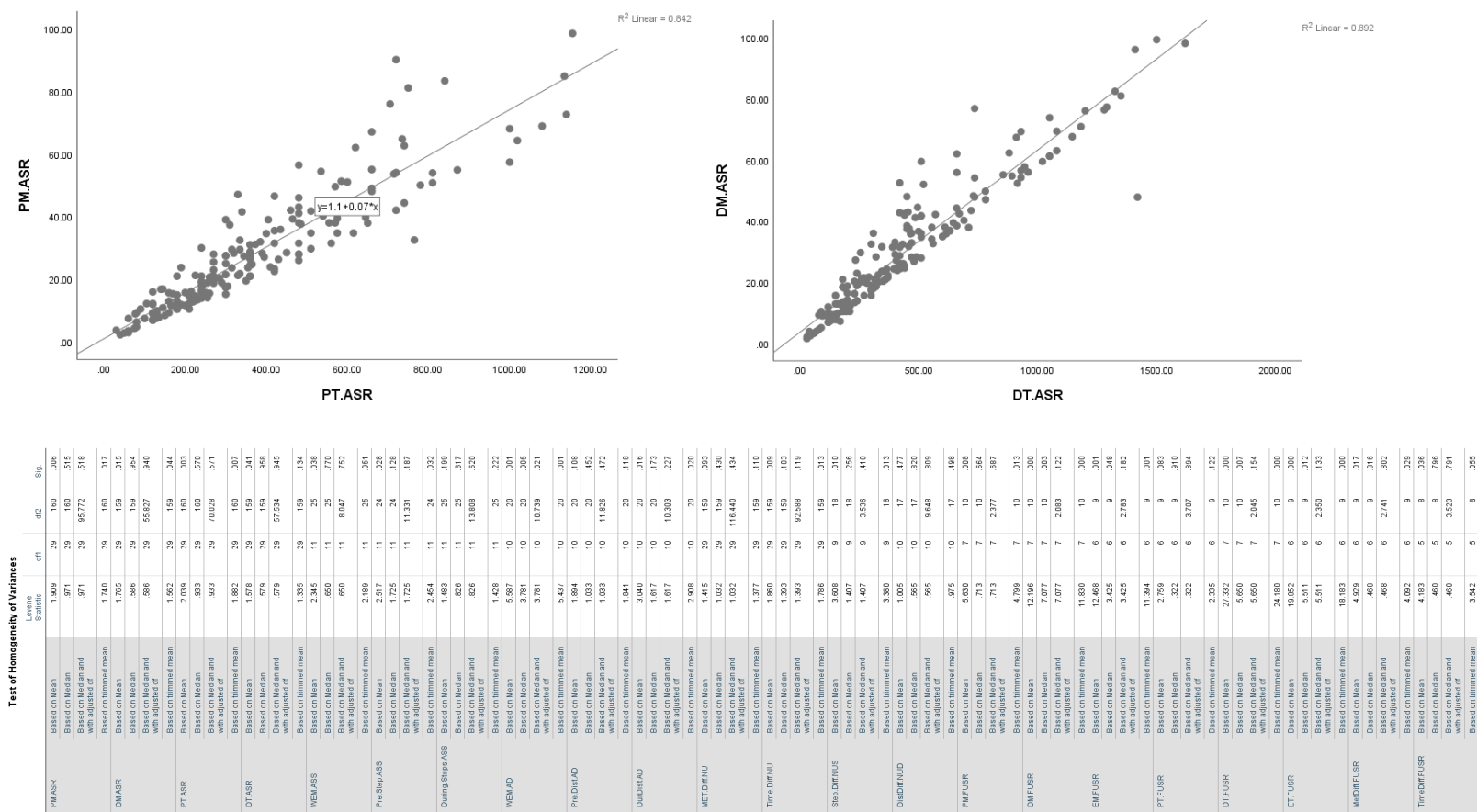
Appendix 9: A Table demonstrating the significances of the tests of differences between Work Statuses and their impact on Mental Wellbeing

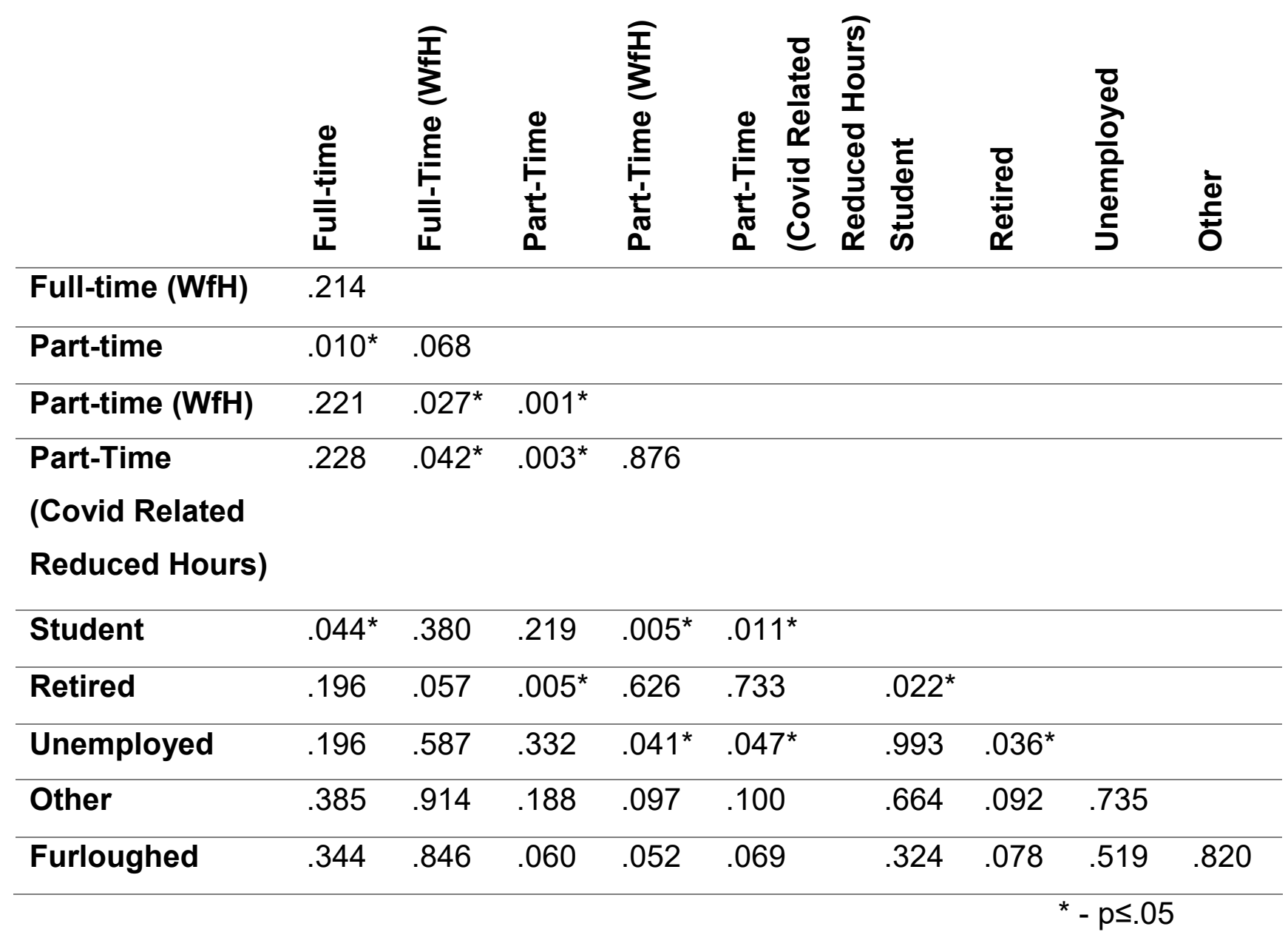


Appendix 10: A Table demonstrating the significances of the tests of differences between types of accessible Open Spaces and their impact on Mental Wellbeing

\begin{tabular}{|c|c|c|c|c|c|}
\hline & 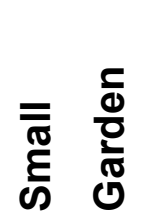 & 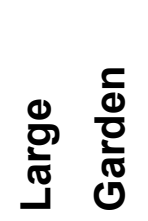 & $\frac{x}{\frac{x}{\pi}}$ & $\frac{\text { 응 }}{i \frac{1}{4}}$ & 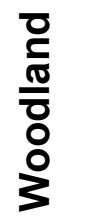 \\
\hline Large Garden & $.002^{*}$ & & & & \\
\hline Park & .313 & $.014^{*}$ & & & \\
\hline Field & .751 & .089 & .282 & & \\
\hline Woodland & .381 & .354 & .156 & .624 & \\
\hline Other & $.030^{*}$ & .306 & $.016^{*}$ & .067 & .151 \\
\hline
\end{tabular}


Appendix 11: A Table demonstrating the significances of the tests of differences between Work Statuses and their impact on METhrs/week difference scores

Full-time (WfH) $\quad .088$

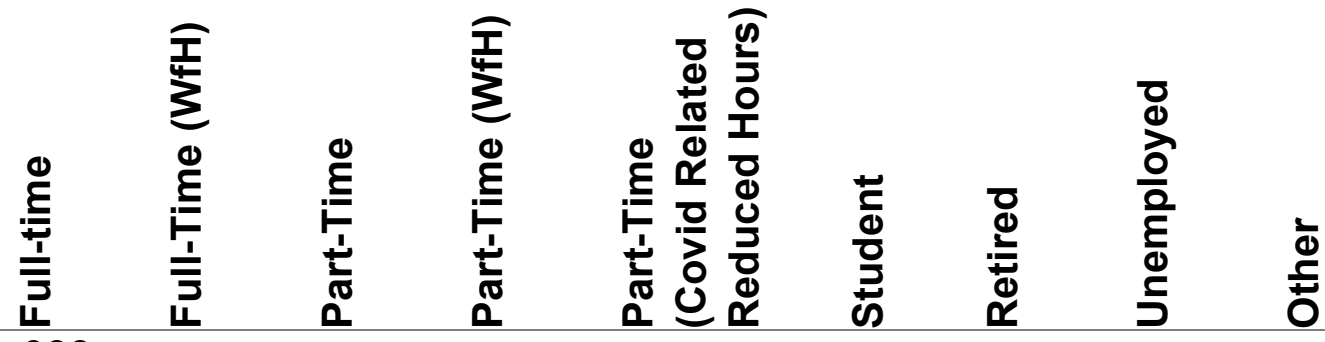

\begin{tabular}{lllll}
\hline Part-time & .289 & $.030^{\star}$ & & \\
\hline Part-time (WfH) & .059 & .542 & $.019^{\star}$ & \\
\hline $\begin{array}{l}\text { Part-Time } \\
\text { (Covid Related }\end{array}$ & .174 & .492 & .054 & .836 \\
Reduced Hours) & & & &
\end{tabular}

\begin{tabular}{lllllllllll}
\hline Student & .340 & .492 & .092 & .264 & .476 & & & \\
\hline Retired & .071 & .318 & $.024^{*}$ & .567 & .492 & .187 & & & \\
Unemployed & .623 & .573 & .222 & .353 & .508 & .900 & .223 & & \\
\hline Other & $.001^{*}$ & $.026^{*}$ & $.001^{*}$ & .124 & .115 & $.010^{*}$ & .532 & $.030^{*}$ & \\
\hline Furloughed & .467 & .398 & .128 & .217 & .410 & .855 & .162 & 1.000 & $.008^{*}$ \\
\hline & & & & & & & & ${ }^{*}-p \leq .05$
\end{tabular}


Appendix 12: A Table demonstrating the significances of the tests of differences between types of accessible Open Spaces and their impact on METhrs/week difference scores

\begin{tabular}{|c|c|c|c|c|c|}
\hline & 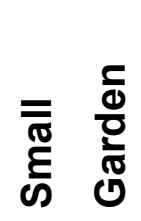 & 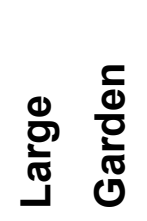 & $\frac{r}{\frac{x}{\pi}}$ & $\frac{\text { 음 }}{i \frac{1}{4}}$ & $\begin{array}{l}\frac{0}{C} \\
\frac{0}{0} \\
\frac{0}{0} \\
0 \\
\vdots\end{array}$ \\
\hline Large Garden & .132 & & & & \\
\hline Park & .877 & .571 & & & \\
\hline Field & .262 & .911 & .567 & & \\
\hline Woodland & $.011^{*}$ & $.001^{*}$ & .064 & $.004^{*}$ & \\
\hline Other & .347 & .704 & .497 & .769 & $.025^{*}$ \\
\hline
\end{tabular}


Appendix 13: A Table demonstrating the significances of the tests of differences between Work Statuses and their impact on time spent engaging in physical activity difference scores

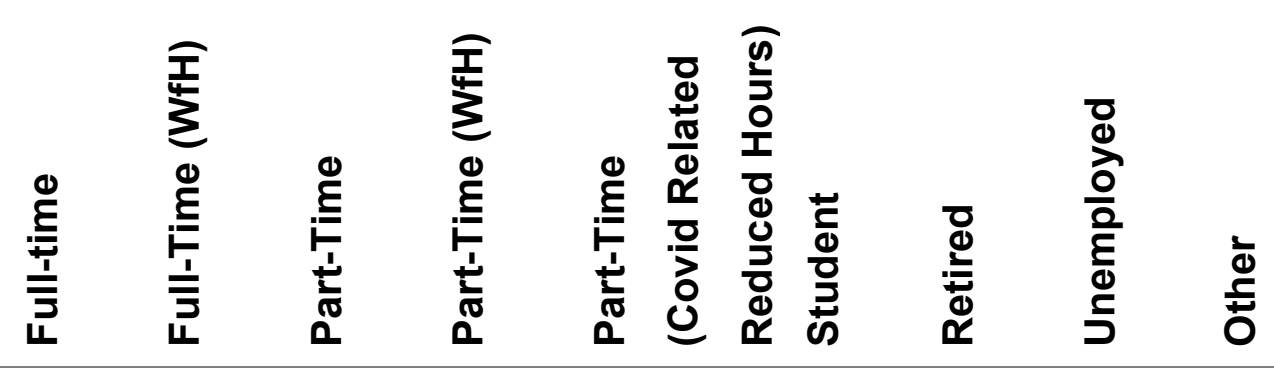

\begin{tabular}{llllll}
\hline Full-time (WfH) & .214 & & & \\
\hline Part-time & $.010^{\star}$ & .068 & & \\
\hline Part-time (WfH) & .221 & $.027^{*}$ & $.001^{*}$ & \\
\hline Part-Time & .228 & $.042^{\star}$ & $.003^{\star}$ & .876
\end{tabular}

(Covid Related

Reduced Hours)

\begin{tabular}{lllllllllll}
\hline Student & $.044^{*}$ & .380 & .219 & $.005^{*}$ & $.011^{*}$ & & & & \\
\hline Retired & .196 & .057 & $.005^{*}$ & .626 & .733 & $.022^{*}$ & & & \\
\hline Unemployed & .196 & .587 & .332 & $.041^{*}$ & $.047^{*}$ & .993 & $.036^{*}$ & & \\
\hline Other & .385 & .914 & .188 & .097 & .100 & .664 & .092 & .735 & \\
\hline Furloughed & .344 & .846 & .060 & .052 & .069 & .324 & .078 & .519 & .820 \\
\hline & & & & & & & & \\
\end{tabular}


Appendix 14: A Table demonstrating the significances of the tests of differences between types of accessible Open Spaces and their impact on time spent engaging in physical activity difference scores

\begin{tabular}{|c|c|c|c|c|c|}
\hline & 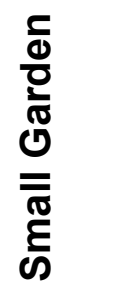 & $\begin{array}{l}\frac{c}{0} \\
\frac{0}{0} \\
\frac{0}{\pi} \\
0 \\
0 \\
\stackrel{0}{J}\end{array}$ & $\begin{array}{l}\frac{r}{\frac{\pi}{\pi}} \\
\mathbb{Q}\end{array}$ & $\frac{\text { 응 }}{i \frac{1}{4}}$ & $\begin{array}{l}\text { 으 } \\
\frac{0}{0} \\
\overline{0} \\
\stackrel{0}{3} \\
3\end{array}$ \\
\hline Large Garden & .129 & & & & \\
\hline Park & .852 & .591 & & & \\
\hline Field & .980 & .335 & .861 & & \\
\hline Woodland & $.031^{*}$ & $.003^{*}$ & .107 & .087 & \\
\hline Other & .323 & .670 & .484 & .363 & $.039 *$ \\
\hline
\end{tabular}

